\title{
ELETROSSÍNTESE E CARACTERIZAÇÃO VOLTAMÉTRICA E ESPECTROSCÓPICA DE FILMES DE POLI-p-FENILENO E DERIVADOS
}

\section{JULIANA COATRINI SOARES}

Dissertação apresentada à Área Interunidades em Ciência e Engenharia de Materiais da EESC, IFSC, IQSC, da Universidade de São Paulo, como parte dos requisitos para obtenção do título de Mestre em

Ciência e Engenharia de Materiais

Orientadora: Profa. Dra. Débora Gonçalves

São Carlos - São Paulo 2006

USP/IFSC/SBI 


Soares,Juliana Coatrini
"Eletrossintese e caracterização voltamétrica e espectroscópica de filmes de poli-p-fenileno
e derivados"
Juliana Coatrini Soares - São Carlos, 2006
Dissertação (Mestrado) - Interunidades Ciência e Engenharia de Materiais da Universidade
de São Paulo, 2006 - páginas: 73
Área: Desenvolvimento,Caracterização e aplicação de materiais
Orientadora: Profa. Dra. Débora Gonçalves
1. poli-p-fenileno
1. Título




\section{Universidade de Săo Paulo Ciência e Engenharia de Materiais}

Fone (16) 3373-9589 - Fax (16) 3373-9777

MEMBROS DA COMISSÃO JULGADORA DA DISSERTAÇÃO DE MESTRADO DE JULIANA COATRINI SOARES, APRESENTADA A ÁREA INTERUNIDADES CIÊNCIA E ENGENHARIA DE MATERIAIS, UNIVERSIDADE DE SÃO PAULO, EM 25/08/2006.

COMISSÃO JULGADORA:

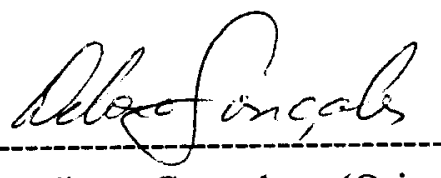

Profa. Dra. Débora Gonçalves (Orientador e Presidente)
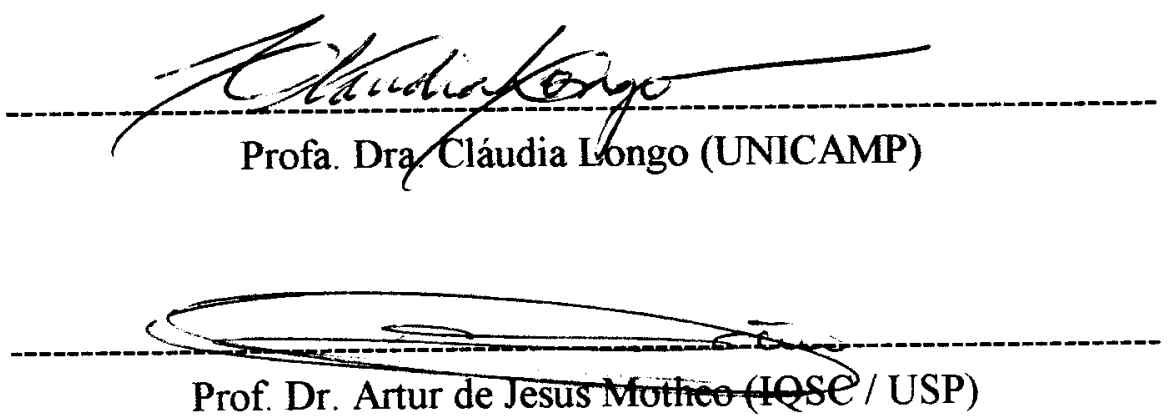
IFSC - Ciência e Engenharia de Materiais

Dedicatória

Dedico esse trabalho aos meus pais Luís Carlos e Neuza e ao meu irmão Andrey pelo exemplo de vida e dedicação e pelo apoio, carinho, paciência nos momentos dificeis e por terem me proporcionado a oportunidade de chegar até aqui. 
IFSC - Ciência e Engenharia de Materiais

\section{Agradecimentos}

Gostaria de expressar meus sinceros agradecimentos a todos que contribuíram direta e indiretamente para a realização desse trabalho:

A minha orientadora, prof. Débora Gonçalves, pelos ensinamentos, confiança e paciência depositada ao longo desse período.

Ao prof. Yoshio Kawano, pela atenção, aprendizado e pelo auxílio durante as medidas de Raman no IQ-USP.

A Carla Eiras e ao Maurício Foschini pelo apoio, amizade e pelos valiosos ensinamentos durante a realização desse trabalho.

À Rosângela, Débora T. Balogh, Berto, Níbio e Ademir pelo apoio técnico.

Aos meus amigos do Grupo de Polímeros do IFSC e em especial os amigos da sala 18: Gustavo Ciniciato, Rafael Longaresi, Adriana Pavinatto, Bruna, Marcelo, Vananélia e Raquel pela amizade e companheirismo.

Aos amigos Fábio (Juliano) Lopes, Rodrigo (Guidoval), Edgar e Rogério Rosa pela grande amizade, apoio e pelos momentos de risos e descontração, que foram essenciais durante esse período e que nunca esquecerei.

A Wladerez e as bibliotecárias pela atenção e competência demonstrada durante esse período.

A Capes pelo apoio financeiro. 


\section{Sumário}

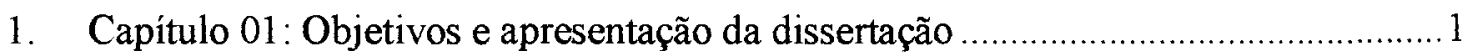

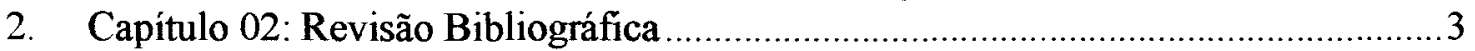

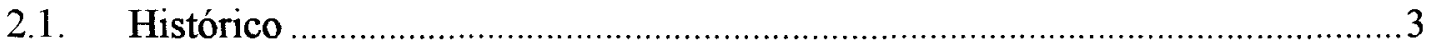

2.2. Processo de dopagem de polímeros conjugados: formação de pólarons,

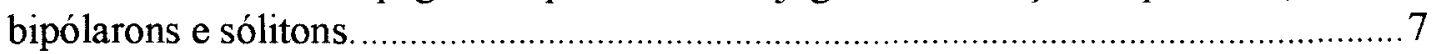

2.3. Copolimerização e formação de filmes mistos ……………………………....... 9

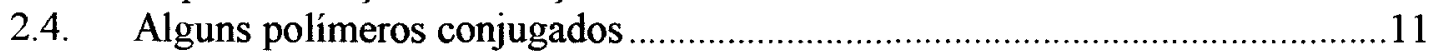

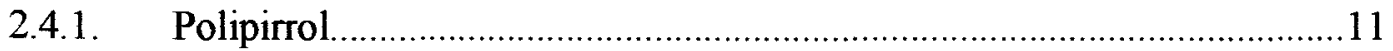

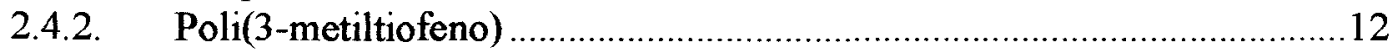

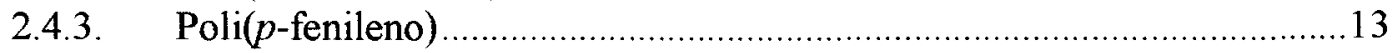

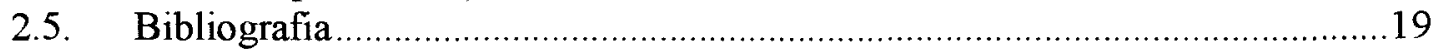

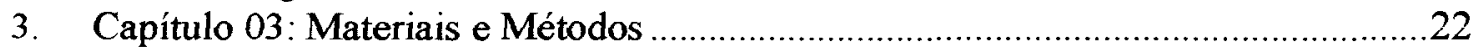

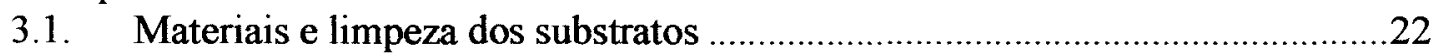

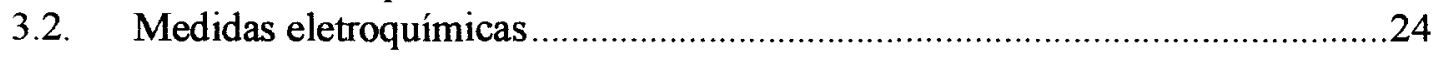

3.3. Técnicas de caracterização dos filmes poliméricos ........................................27

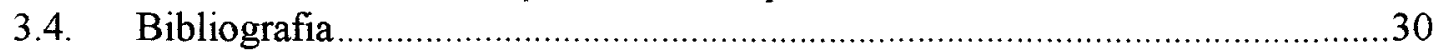

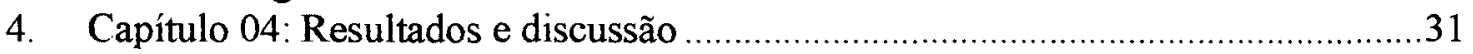

4.1. Medidas de voltametria cíclica para os homopolímeros e para os filmes mistos 31

4.2. Caracterização dos filmes de homopolímeros PPP, P3MET e PPI, por

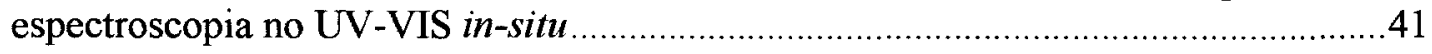

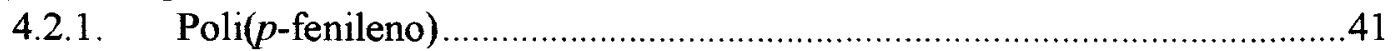

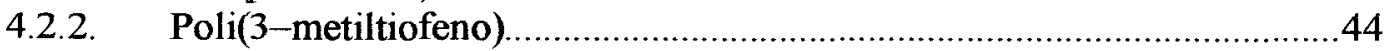

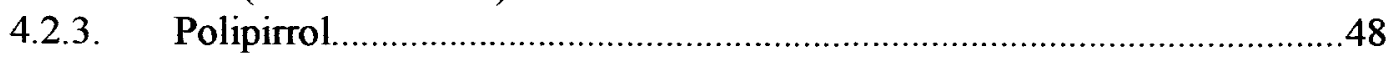

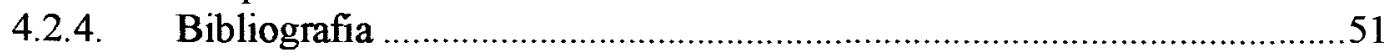

4.3. Caracterização dos filmes dos filmes mistos de CP3MET e CPPI, por

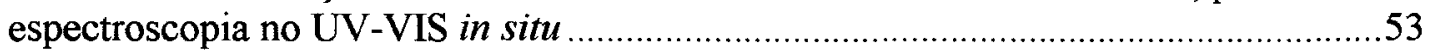

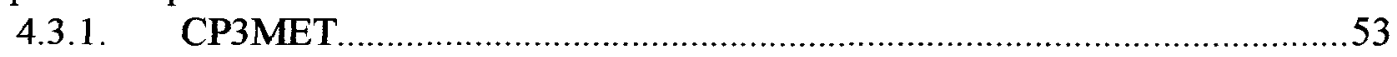

4.3.2. CPPI

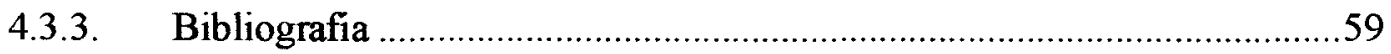

4.4. Caracterização dos filmes dos homopolímeros e dos filmes mistos por FTRaman 60

4.4.1. Bibliografia

4.5. Caracterização dos filmes dos homopolímeros e dos filmes mistos por FTIR

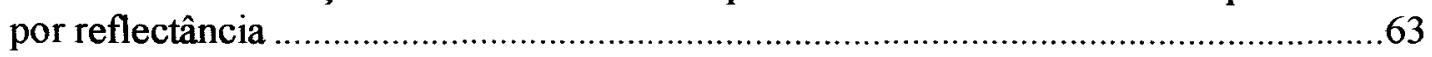

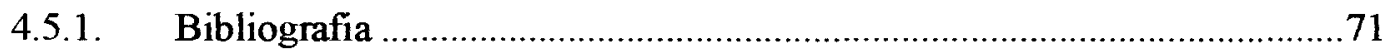

5. Capitulo 05: Conclusões finais e perspectivas futuras...........................................72 


\section{Índice de tabelas}

Tabela 4.1 Valores de carga final total para os filmes de PPP, P3MET, PPI, CP3MET e CPPI após 5 ciclos de varredura de potencial.

Tabela 4.2: Atribuições dos picos Raman nos espectros dos filmes de PPI e CPPI eletrossintetizados sobre FTO e mostrados na Figura 4.1 (c) e 4.2 (b) respectivamente ${ }^{[1]}$.

Tabela 4.3: Atribuições dos picos Raman nos espectros dos filmes de P3MET e CP3MET eletrossintetizados sobre FTO e mostrados na Figura 4.1 (b) e 4.2 (a), respectivamente ${ }^{[1]}$.

Tabela 4.4: Atribuições dos picos Raman nos espectros do filme de PPP eletrossintetizados sobre FTO, mostrado na Figura 4.1 (a).

Tabela 4.5: Atribuições das bandas de FTIR do filme de PPP eletrossintetizado sobre FTO e mostrado na Figura 4.1 (a)

Tabela 4.6: Atribuições das bandas de FTIR de filmes de P3MET e CP3MET eletrossintetizados sobre FTO e mostrado na Figura 4.1 (b) e 4.2 (a), respectivamente ${ }^{[1,2]}$.

Tabela 4.7: Atribuições das bandas de FTIR de filmes de PPI e CPPI eletrossintetizados sobre FTO e mostrado na Figura 4.1 (c) e 4.2 (b), respectivamente ${ }^{[3]}$ 


\section{Índice de figuras}

Figura 2.1 Estruturas de alguns polímeros condutores mais estudados ..............................5

Figura 2.2 Formação da ligação (a) $\sigma$ a partir da sobreposição dos orbitais $\operatorname{sp}^{2}$ e (b) $\pi$ em um plano perpendicular ao plano da cadeia principal, constituída pela ligação $\sigma$.

Figura 2.3 Níveis de energia: (a) sólitons em poliacetileno [4] e (b) pólaron e bipólaron [3]

Figura 2.4 Estruturas da químicas dos polímeros estudados aqui: PPP, PPI e P3MET...11

Figura 2.5 PPP nas formas benzenóide e quinóide. ..................................................14

Figura 2.6 Mecanismo de eletrossíntese do PPP........................................................15

Figura 3.1 Fórmulas estruturais dos monômeros utilizados na síntese dos filmes de PPP,

CPPI e CP3MET. .23

Figura 3.2 Perturbação imposta a um sistema pela técnica de VC e o voltamograma

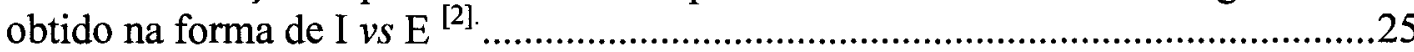

Figura 3.3 Célula eletroquímica utilizada no preparo e caracterização dos filmes poliméricos ${ }^{[3]}$.

Figura 4.1 Voltamogramas cíclicos do eletrodo de FTO durante a síntese (A) em meio de: $0,1 \mathrm{~mol} \mathrm{~L}^{-1}$ de bifenila (a); $0,1 \mathrm{~mol} \mathrm{~L}^{-1}$ de 3-metiltiofeno (c) e $0,1 \mathrm{~mol} \mathrm{~L}^{-1}$ de pirrol (e) e resposta eletroquímica (B) dos filmes de PPP (b), P3MET (d) e PPI (f), em meio de uma solução de $0,01 \mathrm{~mol} \mathrm{~L}^{-1}$ de $\mathrm{TBAClO}_{4} \mathrm{em} \mathrm{ACN} \mathrm{a} \mathrm{v}=50 \mathrm{mVs}^{-1}$. 32

Figura 4.2 Voltamogramas cíclicos do eletrodo de FTO durante a síntese (A) e resposta eletroquímica (B) dos filmes em meio de uma solução de $0,01 \mathrm{~mol} \mathrm{~L}^{-1}$ de $\mathrm{TBAClO}_{4}$ em ACN a v $=50 \mathrm{mVs}^{-1}$ em meio de: $0,1 \mathrm{~mol} \mathrm{~L}^{-1}$ de bifenila e $0,05 \mathrm{~mol}$ $\mathrm{L}^{-1}$ de 3-metiltiofeno (a) e (b) e $0,1 \mathrm{~mol} \mathrm{~L}^{-1}$ de bifenila e $0,01 \mathrm{~mol} \mathrm{~L}^{-1}$ de pirrol e (c) e (d).

Figura 4.3 Voltamogramas cíclicos do eletrodo de FTO durante a resposta eletroquímica dos filmes em meio de uma solução de $0,01 \mathrm{~mol} \mathrm{~L}^{-1}$ de $\mathrm{TBAClO}_{4} \mathrm{em} \mathrm{ACN} \mathrm{a} \mathrm{v}=$ $50 \mathrm{mVs}^{-1}$ em meio de: $0,1 \mathrm{~mol} \mathrm{~L}^{-1}$ de bifenila e $0,05 \mathrm{~mol} \mathrm{~L}^{-1}$ de 3-metiltiofeno (CP3MET), $0,1 \mathrm{~mol} \mathrm{~L}^{-1}$ de bifenila (PPP) e $0,1 \mathrm{~mol} \mathrm{~L}^{-1}$ de 3-metiltiofeno(P3MET).

Figura 4.4 Voltamogramas cíclicos do eletrodo de FTO durante a resposta eletroquímica dos filmes em meio de uma solução de $0,01 \mathrm{~mol} \mathrm{~L}^{-1}$ de $\mathrm{TBAClO}_{4} \mathrm{em} \mathrm{ACN} \mathrm{a} \mathrm{v}=$ $50 \mathrm{mVs}^{-1}$ em meio de: $0,1 \mathrm{~mol} \mathrm{~L}^{-1}$ de bifenila e $0,01 \mathrm{~mol} \mathrm{~L}^{-1}$ de pirrol (CPPI), 0,1 mol L ${ }^{-1}$ de bifenila (PPP) e $0,1 \mathrm{~mol} \mathrm{~L}^{-1}$ de pirrol (CPPI) .........................................38

Figura 4.5 Fotos dos filmes de homopolímeros e dos filmes mistos eletrossintetizados a partir de 5 primeiros ciclos de varredura................................................................40

Figura 4.6 Espectros de absorção no UV-VIS de filmes de PPP em meio de $0,01 \mathrm{~mol} \mathrm{~L}$ ${ }^{1}$ de $\mathrm{TBAClO}_{4}$ em ACN a diferentes potenciais aplicados. As letras representam as diferentes bandas dos espectros.

Figura 4.7 Curvas de desconvolução obtidas a partir dos espectros de absorbância dos filmes de PPP a partir da Figura 4.6.

Figura 4.8 Espectros de absorção no UV-VIS de filmes de P3MET em meio de 0,01 mol $\mathrm{L}^{-1}$ de $\mathrm{TBAClO}_{4}$ em ACN a diferentes potenciais aplicados. As letras representam as diferentes bandas dos espectros. 
Figura 4.9 Curvas de desconvolução dos espectros de absorbância dos filmes de P3MET obtidos a partir da Figura 4.8 .

Figura 4.10 Espectros de absorção no UV-VIS de filmes de PPI em meio de $0,01 \mathrm{~mol} \mathrm{~L}^{-}$ ${ }^{1}$ de $\mathrm{TBAClO}_{4}$ em $\mathrm{ACN}$ a diferentes potenciais aplicados. As letras representam a região das diferentes bandas dos espectros.

Figura 4.11 Curvas de desconvolução dos espectros de absorbância dos filmes de PPI obtidos a partir da Figura 4.10.

Figura 4.12 Espectros de absorção no UV-VIS de filmes de CP3MET em meio de 0,01 mol L ${ }^{-1}$ de $\mathrm{TBAClO}_{4} \mathrm{em} \mathrm{ACN}$ a diferentes potenciais aplicados. As letras representam as diferentes bandas dos espectros.

Figura 4.13 Curvas de desconvolução dos espectros de absorbância dos filmes de CP3MET obtidos a partir da Figura 4.12.

Figura 4.14 Espectros de absorção no UV-VIS de filmes de CPPI em meio de $0,01 \mathrm{~mol}$

$\mathrm{L}^{-1}$ de $\mathrm{TBAClO}_{4}$ em $\mathrm{ACN}$ a diferentes potenciais aplicados. As letras representam

as diferentes bandas dos espectros.

Figura 4.15 Curvas de desconvolução dos espectros de absorbância dos filmes de CPPI obtidos a partir da Figura 4.14.

Figura 4.16 Espectros de FT-Raman dos filmes dos homopolímeros PPP, P3MET e PPI e dos filmes mistos CP3MET e CPPI, sintetizados sobre FTO em meio a ACN e $0,01 \mathrm{~mol} \mathrm{~L}^{-1}$ de $\mathrm{TBAClO}_{4}$

Figura 4.17 Espectro FTIR por reflectância de filmes de PPP eletrossintetizados sobre FTO em meio de uma solução de $0,1 \mathrm{~mol} \mathrm{~L}^{-1}$ de bifenila, $0,01 \mathrm{~mol} \mathrm{~L}^{-1}$ de $\mathrm{TBAClO}_{4} \mathrm{em} \mathrm{ACN} \mathrm{a} \mathrm{v}=50 \mathrm{~m} \mathrm{~V} \mathrm{~s}^{-1}$

Figura 4.18 Espectro FTIR por reflectância do filme de CP3MET eletrossintetizados sobre FTO em meio de uma solução de $0,1 \mathrm{~mol} \mathrm{~L}^{-1}$ de bifenila, $0,05 \mathrm{~mol} \mathrm{~L}^{-1}$ de 3metiltiofeno, $0,01 \mathrm{~mol} \mathrm{~L}^{-1}$ de $\mathrm{TBAClO}_{4} \mathrm{em} \mathrm{ACN} \mathrm{a} \mathrm{v}=50 \mathrm{~m} \mathrm{~V} \mathrm{~s}^{-1}$.

Figura 4.19 Espectro de FTIR por reflectância do filme de CPPI eletrossintetizados sobre FTO em meio de uma solução de $0,1 \mathrm{~mol} \mathrm{~L}^{-1}$ de bifenila, $0,01 \mathrm{~mol} \mathrm{~L}^{-1}$ de pirrol, $0,01 \mathrm{~mol} \mathrm{~L} \mathrm{-1} \mathrm{de} \mathrm{TBAClO}_{4} \mathrm{em} \mathrm{ACN} \mathrm{a} \mathrm{v}=50 \mathrm{~m} \mathrm{~V} \mathrm{~s}^{-1}$. 


\section{Acrônimos}

$\begin{array}{ll}- & \text { carga negativa } \\ + & \text { carga positiva } \\ \text { ACN } & \text { Acetonitrila } \\ \text { CE } & \text { Contra-eletrodo } \\ \text { CP3MET } & \text { Derivado poli-p-fenileno-3-metiltiofeno } \\ \text { CPPI } & \text { Derivado poli-p-fenileno-pirrol } \\ E^{\prime}{ }_{\text {oxi }} & \text { Potencial de oxidação final } \\ E_{\text {red }}^{\prime} & \text { Potencial de redução final } \\ E_{f} & \text { Potencial final } \\ E_{\mathrm{i}} & \text { Potencial inicial } \\ \mathrm{E}_{\max } & \text { Potencial máximo aplicado } \\ \mathrm{E}_{\min } & \text { Potencial mínimo aplicado } \\ \mathrm{E}_{\text {oxi }} & \text { Potencial de oxidação } \\ \text { ER } & \text { Eletrodo de referência } \\ \mathrm{E}_{\text {red }} & \text { Potencial de redução } \\ \text { ET } & \text { Eletrodo de trabalho } \\ \text { FTIR } & \text { Infravermelho com transformada de Fourier } \\ \text { FTO } & \text { Eletrodo de vidro condutor: lâmina de vidro coberta com } \\ & \text { óxido de estanho dopado com flúor } \\ \text { HOMO } & \text { Highest occupied molecular orbital } \\ \text { LEDs } & \text { Dispositivos emissores de luz } \\ \text { LUMO } & \text { Lowest unoccupied molecular orbital } \\ \text { P3MET } & \text { Poli(3-metiltiofeno) } \\ \text { PLEDs } & \text { Dispositivos de polímeros emissores de luz } \\ \text { PPI } & \text { Polipirrol } \\ \text { PPP } & \text { Poli-p-fenileno } \\ \text { QRE-Ag } & \text { Eletrodo de quase referência de prata } \\ \text { TBAClO } & \text { Perclorato de tetrabutilamônio } \\ \text { VC } & \text { Voltametria cíclica } \\ & \\ & \end{array}$




\section{Resumo}

Este trabalho descreve a síntese eletroquímica, a caracterização eletroquímica e estrutural e as propriedades ópticas dos filmes de poli( $p$-fenileno) (PPP), poli-3metiltiofeno (P3MET), polipirrol (PPI) e dos derivados poli-p-fenileno-3-metiltiofeno (CP3MET) e poli-p-fenileno-pirrol (CPPI). Nossa motivação pode ser justificada pelo fato de o PPP e dos derivados serem polímeros conjugados eletroluminescentes na região do azul e importantes candidatos a serem empregados como camadas ativas em dispositivos emissores de luz (LEDs). Os filmes foram eletroquimicamente sintetizados sobre eletrodos de óxido de estanho dopado com flúor (FTO) em um meio não-aquoso de acetonitrila e perclorato de tetrabutilamônio. A resposta eletroquímica dos filmes de PPP, P3MET, PPI, CP3MET e CPPI foi investigada por voltametria cíclica em uma solução livre de monômeros, quando se verificou a formação de filmes eletroativos e estáveis eletroquimicamente. As propriedades ópticas dos filmes foram investigadas por espectroscopia de absorção in situ no UV-VIS, uma técnica amplamente usada para se estudar a estrutura eletrônica da maioria dos polímeros. Os espectros de UV-VIS dos filmes de PPP, P3MET, PPI, CP3MET e CPPI foram obtidos a diferentes potenciais, quando se verificou a ocorrência da transição $\pi$ - $\pi^{*}$ dos filmes em seu estado neutro e a formação de estados polarônicos e bipolarônicos dos polímeros durante a sua oxidação. A caracterização estrutural dos filmes foi investigada por espectroscopia FT-Raman e FTIR, quando se verificou que o espectro dos filmes de CP3MET e CPPI, preparados por eletrooxidação de co-monômeros, apresentavam apenas as bandas características dos filmes dos homopolímeros, P3MET e PPI. 


\section{Abstract}

This work describes the electrochemical synthesis, structural and eletrochemical characterization, and the optical properties of poly(p-phenylene) (PPP), poly(3methylthiophene) (P3MET), polypyrrole (PPI) and their derivatives poly(p-phenylene-3methylthiophene) (CP3MET) and poly(p-phenylene-pyrrole) (CPPI) films. Our motivation cab be justified by the fact that poly(p-phenylene) (PPP) and its derivatives are conjugated polymers that emit in the blue range of energy, and they appoint as potential candidates as active layers in displays (LEDs). The films were electrochemically synthesized on fluorine-tin-oxide glass (FTO) electrodes in a nonaqueous medium contend acetonitrile and $\mathrm{TBAClO}_{4}$. The electrochemical response of the PPP, P3MET, PPI, CP3MET and CPPI films were investigated by cyclic voltammetry in a monomer-free solution with the films showing a typical electroactive response. Their optical properties were investigated by in situ UV-VIS absorption spectroscopy, a technique widely used aiming at understanding the electronic structure of most polymers. The UV-VIS spectra of the PPP, P3MET, PPI, CP3MET and CPPI films were obtained at different p-doping states, i.e., at different applied potential allowing us to calculate the $\pi-\pi^{*}$ transition of the films at their neutral, and polaronic and bipolaronic states. The structural characterization of the films was investigated by FT-Raman and FTIR spectroscopy, where it was verified that the films prepared by the electrooxidation of co-monomers showed only the bands that were typical of those ones observed in the spectra of the homopolymers, P3MET and PPI. 


\section{Capítulo 01: Objetivos e apresentação da dissertação}

Este trabalho teve como principal objetivo a eletrossíntese e caracterização eletroquímica e espectroscópica de alguns polímeros conjugados, sendo eles o poli $(p$ fenileno) (PPP), polipirrol (PPI) e poli(3-metiltiofeno) (P3MET) e os polímeros mistos, poli( $p$-fenileno-pirrol) (CPPI) e poli(p-fenileno-3-metiltiofeno) (CP3MET). Os filmes foram obtidos eletroquimicamente com controle da umidade e em intervalos de potenciais adequados. As técnicas utilizadas para a caracterização in situ e ex situ dos polímeros foram: espectroscopias FT-Raman, FTIR por reflectância, UV-VIS, e voltametria cíclica.

Nesta dissertação foi realizada uma análise químico-estrutural dos polímeros mistos CPPI e CP3MET, os quais são importantes candidatos na fabricação de PLEDs. A motivação em realizar esse trabalho deu-se pelo fato dos PLEDs, em geral, apresentarem algumas vantagens, como a emissão em toda a região do visível, baixo custo quando comparados aos LCDs ou OLEDs e ainda a possibilidade de construção de dispositivos flexíveis.

Para isso, fez-se a síntese do PPP, um polímero eletroluminescente na região do azul do espectro eletromagnético e que também pode ser empregado na fabricação de dispositivos eletroluminescentes (LEDs) e também a síntese dos polímeros PPI, P3MET. O PPI possui algumas características como, estabilidade térmica, facilidade na preparação e baixo potencial de oxidação, podendo ser preparado em meios aquosos e não-aquosos. Já o P3MET conta também com uma maior facilidade na preparação em relação ao PPP, estabilidade e boa adesão em diferentes eletrodos.

Dessa foram, pode-se dizer que a síntese e a caracterização desses filmes mistos, PPP/PPI (CPPI) e PPP/P3MET (CP3MET), foi realizada com a tentativa de facilitar a síntese do PPP e melhorar suas propriedades, além de produzir esses novos materiais derivados do PPP que emitam na região do azul do espectro eletromagnético, já que possuem o PPP em sua composição e ainda, reunir as principais características de ambos os homopolímeros que os compõem. 
Para a apresentação destes resultados, a dissertação foi dividida nos seguintes capítulos: Capítulo 2, que apresenta um breve histórico sobre os polímeros conjugados e as suas propriedades elétricas e eletroluminescentes para aplicações em LEDs, destacando as propriedades do PPP, PPI e P3MET, Capítulo 3, em que são apresentados os métodos de síntese e as técnicas de caracterização dos filmes poliméricos, destacando também o método para a limpeza dos substratos utilizados, Capítulo 4, são apresentados e discutidos os resultados obtidos sobre a síntese e a resposta eletroquímica dos filmes de PPP, PPI, P3MET, CPPI e CP3MET e a caracterização dos filmes mistos, CPPI e CP3MET, pelas técnicas espectroscópicas UV-VIS in situ, FT-Raman e FTIR por reflectância e finalizando com o Capitulo 5, onde são apresentadas as conclusões finais e as perspectivas para trabalhos futuros. 


\section{Capítulo 02: Revisão Bibliográfica}

Este capítulo iniciará com um breve histórico a respeito dos polímeros conjugados, prosseguindo com uma descrição das propriedades e aplicações dos polímeros estudados nesta dissertação.

\subsection{Histórico}

Os primeiros estudos sobre os polímeros condutores surgiram em meados dos anos $70 \mathrm{com}$ a descoberta do poliacetileno. Em 1967, o poliacetileno foi sintetizado na forma de um pó que, posteriormente, foi preparado como um filme brilhante, prateado e flexível por conta de um erro cometido no grupo do professor Shirakawa. Esse procedimento foi repetido várias vezes até se descobrir que a concentração de catalisador de Ziegler-Natta utilizado no preparo de filmes de poliacetileno estava acima da usual ${ }^{[1,2]}$.

Em 1976, foram feitos estudos mais detalhados com o poliacetileno, que passou a ser considerado um tipo de metal sintético. Shirakawa, trabalhando em colaboração com A. G. Mac Diarmid e A.J. Heeger na Universidade da Pensilvânia observou que a condutividade elétrica do poliacetileno aumentava sensivelmente após a dopagem com iodo. Assim, o poliacetileno foi obtido como um filme com brilho metálico dourado e com a condutividade sensivelmente aumentada ${ }^{[1,3]}$. 
Na década de 80 , os pesquisadores Naarmann e Theophilou da BASF, em Ludwingshafen, conseguiram aumentar ainda mais a condutividade do poliacetileno pelo uso de um novo catalisador e, ainda, orientar o filme por estiramento. Por meio destas metodologias, foi possível se obter um filme de poliacetileno com uma condutividade semelhante à do cobre metálico, que é equivalente a $10^{6} \mathrm{~S} \mathrm{~cm}^{-1[4]}$, em temperatura ambiente.

Com os avanços nas pesquisas na área, surgiram outros polímeros conjugados: o polipirrol, politiofeno e polianilina (Figura 2.1), que apresentam relativa estabilidade química, favoráveis propriedades mecânicas e processabilidade em solução, ou seja, características superiores às do poliacetileno, e ainda podem ser aplicados em baterias, sensores, dispositivos eletrocrômicos, etc ${ }^{[1,3,4]}$. 


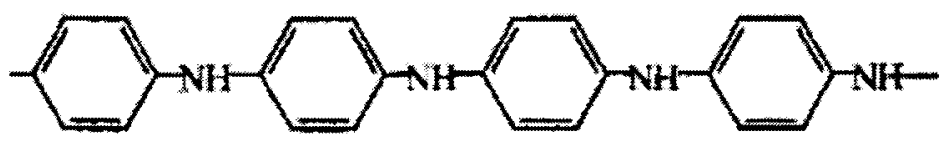

Polianilina

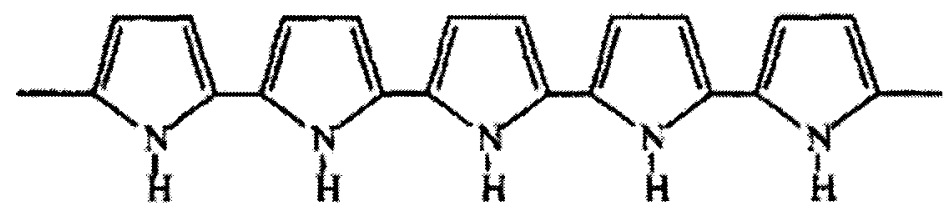

Polipirrol

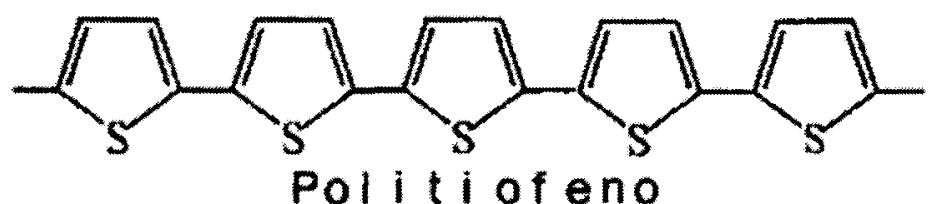

Figura 2.1 Estruturas de alguns polímeros condutores mais estudados

$\mathrm{Na}$ década de 80 surgia o primeiro relato sobre o uso de polímeros em LEDs a partir da descoberta da eletroluminescência do poli-p-fenilenovinileno (PPV). Nesta área, porém, muito ainda há para ser feito visando melhorar as características de LEDs que têm o PPV como camada ativa, como uma melhora em sua eficiência, durabilidade e que possam emitir em uma ampla gama de cores ${ }^{[5,6]}$. Essa década foi marcada pelo grande número de trabalhos sobre a fabricação e caracterização de dispositivos eletrônicos poliméricos e contou com a descoberta dos dispositivos eletroluminescentes de polímeros conjugados (PLEDs) por Friend, em Cambridge em $1990^{[8,9]}$.

Com a descoberta e o desenvolvimento dos polímeros condutores, em 2000, os pesquisadores Heeger, McDiamird e Shirakawa receberam o Prêmio Nobel em Química por contribuições dadas à pesquisa na área ${ }^{[7]}$. 
Esses polímeros ditos condutores fazem parte de uma geração recente de polímeros. É uma classe de materiais muito promissora devido às suas propriedades elétricas e ópticas e que são muito semelhantes às de um metal. Apesar de serem inerentemente isolantes, os materiais poliméricos conjugados se comportam como condutores ou semicondutores a partir de um processo de dopagem química ou eletroquímica, o que eleva os seus valores de condutividade para acima de $1000 \mathrm{~S} \mathrm{~cm}^{-1}$ [10]

A estrutura dos polímeros conjugados se caracteriza pela alternância de ligações saturadas e insaturadas, ou seja, as suas propriedades condutoras se justificam pela existência de elétrons $\pi$ deslocalizados ao longo da cadeia polimérica principal. Os átomos que formam as ligações são hibridizados na forma $\mathrm{sp}^{2}+\mathrm{p}_{\mathrm{z}}$, sendo os elétrons da cadeia principal unidos por ligações $\sigma$ formadas a partir de orbitais $\mathrm{sp}^{2}$ de cada átomo participante da ligação saturada $\mathrm{C}$-C. Já as ligações insaturadas $\mathrm{C}=\mathrm{C}$ são formadas pela sobreposição de orbitais $\mathrm{p}_{\mathrm{z}}$, ou também chamados de orbitais "p puros", de acordo com a Figura $2.2^{[4,8,9,10,11]}$.

\section{(a) Ligações $\sigma$ : C-C e C-H}

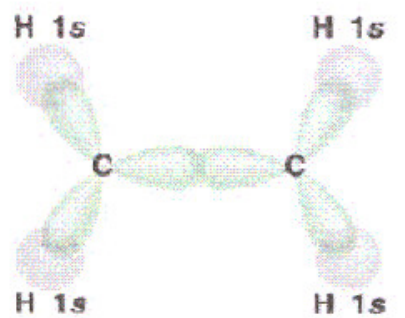

(b) Ligações $\pi$ : $C=C$

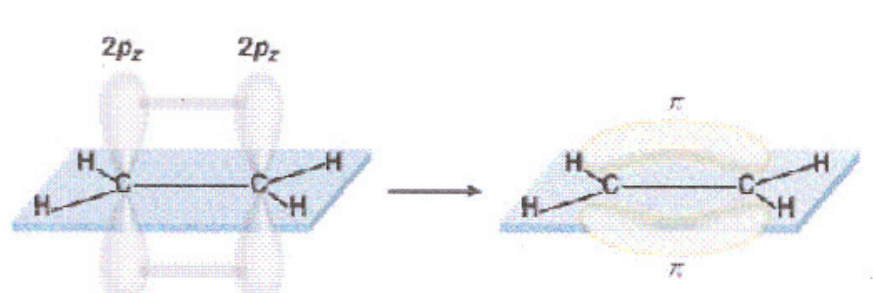

Figura 2.2 Formação da ligação (a) $\sigma$ a partir da sobreposição dos orbitais $\mathbf{s p}^{2}$ e (b) $\pi$ em um plano perpendicular ao plano da cadeia principal, constituída pela ligação $\sigma$. 


\subsection{Processo de dopagem de polímeros conjugados: formação de pólarons, bipólarons e sólitons.}

Como os polímeros conjugados possuem elétrons $\pi$ deslocalizados ao longo da cadeia $\mathrm{C}=\mathrm{C}$, estes podem ser removidos ou adicionados, formando um íon polimérico, em um processo de dopagem química ou eletroquímica ${ }^{[10]}$.

O processo de dopagem de um polímero orgânico conjugado é, de uma forma simplificada, uma reação de transferência de cargas entre o polímero e o agente dopante. À medida que essas cargas são removidas ou adicionadas na cadeia polimérica, ocorrem mudanças tanto na geometria do polímero quanto de alguns parâmetros, tais como o ângulo de torção e do comprimento das ligações ${ }^{[11]}$.

Em se tratando de um processo de dopagem eletroquímico, o nível de dopagem será determinado pelo valor do potencial aplicado a um eletrodo de trabalho onde está depositado o polímero, fazendo com que a sua relativamente baixa condutividade (na faixa de $10^{-10}$ a $10^{-5} \mathrm{~S} \mathrm{~cm}^{-1}$ ) aumente e resulte em mudanças em suas propriedades elétricas, magnéticas, ópticas e estruturais ${ }^{[3,12]}$.

Os termos pólaron, bipólaron e sóliton são freqüentemente citados em artigos relacionados aos polímeros condutores. Um sóliton (Figura 2.3a) é um defeito eletricamente neutro, com spin eletrônico $1 / 2\left(S^{0}\right)$. Quando um sóliton é formado, formase um nível eletrônico não-ligante no centro da banda no nível do gap. Um sóliton neutro apresenta um nível eletrônico não-ligante ocupado por um elétron. No caso de um sóliton positivo ou negativo, ou não há nenhum elétron no nível eletrônico, ou ele está 
ocupado por dois elétrons. Para todos esses tipos de sólitons, ocorre a transição eletrônica apenas na banda no nível do $\operatorname{gap}^{[13,10]}$.

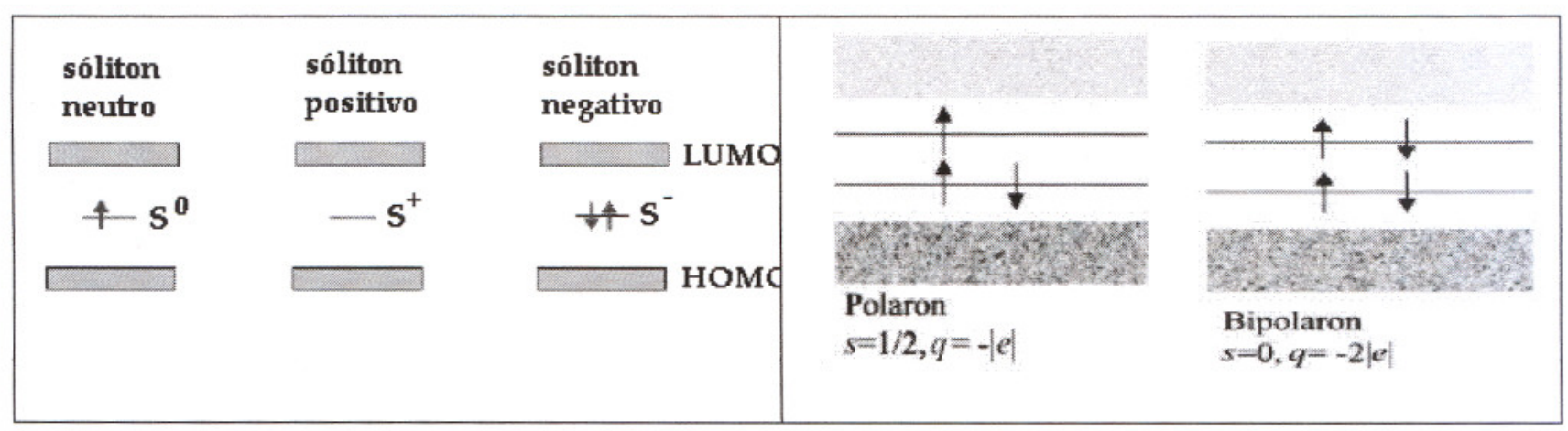

Figura 2.3 Níveis de energia: (a) sólitons em poliacetileno [4] e (b) pólaron e bipólaron ${ }^{[3]}$.

O único polímero que apresenta degenerescência de estado é o transpoliacetileno, pois no caso de todos os outros polímeros, duas regiões da cadeia separadas por um defeito são energeticamente diferentes. Para minimizar a energia do sistema, os defeitos ocorrem na presença de um outro defeito, o anti-sóliton. Esse par sóliton-anti-sóliton é denominado pólaron. Quando dois pares de sóliton-anti-sóliton se encontram, eles dão origem a um defeito com spin nulo, o bipólaron (Figura 2.3b) ${ }^{[11]}$.

No que diz respeito à formação de pólarons e bipólarons, a dopagem tipo- $p$ (oxidativa) de um polímero leva à formação de cátions e dicátions radicais do tipo $\left(\mathrm{p}^{+}\right) \mathrm{e}$ $\left(\mathrm{Bp}^{2+}\right)$ consecutivamente. Com a oxidação, um elétron é removido de uma longa cadeia polimérica ${ }^{[11,12]}$, assim com a dopagem tipo- $p$ ou tipo- $n$ (injeção de buraco ou elétron) 
formará um pólaron positivo ou negativo, dependendo da carga injetada, formando bandas intermediárias entre o HOMO e o LUMO. Em um estado pólaron $\left(\mathrm{p}^{+}\right)$, surgem dois níveis eletrônicos, um ligante e o outro antiligante.

Pela junção de dois pólarons positivos ou negativos, será criado o bipólaron, formando assim outra banda intermediária entre o HOMO e o LUMO. O bipólaron (p") corresponde ao diânion, que se forma com a adição de dois elétrons ao nível antiligante quando então duas transições são esperadas ${ }^{[11]}$. Nessa dopagem do tipo- $n$, formam-se ânions radicais portadores de cargas negativas denominados de pólarons $\left(\mathrm{p}^{-}\right)$e bipólarons $\left(\mathrm{Bp}^{2-}\right)$ ( Figura 2.3 b). Quando um pólaron (p*) é formado, um elétron é adicionado ao nível pólaron antiligante e três transições são esperadas.

Quando um pólaron $\left(\mathrm{p}^{+}\right)$encontra um pólaron $\left(\mathrm{p}^{-}\right)$, eles podem se recombinar e emitir luz, levando à formação de um éxciton singleto ${ }^{[10]}$.

O estudo destes estados polarônicos e bipolarônicos é essencial para o entendimento a respeito do nível de dopagem de polímeros conjugados e de suas estruturas eletrônicas ${ }^{[13]}$.

\subsection{Copolimerização e formação de filmes mistos}

A copolimerização ou a formação de filmes mistos é um importante método a ser utilizado visando melhorar a qualidade dos homopolímeros envolvidos. Este processo permite ter um maior controle sobre algumas propriedades dos polímeros, tais como: condutividade elétrica, estabilidade ao ambiente e processabilidade em solução, contribuindo, desta maneira, para o avanço de suas aplicações ${ }^{[14]}$. 
A síntese eletroquímica de muitos desses filmes resulta no surgimento de novos materiais eletricamente ativos com características de ambos os homopolímeros ${ }^{[14,15]} \mathrm{e}$ melhores propriedades mecânicas, ópticas e morfológicas. A única restrição desta metodologia é que os co-monômeros devem ter potenciais de oxidação relativamente próximos para que a cadeia final apresente unidades monoméricas alternadas ${ }^{[4]}$.

A caracterização desses filmes mistos é de grande relevância, já que se necessita constatar a obtenção de fato de um copolímero ou de uma mistura de homopolímeros com características próprias, ou ainda, de um material depositado sobre outro como uma bicamada ou blenda. ${ }^{[4]}$.

Dentre os polímeros que podem ser sintetizados sob as mesmas condições do PPP estão o polipirrol (PPI) e o politiofeno (PTIO) e seus derivados ${ }^{[4]}$.

Latonen et al. estudaram a copolimerização da bifenila e do 3-octiltiofeno em meio a $\mathrm{LiAsF}_{6}$, bem como as propriedades do copolímero formado e observaram no espectro de UV-VIS in situ dos copolímeros a ocorrência de um deslocamento da banda referente ao estado neutro, sendo a de maior intensidade, para maiores comprimentos de onda. Isso se deve a um aumento na conjugação do copolímero formado, o poli(3octiltiofeno-bifenila). O espectro de UV-VIS in situ do copolímero formado também apresentou características apenas do homopolímero poli(3-octiltiofeno), não apresentando transições referentes ao PPP. Observaram também que o número de unidades monoméricas presentes no produto final é dependente da razão e da concentração de monômeros utilizados e do método eletroquímico empregado ${ }^{[14,15]}$. 


\subsection{Alguns polímeros conjugados}

Neste tópico será feita uma breve discussão sobre os polímeros estudados neste trabalho: PPP, PPI e o P3MET (Figura 2.4), bem como sobre suas propriedades e aplicações.

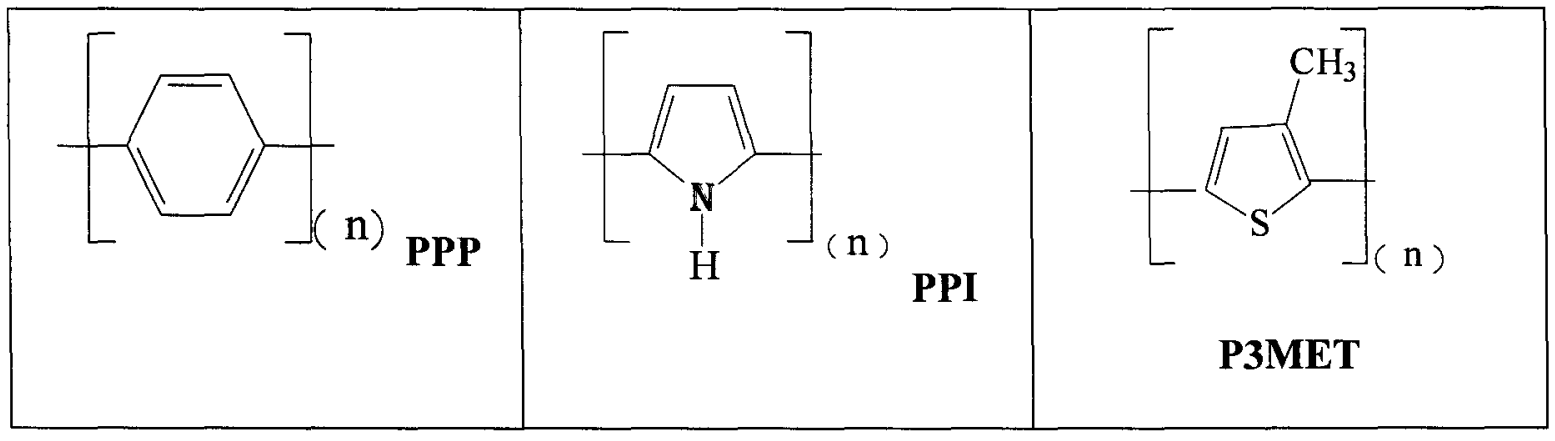

Figura 2.4 Estruturas da químicas dos polímeros estudados aqui: PPP, PPI e P3MET.

\subsubsection{Polipirrol}

O polipirrol (PPI) é um dos polímeros conjugados mais estudados, já que as suas favoráveis propriedades físicas e elétricas e ópticas permitem com que este possa ser aplicado em dispositivos eletrônicos, baterias e sensores ${ }^{[17,18,19]}$. O pirrol pode ser oxidado a um relativamente baixo potencial, se comparado a outros monômeros (tiofenos, benzeno e anilina) e em diferentes meios, aquosos e não-aquosos. 
As propriedades condutoras do PPI estão relacionadas à presença de elétrons deslocalizados ao longo da sua cadeia polimérica conjugada. Como resultado, quanto mais positivamente carregada estiver a cadeia polimérica do PPI e quanto mais longa for, maior será a sua condutividade, com uma maior coplanaridade entre as suas cadeias $[20,21]$.

\subsubsection{Poli(3-metiltiofeno)}

O politiofeno e seus derivados têm atraído considerável atenção nos últimos 20 anos devido à estabilidade desses polímeros no estado dopado e neutro e quando na presença de oxigênio do ar. Além disso, eles apresentam favoráveis propriedades no estado sólido: termocromismo, eletrocromismo, luminescência e fotocondutividade ${ }^{[3]}$.

$\mathrm{Na}$ década de 80, o poli(3-metiltiofeno) (P3MET) era ainda um polímero condutor com poucos resultados sobre a sua síntese e propriedades vibracionais ${ }^{[22]}$. Porém, hoje ele encontra aplicação principalmente em dispositivos eletrônicos e traz como vantagem a sua melhor solubilidade e o menor potencial de oxidação quando comparado ao tiofeno. O politiofeno e o P3MET fazem parte de uma classe de polímeros que possuem um estado de energia não-degenerado. Como resultado, as excitações predominantes nestes polímeros são aquelas relacionadas às espécies pólaron e bipólaron ${ }^{[23,24]}$. Pode-se dizer que o defeito predominante no politiofeno é o bipólaron, ou seja, o pólaron não pode estar presente em politiofenos pela rápida eficiência na evolução da formação do estado bipólaron durante a oxidação do polímero ${ }^{[25]}$. Pode-se 
dizer que as mudanças estruturais e eletrônicas do P3MET são provocadas pelo processo de dopagem, pela variação do comprimento da conjugação da cadeia polimérica e pela distância entre as cadeias através do processo de oxidação do polímero ${ }^{[25,26]}$.

\subsubsection{Poli( $p$-fenileno)}

Desde 1990, muitos polímeros conjugados emissores de luz têm sido estudados, sendo um deles o poli-p-fenileno (PPP), um material de grande interesse devido à sua alta taxa de fotoluminescência, boa estabilidade térmica e também pela sua emissão de luz na região do azul do espectro eletromagnético ${ }^{[3]}$.

O PPP é um polímero conjugado formado por anéis fenilênicos, sendo o ângulo entre eles de aproximadamente $22^{\circ}$. A largura da banda do orbital de mais alta energia (HOMO) do PPP é fortemente afetada pelo valor deste ângulo, que varia entre 3,5 eV e $3.9 \mathrm{eV}$ a $22^{\circ}$, em anéis fenilênicos coplanares ${ }^{[17]}$. O PPP é completamente rígido, altamente cristalino e possui duas formas de ressonância em sua estrutura química, a benzenóide e a quinóide, como mostra a Figura 2.5, que não são energeticamente equivalentes ${ }^{[13,16,17]}$. 


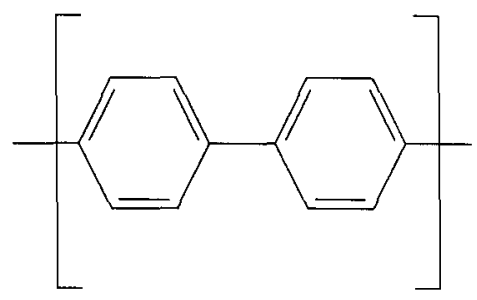

(n) Benzenóide

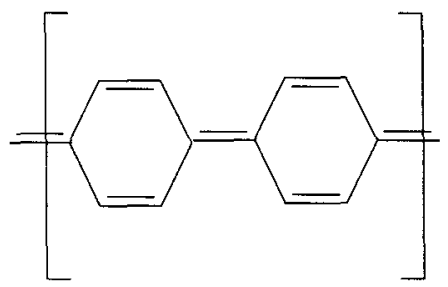

(n)Quinóide

Figura 2.5 PPP nas formas benzenóide e quinóide.

Os filmes de PPP podem ser preparados por várias rotas de síntese, tais como: síntese química, eletrossíntese, ou por deposição a vácuo ${ }^{[3]}$. É um polímero interessante para aplicação em LEDs, baterias e em dispositivos eletrocrômicos ${ }^{[3,16]}$, sendo que o seu uso em LEDs, porém, é limitado quando sintetizado quimicamente, pois o PPP é obtido na forma de um pó insolúvel. No entanto, filmes de PPP e derivados têm sido obtidos por evaporação a vácuo de oligômeros ou por spin casting de soluções de derivados solúveis do PPP. Os filmes de PPP têm sido também obtidos pelo uso de um polímero precursor solúvel, que após tratamento térmico para eliminação de grupos substituintes e aumento da conjugação da cadeia, origina um filme em um substrato ${ }^{[27]}$.

Para evitar as dispendiosas etapas de tratamento térmico de filmes de precursores e também as várias etapas que envolvem a deposição do PPP quimicamente polimerizado, a simultânea síntese e deposição do PPP em substratos condutores pode ser feita eletroquimicamente, quando se tem um relativo controle sobre as suas 
diferentes características, tais como, a espessura e a morfologia do polímero obtido na forma de um filme ${ }^{[27]}$.

Por meio da síntese eletroquímica, o PPP pode ser obtido pela oxidação do benzeno em diferentes meios ácidos, $\mathrm{CF}_{3} \mathrm{SO}_{3} \mathrm{H}, \mathrm{SbF}_{5}$ e $\mathrm{AlCl}_{3}$ ou em meio aquoso ácido de uma microemulsão benzeno/ $\mathrm{H}_{2} \mathrm{SO}_{4}$ e dodecil sulfato de sódio. Filmes de PPP de melhor qualidade podem ser obtidos a partir da eletro-oxidação da bifenila em diferentes

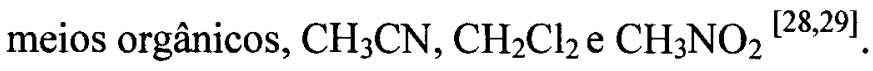

A Figura 2.6 abaixo exemplifica a reação de formação do PPP preparado eletroquimicamente a partir do benzeno como monômero de partida.
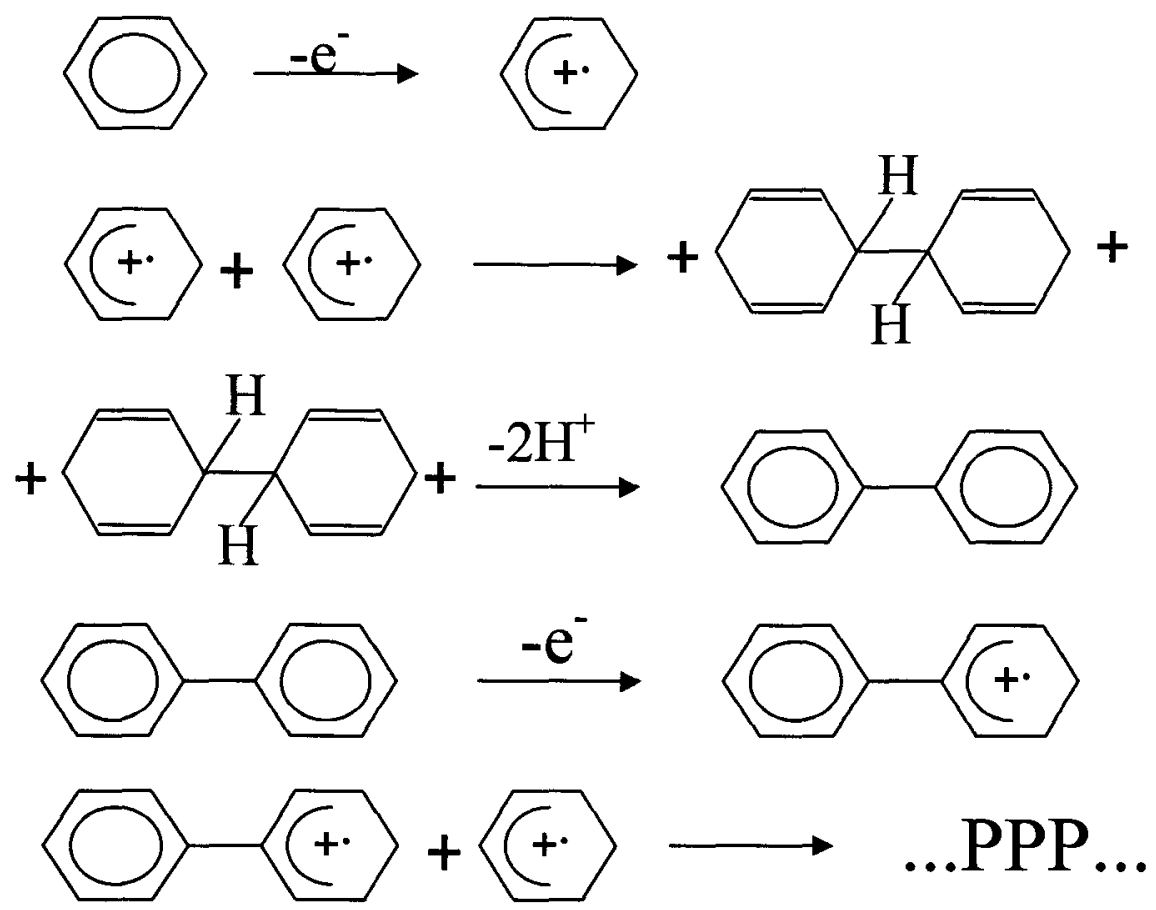

Figura 2.6 Mecanismo de eletrossintese do PPP. 
O mecanismo de eletropolimerização do benzeno (Figura 2.6) envolve tanto etapas químicas, durante o acoplamento dos radicais cátions, como também etapas eletroquímicas de oxidação. Durante a etapa eletroquímica, pode ocorrer também a dopagem do filme via inserção de ânion ou de cátion para que haja o balanceamento de $\operatorname{cargas}^{[4]}$.

Assim, a partir do polímero formado, para se obter maiores informações sobre a estrutura química de filmes de PPP obtidos em diferentes meios e por diferentes técnicas, inclusive eletroquímica, utiliza-se a técnica de espectroscopia no infravermelho (IV), que é uma das mais poderosas ferramentas para tal procedimento. A existência nos espectros de IV do PPP das bandas em 850 e $900 \mathrm{~cm}^{-1}$, atribuídas à deformação C-H fora do plano das vibrações de 1,2,4 benzenos substituídos, caracterizam a presença de ligações cruzadas no polímero ${ }^{[30,31,32]}$. Goldenberg et al. realizaram medidas de absorção no UV-VIS in situ e ex situ com o intuito de se caracterizar os filmes de PPP preparados por eletro-oxidação. Nos espectros de UV-VIS do PPP, pode ser observada uma banda de absorção próxima a 3,5 - 3,0 eV e que é atribuída à energia de gap do PPP. Após a oxidação do filme por meio da aplicação de diferentes potenciais, outras bandas aparecem nos espectros atribuídas aos estados polarônico e bipolarônico do filme de PPP oxidado ${ }^{[31]}$.

Em se tratando das características de filmes de PPP eletrossintetizados, eles apresentam diferentes morfologias e espessuras dependendo da quantidade de carga total utilizada na síntese e do método de preparação, se por eletro-oxidação ou eletro-redução de determinado monômero. Quando diferentes meios são utilizados durante a síntese, o filme de PPP pode ter a sua cadeia modificada de linear para entrecruzada, variando a 
sua morfologia de fibrilar para compacta e, ainda, alterando sua condutividade elétrica de baixa para uma alta condutividade ${ }^{[5,32]}$.

Os filmes de PPP sintetizados a partir da p-terfenila em meio de ACN e $\mathrm{TBAClO}_{4}$ têm sido analisados, de acordo com a literatura, pela técnica de microscopia eletrônica de varredura (MEV) e apresentam três tipos de morfologia: fibrilar, granular e compacta. Estes filmes não se apresentaram viáveis para aplicação em LEDs, devido a uma baixa espessura ${ }^{[4]}$.

De acordo com a literatura, também foram feitos estudos sobre a morfologia de filmes de PPP por meio da técnica de microscopia de força atômica (AFM), quando se constatou que os filmes eram mais espessos após aumentar o número de ciclos, durante a eletro-oxidação da bifenila em meio de $\mathrm{ACN}$ e $\mathrm{TBAClO}_{4}$. Além disso, os filmes apresentaram apenas um tipo de morfologia, compacta globular ${ }^{[4]}$. Recentemente, foram obtidos filmes de PPP cristalinos e que emitiam no azul se excitados a $340 \mathrm{~nm}$. Com o aumento no número de ciclos e, portanto, da espessura dos filmes, a cristalinidade deu lugar a uma característica mais amorfa, desfavorecendo a emissão de luz ${ }^{[33]}$.

Omaba et al. investigaram as características de filmes de PPP eletro-oxidados e eletro-reduzidos a partir de medidas eletroquímicas e ópticas. Foi verificado, que a espessura do filme de PPP no estado oxidado aumentava com o aumento do número de ciclos e que era possível obter filmes espessos e com uma morfologia mais uniforme. Foram produzidos três filmes com diferentes números de ciclos e diferentes valores de carga total, $10,50 \mathrm{e} 100 \mathrm{mC} \mathrm{cm}^{-2}$. Neste caso, observou-se que a espessura estimada dos filmes no estado oxidado foi de 60, 150 e $220 \mathrm{~nm}$ e 70,120 e $140 \mathrm{~nm}$ para os filmes nos 
estados reduzidos. O filme no estado reduzido passou a ter uma morfologia do tipo rugosa com o aumento da espessura ${ }^{[32]}$.

De acordo com a literatura, estudos sobre a fotoluminescência de filmes de PPP preparados a partir do método do precursor solúvel e por eletro-redução foram também realizados na região entre 370 e $550 \mathrm{~nm}$. Foram observadas no espectro de emissão, duas bandas entre 450 e $470 \mathrm{~nm}$, atribuídas à vibração intramolecular dos anéis fenilênicos do PPP na sua forma reduzida. A fotoluminescência do filme de PPP obtido na sua forma eletro-oxidada em meio de $\mathrm{ACN}$, bifenila e $\mathrm{TBAClO}_{4}$ apresentou baixa eficiência em um intervalo de emissão semelhante ao observado para o filme de PPP na sua forma reduzida. Por meio das medidas de FTIR, Omaba et al., observou também que o PPP reduzido possui uma melhor regularidade estrutural do que o PPP oxidado e uma fotoluminescência mais intensa ${ }^{[32]}$.

A fotoluminescência também foi estudada para o PPP sintetizado sobre substratos de óxido de estanho dopado com índio (ITO) em meio de $\mathrm{ACN}$, bifenila, $\mathrm{LiClO}_{4}$ e $\mathrm{HClO}_{4}$ em várias concentrações. Foram obtidos espectros de fotoluminescência com absorções na região entre $400-520 \mathrm{~nm}$, sendo que surgiram duas bandas localizadas em $418 \mathrm{~nm}$ e $440 \mathrm{~nm}$ na região espectral do azul e violeta, comprovando assim, a ocorrência de emissão na região do azul ${ }^{[5]}$. 
IFSC - Ciência e Engenharia de Materiais

\subsection{Bibliografia}

1- MATTOSO L.H.C. Polímeros: Ciência e Tecnologia, ano VI, n. 03, jul/set 1996.

2- SHIRAKAWA H. The discovery of polyacetylene film - the dawning of an era of conducting polymers. Current Applied Physics, v. 01, Issues 4-5, p.281-286, 2001.

3- HEEGER A.J. Semiconducting and metallic polymers: the fourth generation of polymeric materials. Synthetic Metals, v.125, p.23-42, 2002.

4- EIRAS C. Eletrossintese e propriedades ópticas e morfológicas de filmes de poli-p-fenileno e derivados. São Carlos, 2004, 148p. tese (Doutorado)-Instituto de Física de São Carlos, Universidade de São Paulo.

5- IVO A.H., BENVENHO, A.R.V.; SERBENA, J.P.M.; MELLO, R.M.Q. Electrochemical preparation of PPP thin films. Journal of Solid State Electrochemistry, n.7, p.463-467, 2003.

6- QUEIROZ E.L. Propriedades elétricas de dispositivos emissores de luz utilizando óxido de zinco como eletrodo transparente. São Carlos, 2004, 84p. dissertação (Mestrado)-Instituto de Física de São Carlos, Universidade de São Paulo.

7- MILlER J.S. The 2000 Nobel Prize in Chemistry - A Personal Accolade. ChemPhysChem, v.01, p.229-230, 2000.

8- FRIEND R.H., GYMER R.W., HOLMES A.B., BURROUGHES J.H., MARKS R.N., TALIANI C., BRADLEY D.D.C. DOS SANTOS D.A., BREDAS J.L., LOGDLUND M., SALANECK W. R. Electroluminescence in conjugated polymers. Nature, v.39, 1999.

9- FRIEND R.H. Electronic Properties of conjugated polymers. Physics and chemistry of electrons and ions in condensed matter.1984, p.625-651.

10- GREENHAN H., FRIEND R.H.. Semiconducting device physics of conjugated polymers. Physics of the solid state v.49, 1995.

11- FURUKAWA Y.; TASUMI, M. Vibrational Spectroscopy of intact an doped conjugated polymers and their models. Modern Polymer Spectroscopy. New York, 1999. cap 04, p.207. 
12- MC DIAMIRD A. G. Synthetic Metals: a novel role for organic polymers. Synthetic Metals, v.125, p.11-22, 2002.

13- WISE, D. L. Electrical and optical polymer systems: fundamentals, methods, and applications. New York: Marcel Dekker, 1998, p.1239.

14- KVARNSTROM C. In situ UV-VIS and FTIR attenuated total reflectance studies on the electrochemically synthesized copolymer from biphenyl and 3octylthiophene. Journal of Electroanalytical Chemistry. v.512, p.36-48, 2001.

15- LATONEN R., KVARNSTROM C., IVASKA A. Electrochemical synthesis of a copolymer of poly (3-octylthiophene) and poly(paraphenylene).

Electrochimica Acta, v.44, p.1933-1943, 1999.

16- VASCHETTO M.E., MONKMAN A.P., SPRINGBORG M. First principles studies of some conducting polymers PPP, PPy, PPV, PPyV and PANI. Journal of Molecular Structure. v.468, p.181-191, 1999.

17- LINFORD R.G. Electrochemical science and technology of polymers. Elsevier Applied Science, Londres, v.01, 1987.

18- MIGAHED L.D, FAHMY T., ISHRA M., BARAKAT A. Preparation, characterization and electrical conductivity of polypyrrole composite films. Polymer Testing. v.23, p.361-365, 2004.

19- VALASKI R., AYOUB S., MICARONI L. The influence of electrode material on charge transport properties PPY thin films. Thin Solid Films. v.388 (1-2), p.171-176, 2001.

20- CHUAN LIU Y., HWANG B. Identification of oxidized PPY on Raman spectrum.Synthetic Metals. v.113, p.203-207, 2000.

21- CHUAN LIU Y. Characteristics of vibration modes of polypyrrole on surface-enhanced Raman scattering spectra. Journal of Electroanalytical Chemistry, v.571, p.255-264, 2004.

22- STEIGMEIER E.P., AUDERSET H., KOBEL W. Resonance raman scattering on poly (3- methylthiophene). Synthetic Metals, v.18, p.219- 224, 1987.

23- MAZUR M. Preparation of poly (3-methylthiophene). Thin films by in situ polymerization. Thin Solid Films. v.472, p.1- 4, 2005.

24- POPLAWSKI J, EHRENFREUND E., GLENIS S., FRANK A. J. Photoexcitation spectroscopy of poly(3-methylthiophene) - electronic bands and vibrational-modes. Synthetic Metals, v.28, p.335-340, 1989. 
25- HOIER S.N., PARK S.M. Electrochemistry of conductive polymers .11. Spectroelectrochemical studies of poly(3-methylthiophene) oxidation. Journal of Physical Chemistry, v.96 p.5188-5193, 1992.

26- BIN H., XINYI Z., XURONG X., WENBIN Z., SHAOJUN D. Doping Effects on the polymer- chain structure of poly(3-methylthiophene). Journal of Luminescence, v.53, p.546- 548, 1992.

27- ÖSTERGÅRD T., KVARNSTRÖM C., STUBB H., IVASKA A. Electrochemically prepared light-emitting diodes of poly(para-phenylene).Thin Solid Films, v.311, p.58-61 , 1997.

28- KVARNSTROM C., IVASKA A. Characterization and applications of poly(p-phenylene) and and poly(p-phenylenevinylene).Conductive Polymers: Transport, Photophysics andApplications. v.04, cap 09, p.487-515.

29- SOURBIAN P., AEIYACH S., LACAZE, P. C. Formation of polyparaphenylene (PPP) films by electrooxidation of biphenyl in $\mathrm{CH}_{2} \mathrm{Cl}_{2}$. Journal of Electroanalytical Chemistry v.303, p.125-137, 1991.

30- MIYASHITA K., KANEKO M.Vacuum-deposited poly(p-phenylene) thin film and its structure, morphology and electronic properties. Synth. Metals, v.68, p.161-165, 1995.

31- GOLDENBERG L.M., LACAZE P.C. Anodic synthesis of poly(p-phenylene) Synthetic Metals, v.58, p.271-293, 1993.

32- OMABA S, AMANO A., OSAKA T. Electroluminescence properties electropolymerized poly(para-phenylene) films by means of electrochemical oxidation and reduction. Journal of Electroanalytical Chemistry, v.430, p.97-102, 1997.

33- MANI A., PHANI K.L.N. Spherulitic morphology of electrochemicallydeposited polyparaphenylene (PPP) films. Journal of Electroanalytical Chemistry, v.513, p.126-132, 2001. 
IFSC - Ciência e Engenharia de Materiais

\section{Capítulo 03: Materiais e Métodos}

Neste capítulo, serão apresentadas as metodologias de preparação dos filmes de poli-p-fenileno (PPP), poli( $p$-fenileno-pirrol) (CPPI) e poli( $p$-fenileno-3-metiltiofeno) (CP3MET). Serão abordados os métodos de caracterização dos filmes poliméricos e de limpeza do substrato utilizado (FTO) e descritos os equipamentos utilizados nas etapas de síntese e caracterização destes materiais.

\subsection{Materiais e limpeza dos substratos}

Os reagentes abaixo descritos foram adquiridos comercialmente e utilizados como recebidos.

- Bifenila, monômero, $\mathrm{M}_{\mathrm{w}}=154,22 \mathrm{~g} \mathrm{~mol}^{-1}$ (Aldrich).

- 3-metiltiofeno, monômero, $\mathrm{M}_{\mathrm{w}}=98,17 \mathrm{~g} \mathrm{~mol}^{-1}, \rho=1,014 \mathrm{~g} \mathrm{~mL}^{-1}$ (Avocado).

- Pirrol, monômero, $\mathrm{M}_{\mathrm{w}}=72,13 \mathrm{~g} \mathrm{~mol}^{-1}, \rho=1,039 \mathrm{~g} \mathrm{~mL}^{-1}$ (Aldrich).

- Perclorato de tetrabutilamônio $\left(\mathrm{TBAClO}_{4}\right)$, eletrólito de suporte, $\mathrm{M}_{\mathrm{w}}$ $341,92 \mathrm{~g} \mathrm{~mol}^{-1}$ (Alfa Aesar).

A figura 3.1 mostra as fórmulas estruturais dos monômeros utilizados. 


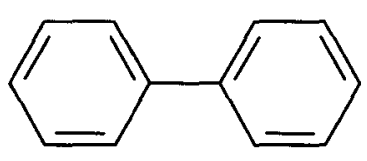

Bifenila

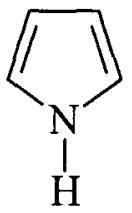

Pirrol<smiles>Cc1ccsc1</smiles>

3-Metiltiofeno

Figura 3.1 Fórmulas estruturais dos monômeros utilizados na síntese dos filmes de PPP, CPPI E CP3MET.

Para a limpeza dos substratos de FTO, que deve ser realizada rigorosamente antes da deposição dos filmes poliméricos, foi utilizada somente a etapa básica do método RCA de hidrofilização para a limpeza de lâminas de $\mathrm{Si}$ e $\mathrm{SiO}_{2}{ }^{[1]}$. Quando se tratar da limpeza de FTO, utiliza-se somente a parte básica de hidrofilização, uma vez que o ácido, neste caso, $\mathrm{HCl}$, poderá atacar o FTO. Portanto, utilizando-se da parte básica, os substratos de FTO foram imersos em uma solução 1:1:5 v/v de $\mathrm{NH}_{4} \mathrm{OH} 28 \%$, $\mathrm{H}_{2} \mathrm{O}_{2} 30 \%$ e $\mathrm{H}_{2} \mathrm{O}$ ultrapura. Em seguida, a solução contendo os substratos imersos foi aquecida a $75-80^{\circ} \mathrm{C}$, permanecendo nesta temperatura por $30 \mathrm{~min}$. Após esse periodo de tempo, os substratos foram retirados e lavados em água ultrapura em abundância. Como segunda parte da limpeza do método RCA, a parte ácida, uma solução de 1:1:6 v/v, respectivamente, de $\mathrm{HCl}, \mathrm{H}_{2} \mathrm{O}_{2}$ e de água ultrapura é aquecida até $70^{\circ} \mathrm{C}$, quando as lâminas são imersas por 15 minutos. Essa segunda parte não foi realizada neste presente trabalho. Para finalizar, os substratos são lavados com água ultrapura em abundância e posteriormente, são secos com um jato de nitrogênio superseco e armazenados individualmente em porta amostras. 
Para se evitar a presença de água no meio de síntese e na resposta eletroquímica dos polímeros, adicionou-se o solvente $(\mathrm{ACN})$ em peneira molecular ativada. A ativação da peneira molecular foi feita a partir de lavagem com água ultrapura e do posterior tratamento da peneira a $300^{\circ} \mathrm{C}$ durante 120 minutos em uma mufla. O eletrólito de suporte, $\mathrm{TBAClO}_{4}$ e a bifenila foram mantidos em um dessecador sob vácuo para proteção contra umidade. O pirrol foi purificado por destilação simples a vácuo e armazenado em porta amostras, ao abrigo da luz e do calor. Esses procedimentos possibilitaram a obtenção de filmes poliméricos mais homogêneos e espessos, conforme estudos prévios realizados em nosso laboratório ${ }^{[2,3]}$.

\subsection{Medidas eletroquímicas}

Os filmes poliméricos foram preparados pela técnica de voltametria cíclica (VC), que consiste na aplicação de uma varredura de potenciais a um eletrodo de trabalho na forma de uma curva triangular repetitiva, de acordo com a Figura 3.2. 


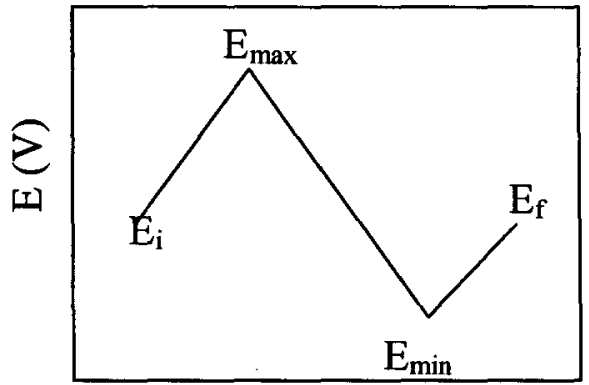

$\mathrm{t}(\mathrm{s})$

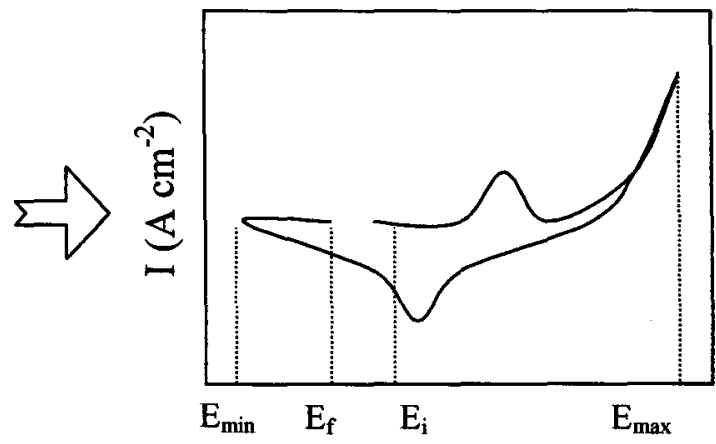

$\mathrm{E}(\mathrm{V})$

Figura 3.2 Perturbação imposta a um sistema pela técnica de VC e o voltamograma obtido na forma de I vs $\mathbf{E}^{\text {[2]. }}$

As medidas eletroquímicas foram realizadas com o auxílio de um potenciostatogalvanostato EG\&PAR 283. A célula eletroquímica apresentada na Figura 3.3 foi colocada em uma caixa seca, onde se tinha o controle da umidade atmosférica. Esta célula comportava entradas para três eletrodos, sendo eles o de trabalho (ET), o contraeletrodo (CE) e o eletrodo de referência (ER) e também uma entrada para um borbulhador de nitrogênio superseco. O eletrodo de referência utilizado foi um fio de $\mathrm{Ag}$ mergulhado em ACN e acondicionado em um tubo de vidro (eletrodo de quasereferência, QRE-Ag). O contra-eletrodo utilizado foi uma placa de Pt e o eletrodo de trabalho, uma lâmina de vidro com uma camada de óxido de estanho dopado com flúor (FTO). A solução de trabalho utilizada foi $\mathrm{ACN}$ com os monômeros bifenila, 3metiltiofeno e pirrol e o eletrólito de suporte, perclorato de tetrabutilamônio $\left(\mathrm{TBAClO}_{4}\right)$. 


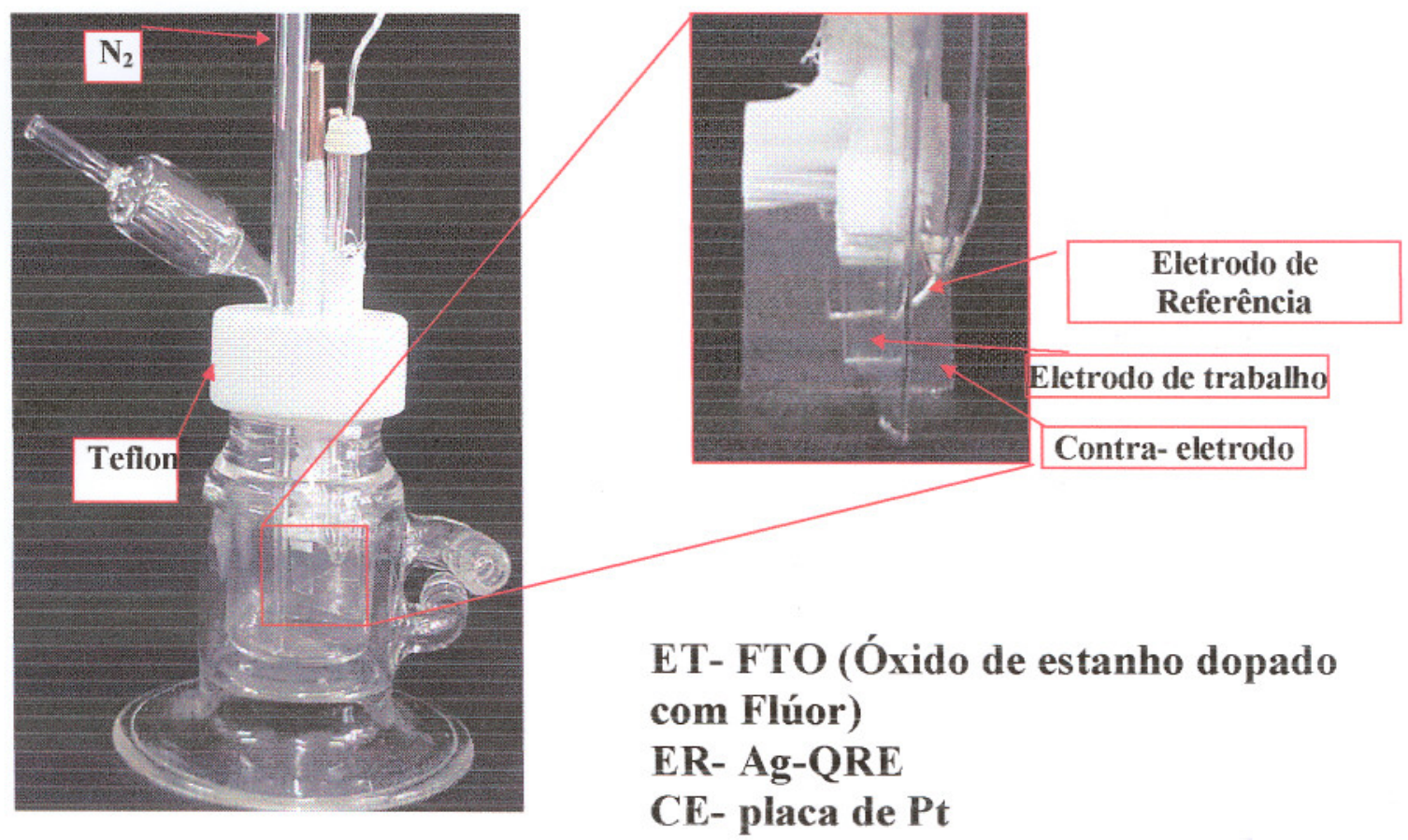

Figura 3.3 Célula eletroquímica utilizada no preparo e caracterização dos filmes poliméricos ${ }^{[3]}$.

Os filmes de PPP foram preparados eletroquimicamente em meio de uma solução de $\mathrm{ACN}$ contendo $\mathrm{TBAClO}_{4}$ e bifenila por meio da técnica de voltametria cíclica. $\mathrm{O}$ potencial foi variado entre 0,0 a $+2,0 \mathrm{~V}$ vs QRE-Ag, a $50 \mathrm{mV} \mathrm{s}^{-1} \mathrm{com} 10$ ciclos de varredura até a formação de um filme de PPP espesso, aderente ao eletrodo (FTO) e com uma coloração marrom.

Os filmes de CPPI foram preparados eletroquimicamente em uma solução contendo $\mathrm{ACN}$ em presença de $\mathrm{TBAClO}_{4}$ e os co-monômeros bifenila e pirrol nas concentrações de $0,1 \mathrm{~mol} \mathrm{~L}^{-1}$ e $0,01 \mathrm{~mol} \mathrm{~L}^{-1}$, respectivamente, por meio da técnica da voltametria cíclica. Os filmes foram sintetizados em um intervalo de potencial entre $-0,3$ $\mathrm{V}$ a $+1,1 \mathrm{~V}$ vs QRE-Ag a $50 \mathrm{mV} \mathrm{s}^{-1}$. Com os 10 ciclos, foi obtido um filme de CPPI 
espesso, homogêneo, aderente ao eletrodo e com uma coloração esverdeada, característica dos filmes do homopolímero, PPI.

Os filmes de CP3MET foram preparados eletroquimicamente em $\mathrm{ACN}$ contendo $\mathrm{TBAClO}_{4}$ e os co-monômeros bifenila e 3-metiltiofeno, nas concentrações de $0,1 \mathrm{~mol} \mathrm{~L}{ }^{-}$ ${ }^{1}$ e $0,05 \mathrm{~mol} \mathrm{~L}^{-1}$, respectivamente. A técnica de voltametria cíclica foi utilizada entre 0,0 $\mathrm{V} \mathrm{a}+1,8 \mathrm{~V}$ vs QRE-Ag a $50 \mathrm{mV} \mathrm{s}^{-1}$. Com 10 ciclos de crescimento, foi possível obter filmes de CP3MET espessos, homogêneos, aderentes ao eletrodo (FTO) e com coloração avermelhada, característica dos filmes do homopolímero, P3MET.

A análise da resposta voltamétrica de eletrodos modificados quando em solução livre de monômero pode dar informações sobre a cinética de transferência de elétrons na interface eletrodo-solução ${ }^{[2]}$. Assim, a caracterização eletroquímica dos filmes foi realizada em solução de $\mathrm{ACN}$ contendo $\mathrm{TBAClO}_{4}$ como eletrólito de suporte. O potencial aplicado para a obtenção das respostas do filme de PPP foi entre $0,0 \mathrm{~V}$ e $+1,6 \mathrm{~V}$ vs QRE-Ag. Para os filmes de CPPI, o potencial foi varrido entre $-0,1$ a $+0,9 \mathrm{~V}$ vs QRE$\mathrm{Ag}$, e para os filmes de CP3MET, entre $-0,1 \mathrm{~V}$ a $+1,6 \mathrm{~V}$ vs QRE-Ag.

\subsection{Técnicas de caracterização dos filmes poliméricos}

Neste item, serão brevemente discutidas as técnicas de caracterização espectroscópicas dos filmes poliméricos por FT-Raman, UV-VIS in situ e FTIR por reflectância. Os filmes foram eletrossintetizados por voltametria cíclica, conforme discutido anteriormente. 
Os resultados de medidas de espectroscopia na região do UV-VIS in situ permitem com que seja observada a formação de pólarons e bipólarons em polímeros nos estados oxidados, bem como suas transições eletrônicas após a aplicação de diferentes potenciais. Para a realização destas medidas, foi utilizado um espectrofotômetro Hitachi, modelo U-2001, de feixe duplo acoplado ao potenciostatogalvanostato da EG\&PAR no Grupo de Polímeros do IFSC/USP. As medidas foram realizadas na mesma célula eletroquímica da Figura 3.3 posicionada dentro de um espectrômetro, onde os eletrodos de trabalho eram os filmes poliméricos depositados sobre FTO, tendo um fio de Ag como eletrodo de quase-referência e Pt como contraeletrodo. Os eletrodos foram imersos em solução de ACN contendo $0,01 \mathrm{~mol} \mathrm{~L}^{-1}$ de $\mathrm{TBAClO}_{4}$.

Para a caracterização dos filmes de PPP, utilizou-se uma janela de potencial entre $0,0 \mathrm{~V}$ e $+1,6 \mathrm{~V}$ vs $\mathrm{QRE}-\mathrm{Ag}$ para não degradar o filme a mais altos potenciais de oxidação. Para a caracterização dos filmes de CPPI, o potencial foi varrido entre $-0,1 \mathrm{~V}$ e $+0,9 \mathrm{~V}$ vs QRE-Ag e de PPI, entre $-1,7 \mathrm{~V} \mathrm{a}+0,9 \mathrm{~V}$ vs QRE-Ag. Para os filmes de P3MET, utilizou-se uma janela de potencial entre $-0,3 \mathrm{~V}$ a $+1,7 \mathrm{~V}$ vs QRE-Ag e de CP3MET, entre $-0,3 \mathrm{~V} a+1,8 \mathrm{~V}$ vs QRE-Ag.

Para a caracterização estrutural dos polímeros estudados, foram utilizados duas técnicas de espectroscopia vibracional, a absorção no infravermelho (FTIR) e o espalhamento Raman (FT-Raman). 
As medidas de espectroscopia por FT-Raman foram realizadas no Departamento de Química da Universidade de São Paulo (IQ/USP). Para essas medidas foi utilizado um aparelho da Bruker, RFS 100/s, sob uma radiação de 1064 nm.

As medidas de FTIR por reflectância foram realizadas com o auxílio de um espectrômetro no laboratório do Grupo de Polímeros do IFSC/USP. Os filmes poliméricos a serem analisados foram depositados eletroquimicamente sobre placas de Pt previamente lavadas em sulfonítrica e polidas com alumina. Foi adotado o mesmo procedimento de síntese das medidas anteriores.

O espectrômetro de FTIR consiste de dois espelhos planos e uma placa munida de uma abertura. O primeiro espelho dirige o feixe IR ao orifício da placa onde está a amostra, o segundo espelho coleta o feixe refletido pela amostra e o dirige ao detector ${ }^{[4]}$.

De início foi obtido o espectro de referência apenas com o substrato de Pt sem o filme de polímero. Em seguida foram obtidos os espectros dos filmes poliméricos, com nitrogênio superseco sendo bombeado no porta amostra durante as medidas, para impedir que a umidade interfira e não haja a presença de bandas características da molécula de água no espectro. Dessa forma, nos espectros de FTIR dos filmes poliméricos não constará as bandas referentes ao substrato de Pt e à água, ou seja, consistirá apenas das bandas que caracterizam os filmes poliméricos de PPP, PPI, P3MET e dos filmes mistos CPPI e CP3MET ${ }^{[4]}$. 
IFSC - Ciência e Engenharia de Materiais

\subsection{Bibliografia}

1- KERN W., Purifying $\mathrm{Si}$ and $\mathrm{SiO}_{2}$ surfaces with hydrogen peroxide. Semiconductor International, v.94, 1984.

2- EIRAS C. Eletrossintese e propriedades ópticas e morfológicas de filmes de poli-p-fenileno e derivados. São Carlos, 2004, 148p. tese (Doutorado) - Instituto de Física de São Carlos, Universidade de São Paulo.

3- FOSCHINI M. Síntese e determinação da afinidade eletrônica e potencial de ionização e energia de banda proibida de polímeros luminescentes. São Carlos, 2004, Dissertação (Mestrado) - Instituto de Física de São Carlos, Universidade de São Paulo.

4- CANEVAROLO Sebastião V.Jr. Técnicas de Caracterização de Polímeros. 1.ed. São Paulo, Ed. Artliber, 2003. Cap. 01, p.34-35: Espectroscopia vibracional de absorção no infravermelho. 


\section{Capítulo 04: Resultados e discussão}

Neste capítulo, serão discutidos os resultados obtidos na parte de caracterização dos filmes dos homopolímeros, PPP, PPI e P3MET, e dos filmes mistos CPPI e CP3MET.

\subsection{Medidas de voltametria cíclica para os homopolímeros e para os filmes mistos}

A Figura 4.1 mostra os voltamogramas cíclicos obtidos durante a síntese dos filmes dos homopolímeros e as respostas eletroquímicas dos mesmos. Ambas as medidas foram realizadas em meio de $0,01 \mathrm{~mol} \mathrm{~L}^{-1}$ de $\mathrm{TBAClO}_{4} \mathrm{em} \mathrm{ACN} \mathrm{a} \mathrm{v}=50 \mathrm{mVs}^{-1}$ 

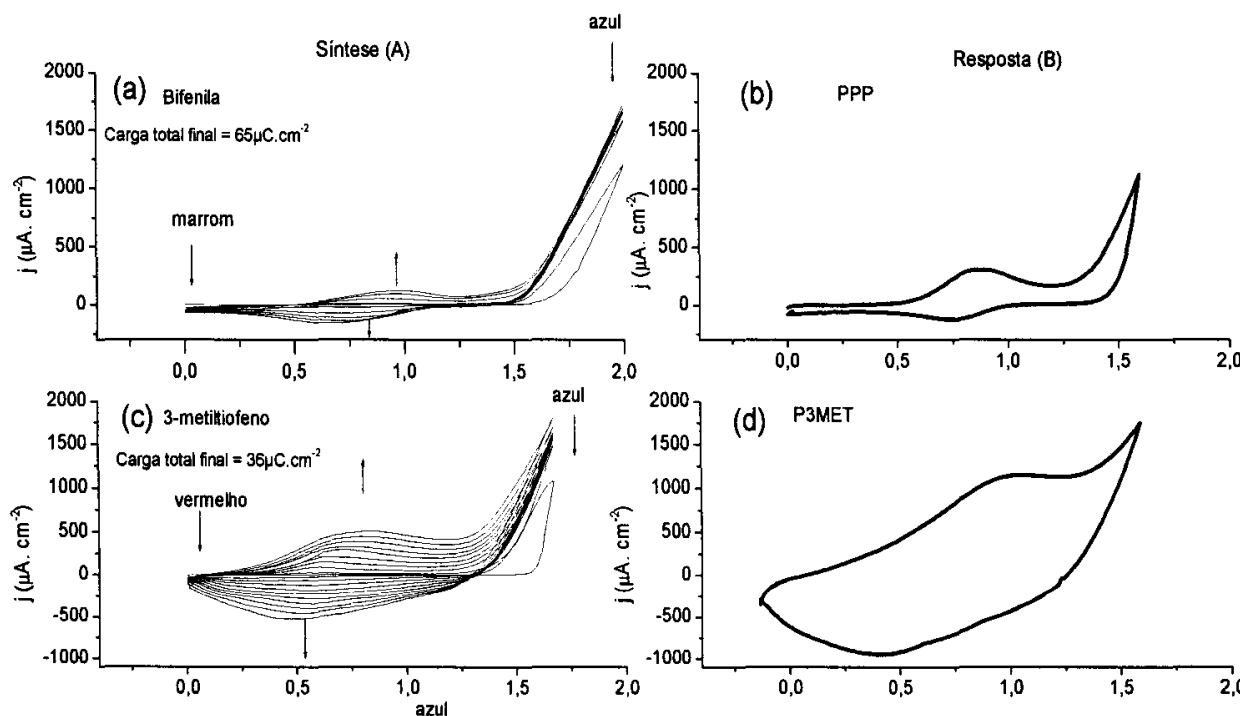

(d) P3MET

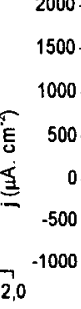

(d) P3MET
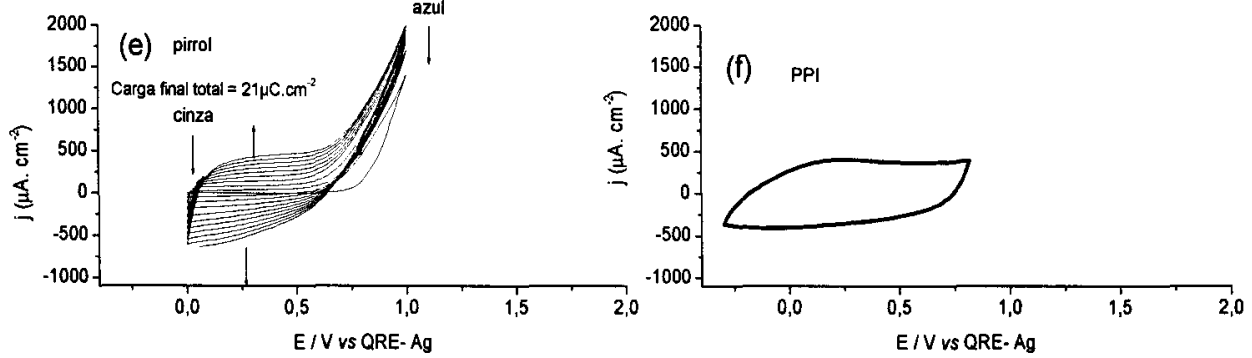

Figura 4.1 Voltamogramas cíclicos do eletrodo de FTO durante a síntese (A) em meio de: $0,1 \mathrm{~mol} \mathrm{~L}^{-1}$ de bifenila (a); $0,1 \mathrm{~mol} \mathrm{~L}^{-1}$ de 3-metiltiofeno (c) e $0,1 \mathrm{~mol} \mathrm{~L}^{-1}$ de pirrol (e) e resposta eletroquímica (B) dos filmes de PPP (b), P3MET (d) e PPI (f), em meio de uma solução de $0,01 \mathrm{~mol} \mathrm{~L}^{-1}$ de $\mathrm{TBAClO}_{4} \mathrm{em} \mathrm{ACN} \mathrm{a} \mathrm{v}=50 \mathrm{mVs}^{-1}$.

De acordo com a Figura 4.1 A (a), onde se observa os voltamogramas cíclicos do eletrodo de $\mathrm{FTO}$ em meio a $\mathrm{ACN}$ e $\mathrm{TBAClO}_{4}$ durante a polimerização da bifenila, há um aumento da densidade de corrente com os sucessivos ciclos, indicando um espessamento do filme de PPP com a ciclagem sucessiva de potenciais. $\mathrm{O}$ aumento de corrente a 1,5 V vs QRE-Ag, durante o primeiro ciclo, é devido ao início do processo de oxidação da bifenila que, em seguida, sofre reações de acoplamento, formando uma 
espécie dimérica. Em seguida, espécies oligoméricas são formadas e posteriormente, um filme de PPP é adsorvido sobre a superfície do eletrodo. Observa-se na mesma figura um par redox na região de $+0,7 \mathrm{~V} \mathrm{e}+1,0 \mathrm{~V} v s$ QRE-Ag que, com as varreduras sucessivas, aumenta de intensidade, o que caracteriza a formação de um filme eletroativo que se espessa com o aumento do número de ciclos. Durante a eletrossíntese do filme de PPP, houve a mudança da coloração da superfície do eletrodo de marrom-claro, a $0,0 \mathrm{~V} v s$ QRE-Ag, e que corresponde ao filme no seu estado neutro, para azul, a + 2,0 V vs QRE$\mathrm{Ag}$, que corresponde ao filme no seu estado totalmente oxidado.

$\mathrm{Na}$ resposta eletroquímica do filme de PPP (Figura 4.1 B (b)), nota-se um par redox bem definido com valores de $\mathrm{E}_{\text {oxi }}$ e $\mathrm{E}_{\text {red }}$ em torno de $+0,9$ e $+0,7$ vs $\mathrm{QRE}-\mathrm{Ag}$, respectivamente, e que são bem próximos aos valores do par redox observado nos voltamogramas durante a síntese do PPP, caracterizando que houve a formação de um filme de PPP eletroativo e estável frente aos ciclos sucessivos de varredura de potencial.

Na Figura 4.1 A (c), observa-se o voltamograma cíclico do eletrodo de FTO durante a polimerização do 3-metiltiofeno. Nesta figura pode-se notar o aumento da densidade de corrente com os sucessivos ciclos, o par redox na região de $+0,5 \mathrm{~V}$ e $+0,9$ $\mathrm{V} v s$ QRE-Ag e a corrente de início do processo de oxidação do 3-metiltiofeno a 1,3 V vs QRE-Ag no primeiro ciclo. Durante a síntese do filme de P3MET, houve a mudança da coloração da superfície do eletrodo de marrom avermelhado, do filme no seu estado neutro, a 0,0 V vs QRE-Ag, para azul, no seu estado dopado, a +1,67 V vs QRE-Ag. A Figura 4.1 B (d) será discutida posteriormente.

Na Figura 4.1 A (e), observa-se o voltamograma cíclico do eletrodo de FTO durante a polimerização do pirrol a potenciais menos positivos. A densidade de corrente 
também aumenta com os sucessivos ciclos, há a definição de um par redox a $+0,1 \mathrm{~V}$ e $+0,2 \mathrm{~V}$ vs QRE-Ag e, durante o primeiro ciclo, uma corrente de início do processo de oxidação do pirrol a 0,6 V vs QRE-Ag. A mudança na coloração do eletrodo é de cinza, do filme no seu estado neutro, a 0,0 V vs QRE-Ag, para azul a +1,0 V vs QRE-Ag, no seu estado dopado. A Figura 4.1 B (f) será discutida posteriormente.

Enquanto que, em meio de $\mathrm{TBAClO}_{4} / \mathrm{ACN}$, são necessários, para que a bifenila oxide, 2,0 V vs QRE-Ag, o 3-metiltiofeno oxida na região de 1,7 V vs QRE-Ag, ou seja, a um potencial mais baixo do que a bifenila, já que ele apresenta em sua estrutura química um átomo de enxofre, que é responsável por um efeito indutivo captor de elétrons, fazendo com que diminua o seu potencial de oxidação, porém, o 3-metiltiofeno possui um substituinte, o grupo metila, que é um grupo doador de elétrons para a cadeia aromática, mas o seu efeito doador não interfere fortemente em seu potencial de oxidação.

Já para o pirrol, é necessário $1,0 \mathrm{~V} v s$ QRE-Ag para que ele oxide, ou seja,um potencial ainda mais baixo do que o do benzeno e bifenila, já que o pirrol possui um orbital molecular de mais baixa energia devido a eletronegatividade do seu átomo de nitrogênio, que por sua vez, é mais eletronegativo do que o carbono e torna o pirrol mais estável e menos reativo, ou seja, um efeito indutivo captor de elétrons pelo nitrogênio facilita a retirada de um elétron da sua estrutura química mais facilmente que na estrutura da bifenila.

A Figura 4.2 mostra os voltamogramas cíclicos da síntese e resposta dos filmes de CP3MET e CPPI. As medidas foram realizadas em meio a de $0,01 \mathrm{~mol} \mathrm{~L}^{-1}$ de $\mathrm{TBAClO}_{4} \mathrm{em} \mathrm{ACN} \mathrm{a} \mathrm{v}=50 \mathrm{mVs}^{-1}$. 

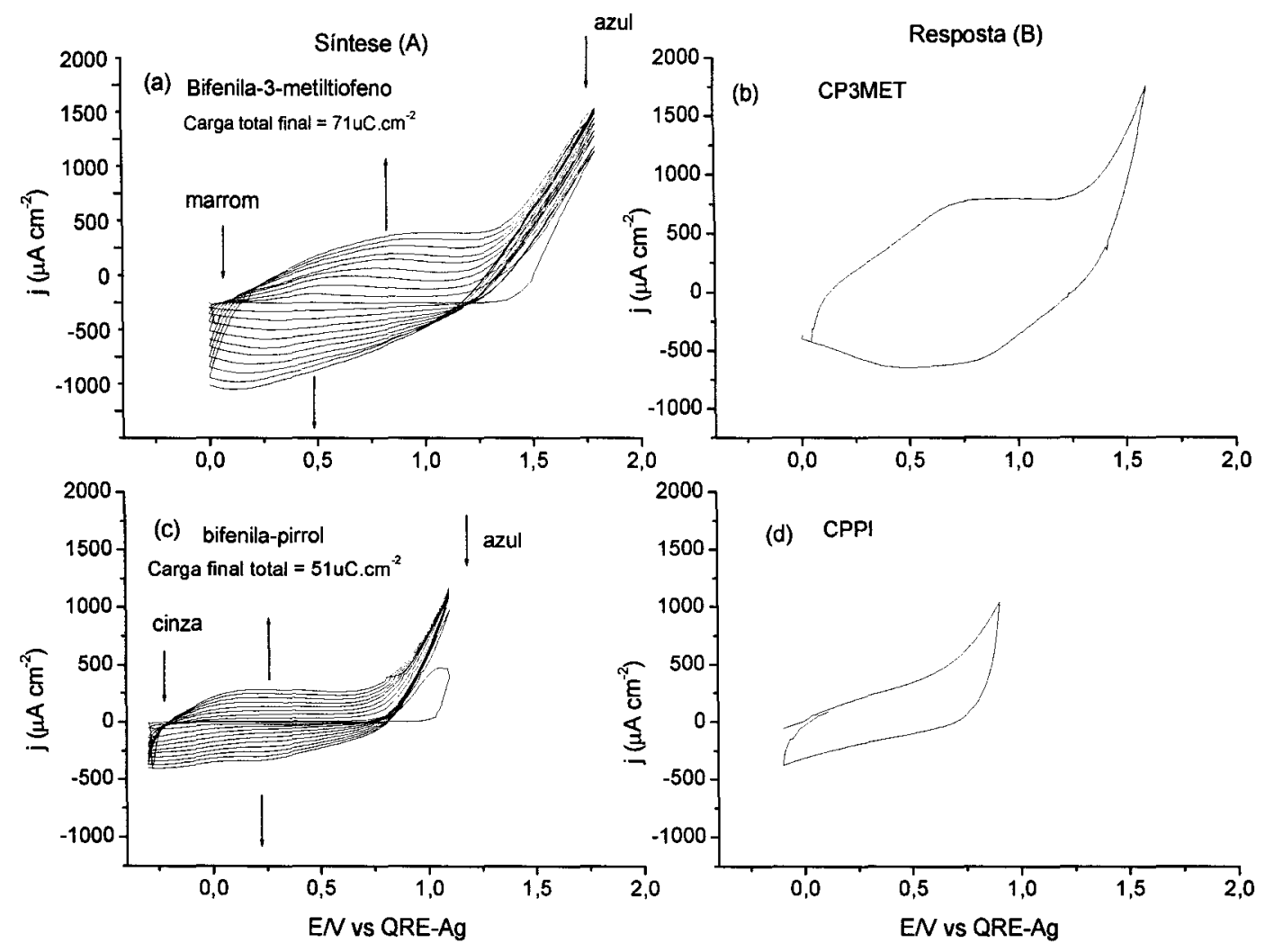

Figura 4.2 Voltamogramas cíclicos do eletrodo de FTO durante a síntese (A) e resposta eletroquímica (B) dos filmes em meio de uma solução de $0,01 \mathrm{~mol} \mathrm{~L}^{-1}$ de TBAClO $_{4}$ em ACN a v $=50 \mathrm{mVs}^{-1} \mathrm{em}$ meio de: $0,1 \mathrm{~mol} \mathrm{~L}^{-1}$ de bifenila e $0,05 \mathrm{~mol} \mathrm{~L}^{-1}$ de 3-metiltiofeno (a) e (b) e $0,1 \mathrm{~mol} \mathrm{~L}^{-1}$ de bifenila e $0,01 \mathrm{~mol} \mathrm{~L}^{-1}$ de pirrol e (c) e (d).

Na Figura 4.2 A (a), pode-se observar o início de um processo de oxidação do eletrodo em meio a uma solução contendo o par de monômeros, bifenila e 3metiltiofeno, $\mathrm{a}+1,3 \mathrm{~V} v s \mathrm{QRE}-\mathrm{Ag}$, durante o primeiro ciclo. Pode-se observar, ainda na mesma figura, um par redox na região de $+0,5 \mathrm{~V}$ e $+0,8 \mathrm{~V} v s$ QRE-Ag, cujos valores de densidade de corrente anódica e catódica aumentam com o número de ciclos. Durante a 
síntese do filme de CP3MET, ocorreu uma mudança na coloração do eletrodo de marrom avermelhado, a $0,0 \mathrm{~V}$, para azul, a $+1,7 \mathrm{~V}$, no seu estado dopado.

Nas Figuras 4.1 B (d) e 4.2 B (b), observa-se uma resposta voltamétrica semelhante para os filmes de P3MET e CP3MET, porém com valores de $E_{o x i}$ e $E_{\text {red }}$ deslocados de $+1,0 \mathrm{~V}$ e $+0,5 \mathrm{~V}$ vs QRE-Ag, para o filme de P3MET, e $+0,7$ e $+0,5$ vs QRE-Ag, para o filme de CP3MET. A resposta voltamétrica do filme de CP3MET apresenta uma melhor definição do par redox, ou seja, caracterizando a formação de um filme mais eletroativo. Estes valores de potenciais para o filme de CP3MET são intermediários dos obtidos nos voltamogramas dos filmes de PPP e de P3MET.

Na Figura 4.2 A (c), observa-se o voltamograma cíclico do eletrodo de FTO em meio de $\mathrm{ACN}$ e $\mathrm{TBAClO}_{4}$ durante a polimerização dos co-monômeros bifenila e pirrol. O processo de oxidação do pirrol tem início na região de potencial de $+0,7 \mathrm{~V}$ vs $\mathrm{QRE}-$ $\mathrm{Ag}$, a densidade de corrente aumenta até o terceiro ciclo de varredura e depois diminui até o décimo ciclo, indicando uma oxidação preferencial e inicial do pirrol que ocorre a potenciais mais negativos do que da bifenila. Pode-se observar, na mesma figura, um par redox na região de $+0,1 \mathrm{~V}$ e $+0,2 \mathrm{~V} v s$ QRE-Ag, cujos valores de densidade de corrente aumentam com o número de ciclos.

Durante a síntese do filme de CPPI, houve uma mudança na coloração do filme de cinza, a $-0,3 \mathrm{~V}$, para azul, a $+1,1 \mathrm{~V}$, no seu estado dopado.

Nas Figuras 4.1 B (f) e 4.2 B (d), podem ser comparadas as respostas eletroquímicas dos filmes de PPI e CPPI. Para o filme de PPI, observa-se um par redox de $\mathrm{E}_{\text {oxi }}$ e $\mathrm{E}_{\text {red }}$ entre $0,0 \mathrm{~V}$ e $+0,2 \mathrm{~V} v s$ QRE-Ag e um aumento da corrente de oxidação a 0,7 V vs QRE-Ag, característica da oxidação do pirrol. Para o filme de CPPI, os valores 
de $\mathrm{E}_{\text {oxi }}$ e $\mathrm{E}_{\mathrm{red}}$ são observados entre + 0,1V e +0,3 V vs QRE-Ag. Os filmes de PPI e CPPI se mostraram bastante estáveis frente aos ciclos sucessivos de potenciais.

Assim, observou-se por meio das medidas de resposta eletroquímica, que os filmes mistos de CPPI e de CP3MET possuem características distintas dos filmes dos homopolímeros por eles formados.

Comparando-se a resposta eletroquímica dos filmes de PPP, P3MET e CP3MET (Figura 4.3) observa-se que o par redox da resposta eletroquímica do filme misto CP3MET encontra-se numa região de potencial intermediária, ou seja, entre ambos os pares redox dos homopolímeros PPP e P3MET. O mesmo ocorre com o filme misto de CPPI. O par redox da resposta eletroquímica do filme de CPPI apresenta-se numa região de potencial entre os pares redox do PPP e do PPI, de acordo com a Figura 4.4. 


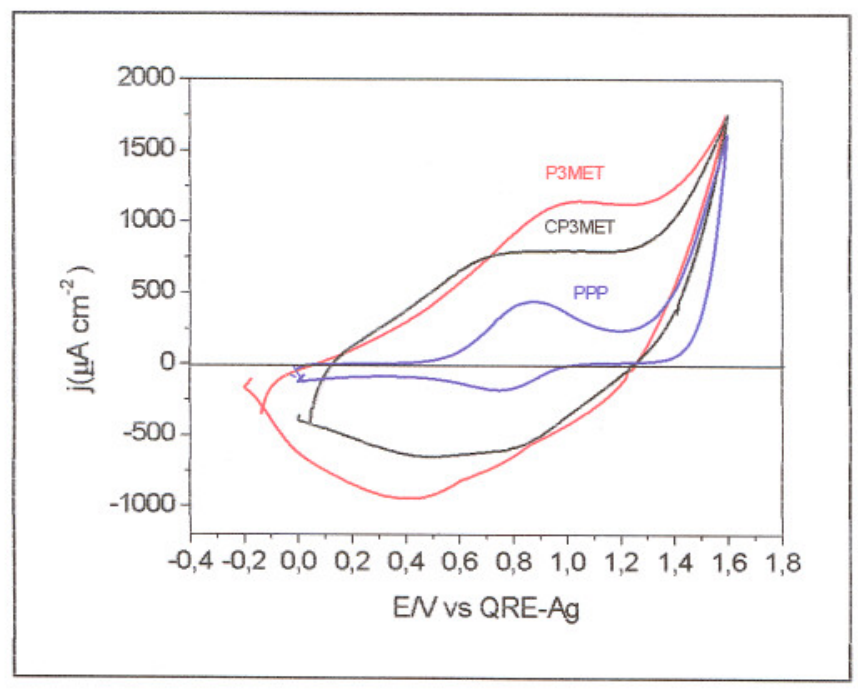

Figura 4.3 Voltamogramas cíclicos do eletrodo de FTO durante a resposta eletroquímica dos filmes em meio de uma solução de $0,01 \mathrm{~mol} \mathrm{~L}^{-1}$ de $\mathrm{TBAClO}_{4} \mathrm{em}$ ACN a v $=50 \mathrm{mVs}^{-1}$ em meio de: $0,1 \mathrm{~mol} \mathrm{~L}^{-1}$ de bifenila e $0,05 \mathrm{~mol} \mathrm{~L}^{-1}$ de 3metiltiofeno (CP3MET), 0,1 mol $\mathrm{L}^{-1}$ de bifenila (PPP) e $0,1 \mathrm{~mol} \mathrm{~L}^{-1}$ de 3metiltiofeno(P3MET).

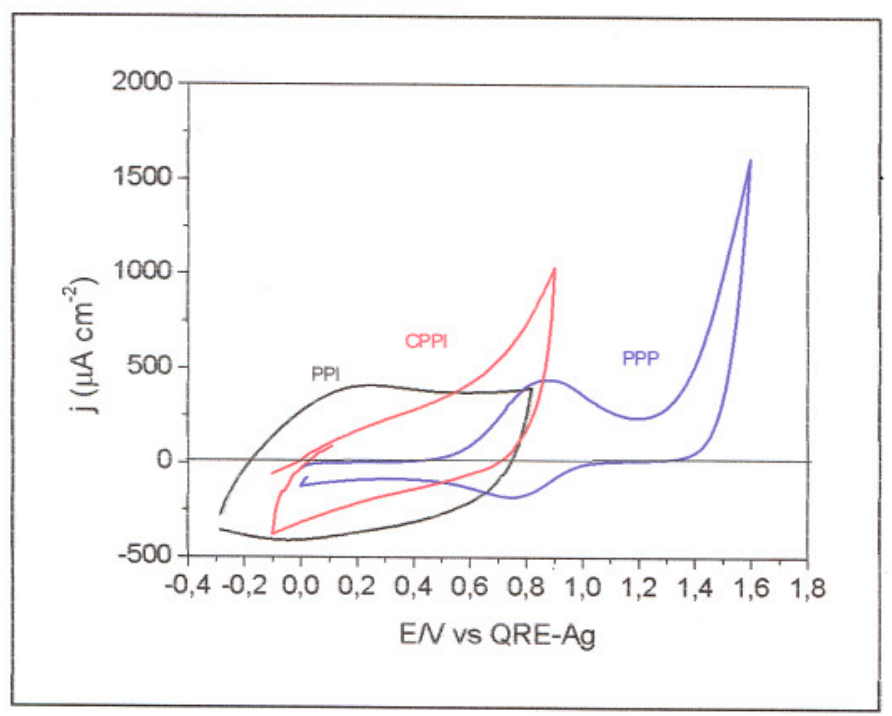

Figura 4.4 Voltamogramas cíclicos do eletrodo de FTO durante a resposta eletroquímica dos filmes em meio de uma solução de $0,01 \mathrm{~mol} \mathrm{~L}^{-1}$ de $\mathrm{TBAClO}_{4} \mathrm{em}$ ACN a v $=50 \mathrm{mVs}^{-1}$ em meio de: $0,1 \mathrm{~mol} \mathrm{~L} \mathrm{~L}^{-1}$ de bifenila e $0,01 \mathrm{~mol} \mathrm{~L}^{-1}$ de pirrol (CPPI), 0,1 mol L de bifenila (PPP) e 0,1 $\mathrm{mol} \mathrm{L}^{-1}$ de pirrol (PPI). 
Para o mesmo número de ciclos, obtivemos os valores de carga total final para os filmes de PPP, PPI, P3MET, CP3MET e CPPI durante suas sínteses.

$O$ valor de carga final total para os filmes poliméricos foi calculado utilizando-se o programa Microcal Origin. A partir dos valores de densidade de corrente especificados no voltamograma cíclico com os cinco primeiro ciclos varridos durante a síntese dos filmes, foi construído um gráfico de densidade de corrente $v s$ tempo e posteriormente foi integrada a área abaixo dos picos formados. Os valores podem ser vistos na tabela 4.1.

Tabela 4.1 Valores de carga final total para os filmes de PPP, P3MET, PPI, CP3MET e CPPI após 5 ciclos de varredura de potencial.

\begin{tabular}{|c|c|}
\hline Homopolímeros & $\begin{array}{c}\text { Valores de } \\
\text { carga } \\
\text { total final } \\
\left(\boldsymbol{\mu C} . \text {.m }^{-2}\right)\end{array}$ \\
\hline PPP & 65 \\
\hline P3MET & 36 \\
\hline CP3MET & 71 \\
\hline PPI & 21 \\
\hline CPPI & 51 \\
\hline
\end{tabular}

Segundo os dados da Tabela 4.1, se considerarmos que os filmes mais espessos são aqueles obtidos a mais altos valores de carga final total, então a eletro-oxidação do CP3MET foi quem levou a filmes mais espessos, seguido do CPPI, PPP e P3MET e PPI. Comparando-se os filmes mistos de CP3MET e CPPI, a eletrossíntese da bifenila-3metiltiofeno levou a filmes mais espessos em relação à eletrossíntese da bifenila-pirrol. 
Outro aspecto a se observar é a textura dos filmes dos homopolímeros e dos filmes mistos, através de suas fotos mostradas na Figura 4.5.

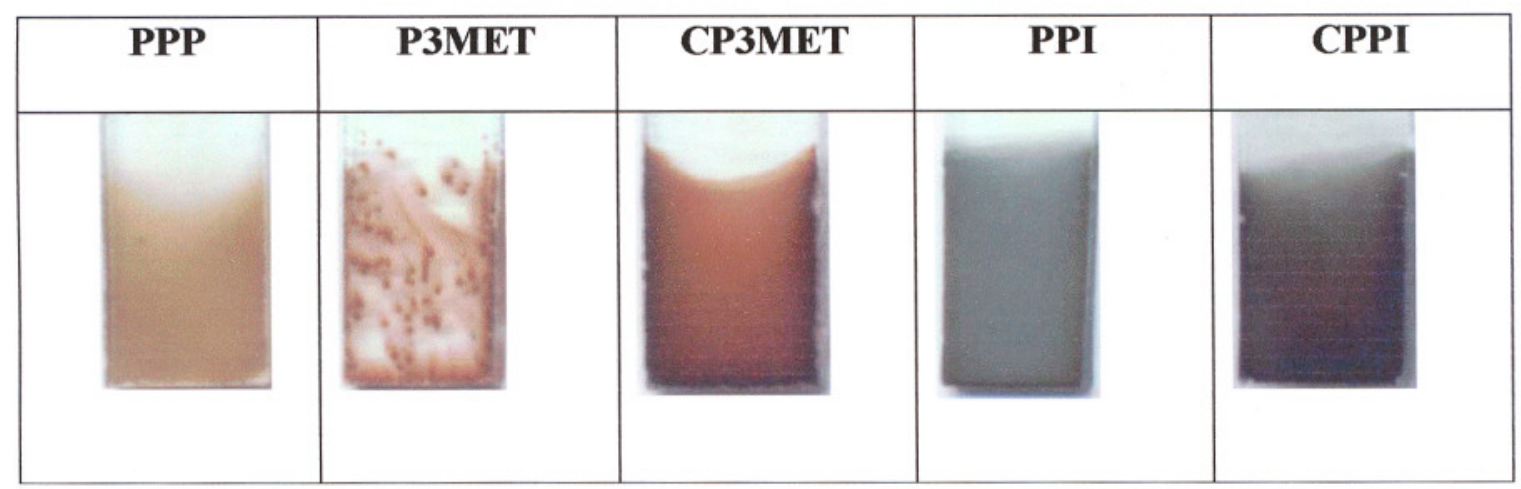

Figura 4.5 Fotos dos filmes de homopolímeros e dos filmes mistos eletrossintetizados a partir de 5 primeiros ciclos de varredura.

Fazendo uma análise em relação ao seu aspecto e seu valor de carga total final, observa-se que o filme de P3MET não foi depositado homogeneamente sobre o substrato de FTO, ao contrário, o filme de CP3MET é homogêneo e visivelmente mais espesso e aderente ao FTO, fato esse explicado pelo valor mais alto de carga total final apresentado pelo filme CP3MET. Poucas diferenças podem ser observadas ao comparar os filmes de PPI e CPPI, ou seja, o filme de CPPI apresenta uma coloração um pouco mais escura e é mais espesso que o filme de PPI obtido com o mesmo número de ciclo, porém, o filme de CPPI apresentou uma carga total final mais alta e é, portanto, mais eletroativo que o filme do homopolímero PPI. 


\subsection{Caracterização dos filmes de homopolímeros PPP, P3MET e PPI, por espectroscopia no UV-VIS in-situ}

Neste tópico, serão discutidos os resultados obtidos com a técnica de espectroscopia no UV-VIS in situ com os filmes de PPP, P3MET e PPI .

\subsubsection{Poli $(p$-fenileno)}

Na Figura 4.6 podem ser observados os espectros de absorção na região do UVVIS durante a aplicação de diferentes potenciais aos eletrodos de trabalho modificados com filmes de PPP eletrossintetizados a partir da oxidação da bifenila. Na parte interior do espectro, é apresentada a resposta voltamétrica deste filme. Os potenciais foram aplicados entre $0,0 \mathrm{~V} \mathrm{e}+1,6 \mathrm{~V}$ vs QRE-Ag. 


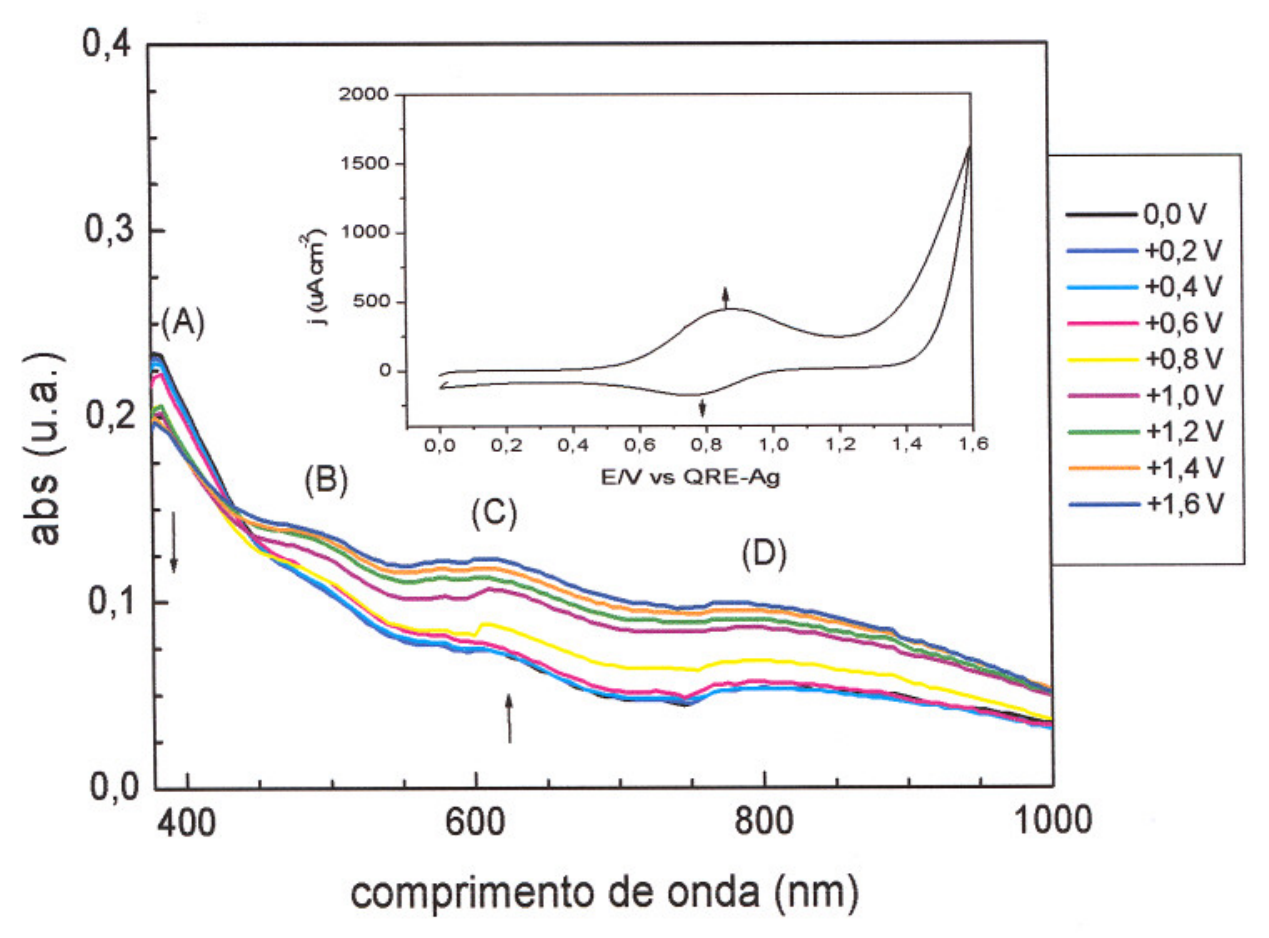

Figura 4.6 Espectros de absorção no UV-VIS de filmes de PPP em meio de $0,01 \mathrm{~mol}$ $\mathrm{L}^{-1}$ de $\mathrm{TBAClO}_{4}$ em $\mathrm{ACN}$ a diferentes potenciais aplicados. As letras representam as diferentes bandas dos espectros.

Para melhor visualização, as curvas da Figura 4.6 foram desconvoluídas em diferentes regiões espectrais (Figura 4.7). 

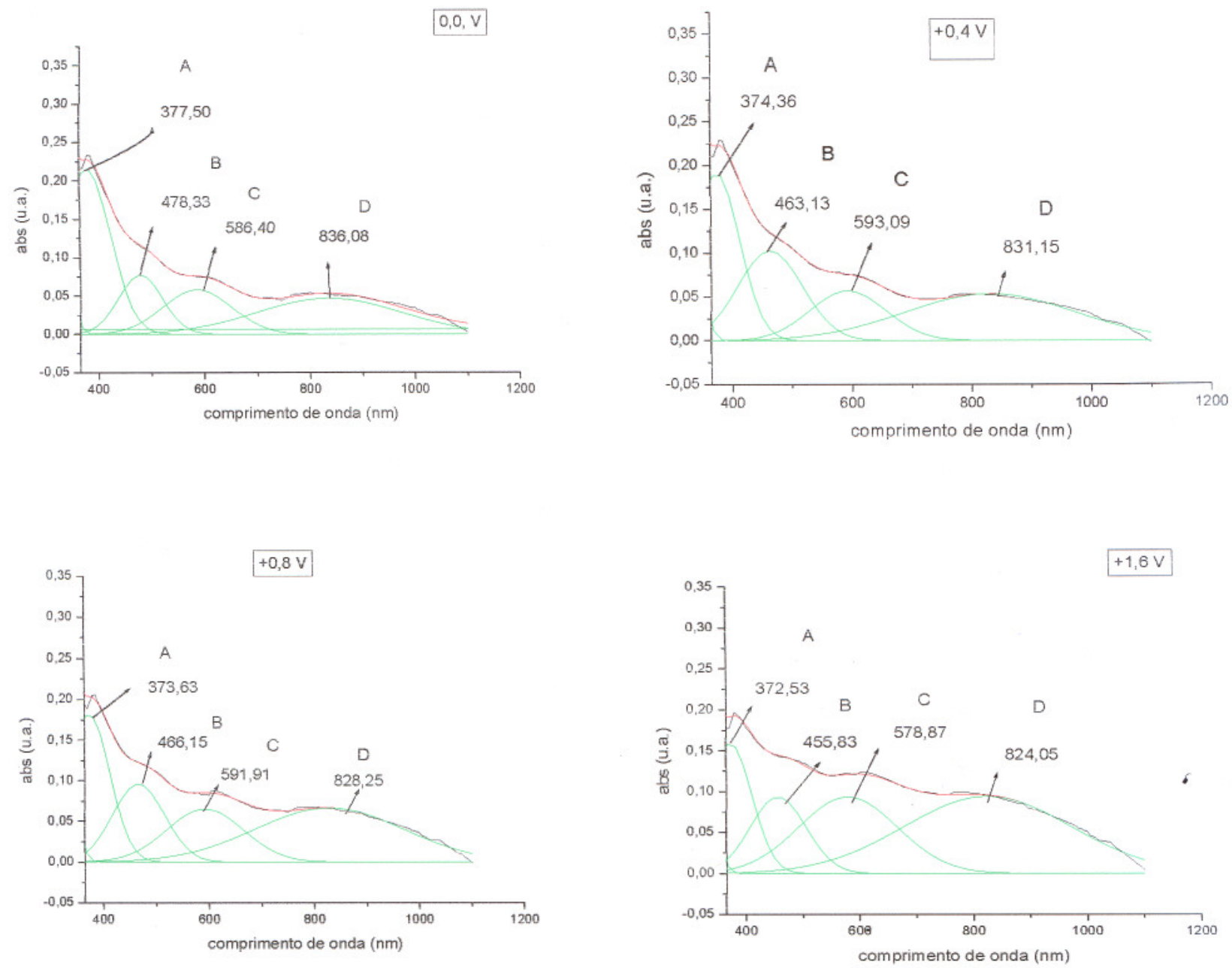

Figura 4.7 Curvas de desconvolução obtidas a partir dos espectros de absorbância dos filmes de PPP a partir da Figura 4.6.

Durante o processo de oxidação do filme de PPP na direção positiva de potenciais de $0,0 \mathrm{~V}$ a $1,6 \mathrm{~V} v s$ QRE-Ag foram obtidas bandas de absorção em diferentes regiões: $370-375 \mathrm{~nm}(\mathrm{~A}), 455-480 \mathrm{~nm}$ (B), 570-600 nm (C) e 800-840 nm (D). 
A banda localizada na região entre $370-375 \mathrm{~nm}$ (A) pode ser atribuída às transições eletrônicas $\pi-\pi^{*}$ do filme de PPP no seu estado neutro ${ }^{[1,2,5]}$. Para potenciais mais positivos, o filme de PPP se torna mais oxidado, fazendo com que esta banda diminua de intensidade com a diminuição da concentração de espécies neutras no filme. Neste caso, a banda (A) se desloca para menores comprimentos de onda e o espectro passa a apresentar com melhor definição as bandas atribuídas às transições entre os estados pólaron e bipólaron do PPP entre 455 e $840 \mathrm{~nm}$ (bandas B a D) ${ }^{[3]}$. A intensidade das bandas $\mathrm{B}, \mathrm{C}$ e D nos espectros aumentam quando se aplicam potenciais mais positivos e se deslocam para diferentes comprimentos de onda devido às diferenças nos níveis de dopagem do filme de PPP. Na literatura ${ }^{[3]}$, as bandas entre $455-480 \mathrm{~nm}$ (B) e 800-840 nm (D) foram atribuídas às transições eletrônicas do filme de PPP dopado em seu estado polarônico, e entre 570- 600 nm (C), no seu estado bipolarônico.

Ao final das medidas, a um potencial de $+1,6 \mathrm{~V}$ vs $\mathrm{QRE}-\mathrm{Ag}$, o filme de PPP apresentou uma coloração marrom. Não foram observadas mudanças significativas nas características superficiais do filme após a aplicação de potenciais positivos.

\subsubsection{Poli(3-metiltiofeno)}

Na Figura 4.8 podem ser observados os espectros de absorção na região do UVVIS durante a aplicação de diferentes potenciais dos filmes de P3MET Na parte interior do espectro, é apresentado o voltamograma deste filme. Os potenciais foram aplicados entre $-0,3 \mathrm{~V}$ e $+1,7 \mathrm{~V}$ vs QRE. 


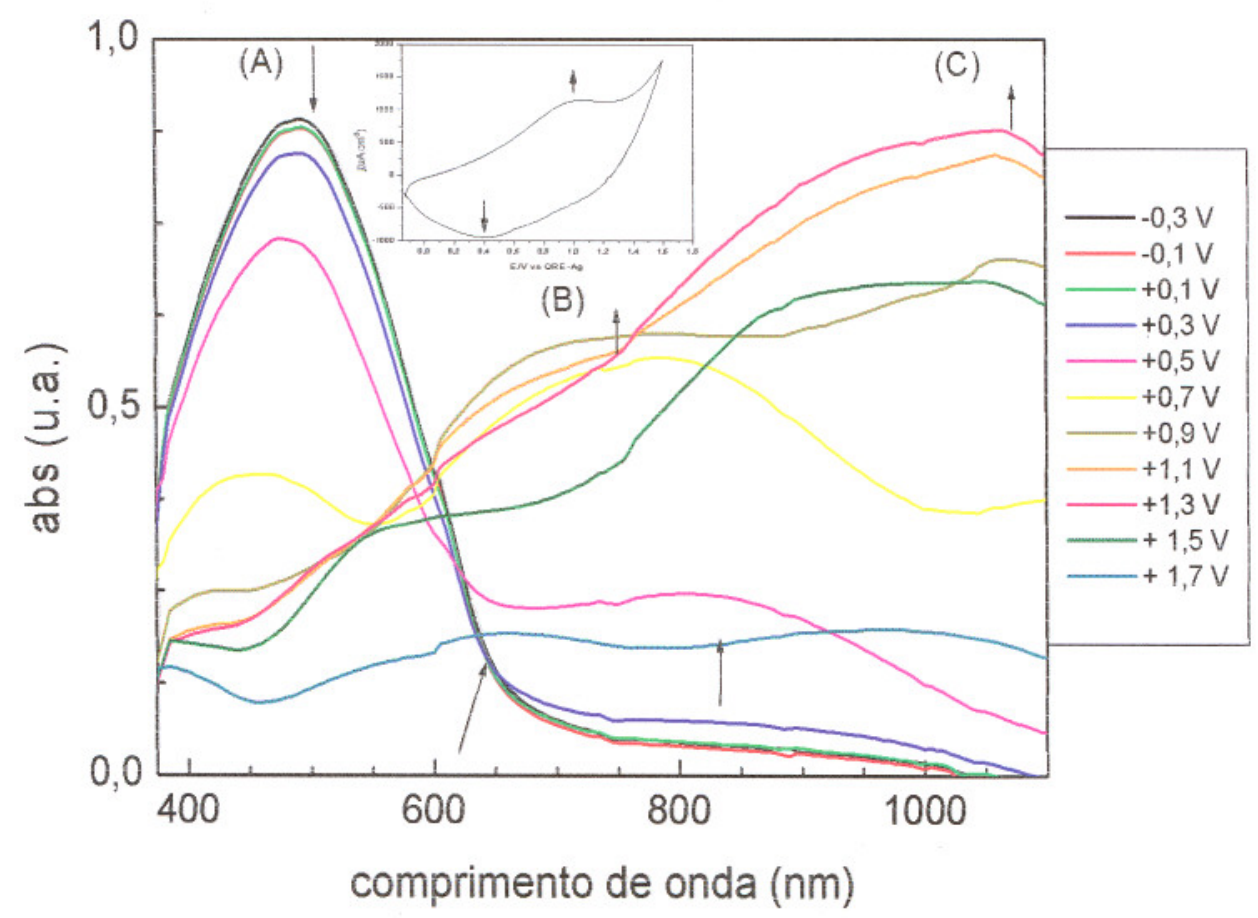

Figura 4.8 Espectros de absorção no UV-VIS de filmes de P3MET em meio de 0,01 mol $\mathrm{L}^{-1}$ de $\mathrm{TBAClO}_{4}$ em $\mathrm{ACN}$ a diferentes potenciais aplicados. As letras representam as diferentes bandas dos espectros.

Para melhor visualização, as curvas foram desconvoluídas em diferentes regiões espectrais (Figura 4.9). 
IFSC - Ciência e Engenharia de Materiais
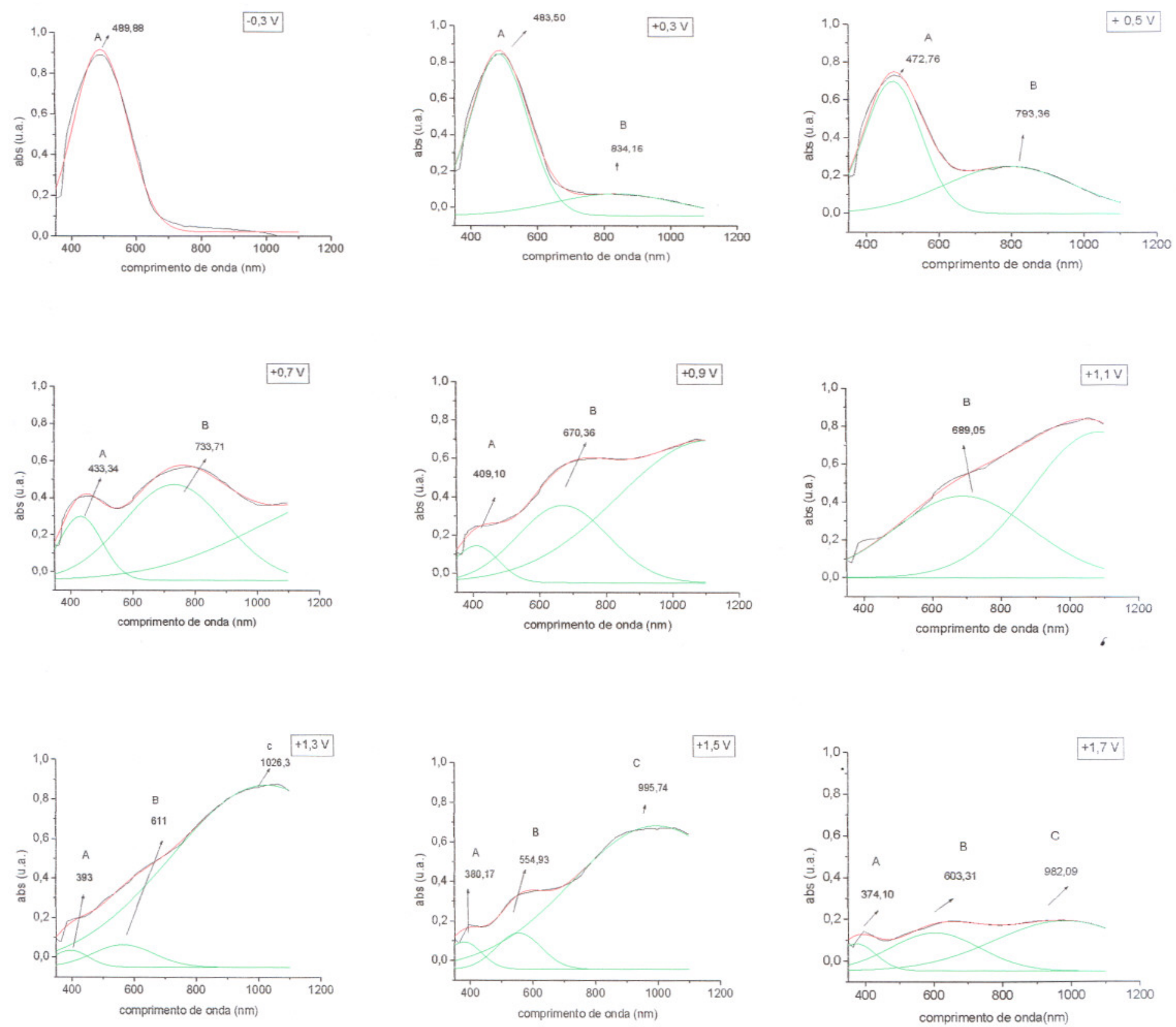

Figura 4.9 Curvas de desconvolução dos espectros de absorbância dos filmes de P3MET obtidos a partir da Figura 4.8. 
A partir dos espectros no UV-VIS in situ (Figura 4.8), pode ser feita uma estimativa a respeito do estado de oxidação do filme de P3MET, ou seja, se ele está nas suas formas neutra a oxidada, dependendo do potencial aplicado.

A banda de absorção entre $472-490 \mathrm{~nm}$ (A) pode ser atribuída às transições eletrônicas do P3MET em seu estado neutro ${ }^{[6,7]}$. À medida que o potencial aumenta para valores mais positivos, a intensidade desta banda diminui gradualmente até surgir no espectro uma nova banda, (B), com um máximo em 795-835 nm. Esta banda pode ser atribuída às transições eletrônicas do P3MET oxidado, após a formação de espécies polarônicas formadas a partir do primeiro ponto isosbéstico entre o decaimento da banda do P3MET no estado neutro (A) e a evolução da banda (B) até $+0,3$ V. A partir de $+0,3 \mathrm{~V}$ há a formação de espécies bipolarônicas até se atingir um potencial de $+0,7 \mathrm{~V}$. Para valores de potencial mais positivos, a intensidade da banda (B) decai para dar origem a uma banda larga em 1,3 V (C); em 1,7 V, ela volta a se definir bem. $\mathrm{Na}$ literatura, a banda (B) nos espectros de UV-VIS do P3MET tem sido utilizada para confirmar se há a presença na superfície do eletrodo de um polímero adsorvido e, portanto, com um certo grau de polimerização (e não de espécies oligoméricas ou de monômero adsorvido) ${ }^{[6,8]}$.

A banda de absorção entre 900 e $1000 \mathrm{~nm}(\mathrm{C})$, pode ser atribuída à transição eletrônica da banda de valência para dois estados de energia contendo a banda de gap do bipólaron do P3MET ${ }^{[8]}$. Ao final da medida, a um potencial aplicado de $+1,7 \mathrm{~V}$ vs QRE-Ag, o filme de P3MET apresentou uma coloração marrom avermelhada, como no seu estado neutro, evidenciando que este valor de potencial final escolhido não foi suficiente para oxidar o filme por completo. 


\subsubsection{Polipirrol}

Na Figura 4.10 podem ser observados os espectros de absorção no UV-VIS durante a aplicação de diferentes potenciais para filmes de PPI. Na parte interior do espectro é apresentada a resposta voltamétrica de um filme de PPI. Os potenciais foram aplicados entre $-1,7 \mathrm{~V} \mathrm{e}+0,9 \mathrm{~V} v s$ QRE-Ag.

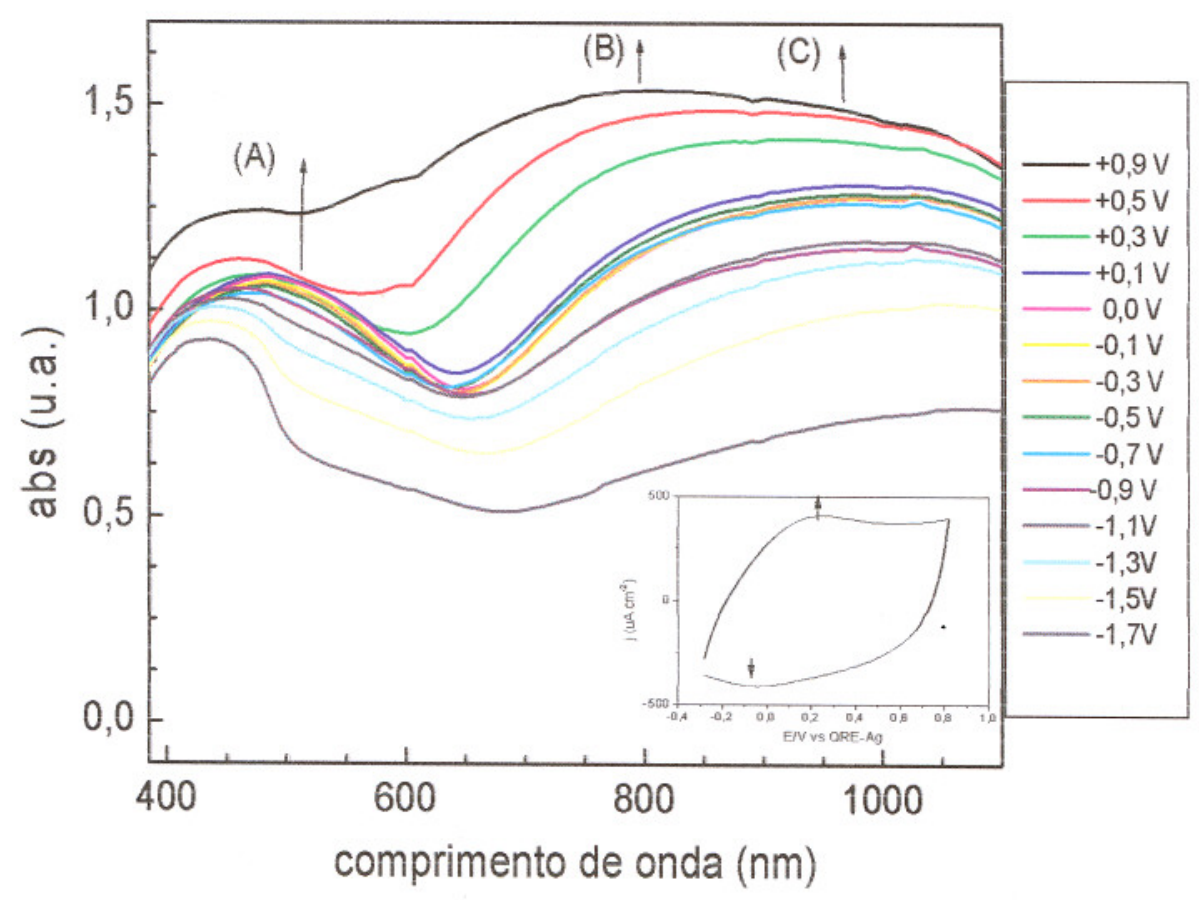

Figura 4.10 Espectros de absorção no UV-VIS de filmes de PPI em meio de 0,01 mol $\mathrm{L}^{-1}$ de $\mathrm{TBAClO}_{4} \mathrm{em} \mathrm{ACN}$ a diferentes potenciais aplicados. As letras representam a região das diferentes bandas dos espectros.

Para melhor visualização dos espectros da Figura 4.10, as curvas foram desconvoluídas em diferentes regiões espectrais ( Figura 4.11). 
IFSC - Ciência e Engenharia de Materiais
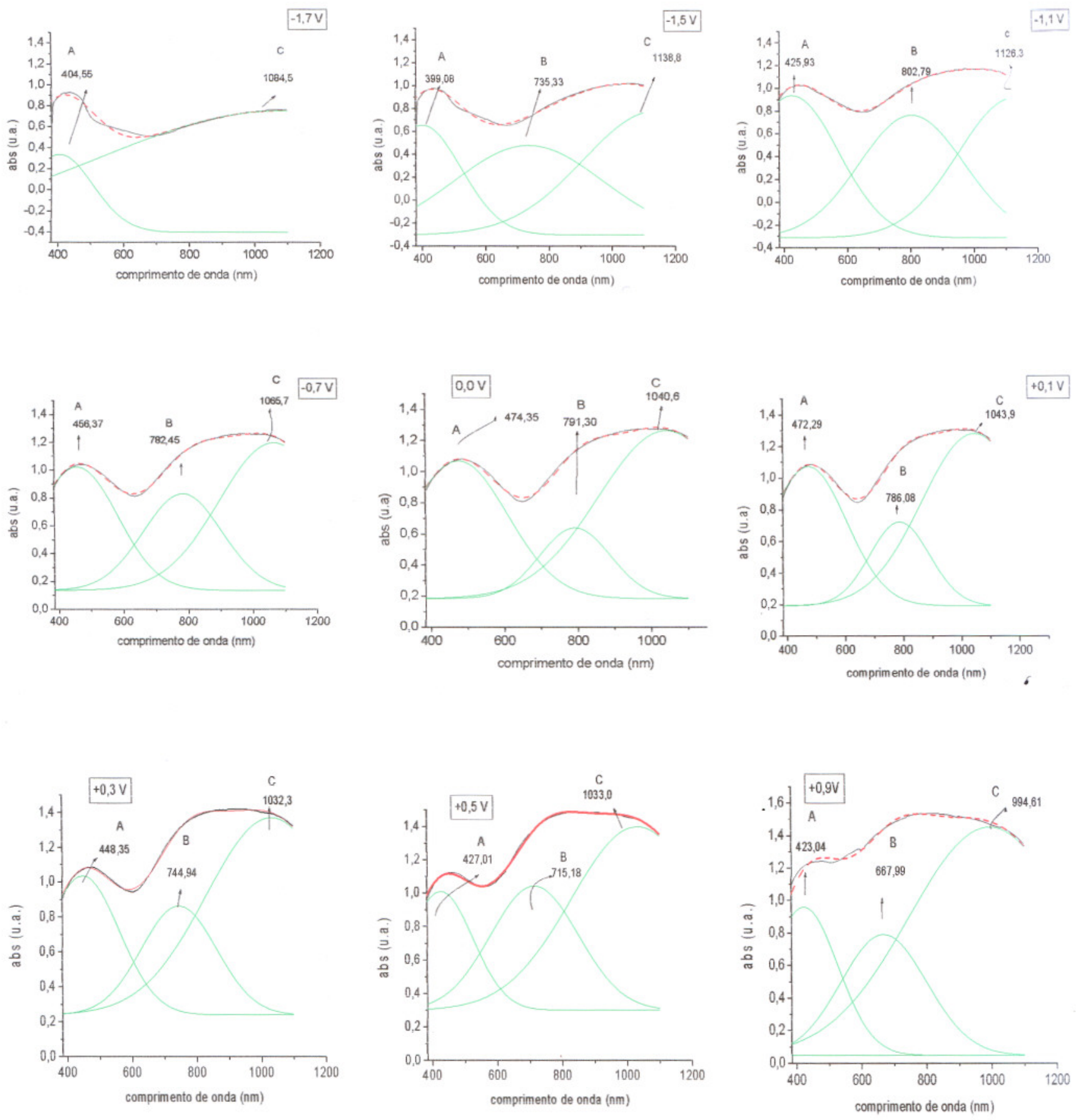

Figura 4.11 Curvas de desconvolução dos espectros de absorbância dos filmes de PPI obtidos a partir da Figura 4.10. 
Tendo como base os resultados semelhantes aos da literatura [9], podemos considerar que os espectros do filme de PPI apresentam três estados eletrônicos: neutro, dopado e dopado-desprotonado.

De acordo com os resultados obtidos, a banda localizada a aproximadamente entre 390-425 nm (A) corresponde às transições $\pi-\pi^{*}$ do filme de PPI em seu estado neutro ${ }^{[10,11]}$. Para o filme no estado pólaron, esta transição é observada entre $700-800$ nm (B) e bipólaron, entre 900-1000 nm (C). Para potenciais aplicados mais positivos, a intensidade das bandas referentes às espécies neutras diminui e há um concomitante aumento nas bandas entre 500 e $840 \mathrm{~nm}$ devido à formação de estruturas oxidadas. Assim, as bandas na região de (B), caracterizam um novo estado, o polarônico, entre 0,9 e $+0,1 \mathrm{~V} v s$ QRE-Ag e as bandas em $(\mathrm{C})^{[11]}$ podem ser atribuídas ao estado mais oxidado do filme de PPI para potenciais superiores a $-1,1 \mathrm{~V} v s$ QRE-Ag, sendo que na região entre 802 e $873 \mathrm{~nm}(\mathrm{C})$, são observadas as bandas correspondentes às transições do filme no seu estado bipólaron nos potenciais de -1,1 V e -1,3 V vs QRE-Ag. A partir de $-0,9 \mathrm{~V}$, a banda do estado bipolarônico, em $873 \mathrm{~nm}$, aumenta em intensidade e decai, em $-0,7 \mathrm{~V}$ e permanece estável até quando se aplica o potencial de $+0,9 \mathrm{~V}$. A partir daí, a banda em $1065 \mathrm{~nm}$, a $-0,7 \mathrm{~V}$, aumenta de intensidade, permanecendo com uma intensidade estável até o final da medida, em $+0.9 \mathrm{~V}$.

Na região acima de $1000 \mathrm{~nm}$, são observadas as transições da estrutura do PPI em estado dopado-desprotonado ${ }^{[9]}$.

De acordo com estudos teóricos ${ }^{[12]}$, há três absorções para os estados polarônicos de filmes de PPI no UV-VIS. Pode-se prever o aparecimento no espectro UV-VIS desses filmes de uma primeira banda de absorção em $1772 \mathrm{~nm}$, atribuída à 
transição da banda de valência para a banda no estado pólaron, em $886 \mathrm{~nm}$, da banda para a antibanda pólaron e finalmente, em $590 \mathrm{~nm}$, da banda de valência para a antibanda pólaron. Uma transição entre a banda pólaron e a banda de condução também deve ser observada em $496 \mathrm{~nm}$.

Portanto, observa-se que, com o potencial aplicado mais positivamente, a intensidade das bandas aumenta de acordo com o grau de oxidação do filme, ou seja, a partir da queda na intensidade de uma, a intensidade de outra correspondente ao estado mais oxidado seguinte aumenta e assim por diante.

Ao final das medidas, o filme polimérico permaneceu com uma coloração cinza, característica do filme no seu estado neutro.

\subsubsection{Bibliografia}

1. LEE H., CUI S., PARK S. Electrochemistry of conductive polymers. Journal of Electrochemical Society, v.148 p.139-145, 2001.

2. GOLDENBERG L.M., LACAZE P. C. Anodic synthesis of poly(p-phenylene). Synthetic Metals, v.45, 35-48, 1991.

3 .BERTHELOT J. R., HASSANI J. T. Anodic oxidation of biphenyl and pterfenyl in dry $\mathrm{CH}_{2} \mathrm{Cl}+0.2 \mathrm{M} \mathrm{Bu}_{4} \mathrm{NBF}_{4}$. Towards poly(p-phenylene) possessing stable and reversible $p$ - and n-doping processes. Journal of Electroanalytical Chemistry, v.408 , p. 247-256, 1996.

4. TABATA M., SATOH M.; KANETO K., YOSHINO K. Electrochemical ntype doping of poly(p-phenylene) film. Journal of Physics. C: Solid State Physics v 19, p101 -105, 1986.

5. SOURBIAN P., AEIYACH S., AARON, J.J., DELAMAR M., LACAZE P.C. Electrosynthesis and spectroscopy characterization of poly-para-phenylene films prepared by oxidation of benzene in liquid sulfur dioxide. Journal of Electroanalytical Chemistry, v.251, p.89-102, 1998. 
6- MAZUR M. Preparation of poly(3-methylthiophene) thin films by in situ polymerization. Thin Solid Films, v.472, p.1-4, 2005.

7- COLANERI N., NOWAK M., SPIEGEL D., HOTTA S., HEEGER A.J. Bipolarons in poly(3-methylthiophene): spectroscopic, magnetic and electrochemical measurements. Physical Review B. v.36, p.7964-7968, 1987.

8- HOIER S.N., PARK S.M. Electrochemistry of conductive polymers: 11. Spectrochemical studies of poly(3-methylthiophene) oxidation. Journal of Physics Chemistry, v.96, p.5188- 5193, 1992.

9- QIBING P., RENYUAN Q. Protonation and deprotonation of polypyrrole chain in aqueous solutions. Synthetic Metals, v.45, p.35-48, 1991.

10- CROWEL K., CASSIDY J. In situ resonance Raman spectroelectrochemistry of polypyrrole doped with dodecylbenzenesulfonate. Journal of Electroanalytical Chemistry, v.547, p.75 -82, 2003.

11- FERMÍM D.J., TERUEL H., SCHARIFKER B. R. Changes in the population of neutral species and charge carriers during electrochemical oxidation of polypyrrole. Journal of Electroanalytical Chemistry, v. 401, p.207214, 1996.

12- BRÉDAS J.L., SCOTT J.C., YAKUSHI K., STREET G.B. Pólarons $e$ bipólarons in polypyrrole: Evolution of the band structure and optical spectrum upon doping. Physical Review B, v.30, p.1023 -1025, 1984. 


\subsection{Caracterização dos filmes dos filmes mistos de CP3MET e CPPI, por espectroscopia no UV-VIS in situ}

Neste tópico, serão discutidos os resultados obtidos com a técnica de espectroscopia no UV-VIS in situ para os filmes de CP3MET e CPPI em meio de 0,01 mol L ${ }^{-1}$ de $\mathrm{TBAClO}_{4}$ em ACN, com o espectrofotômetro Hitachi, modelo U-2001, de feixe duplo acoplado ao potenciostato-galvanostato da EG\&PAR 283.

\subsubsection{CP3MET}

Na Figura 4.12, podem ser observados os espectros de absorção no UV-VIS durante a aplicação de diferentes potenciais para filmes de CP3MET. Na parte interior do espectro, é apresentada a resposta voltamétrica de um filme de CP3MET. Os potenciais foram aplicados entre $-0,3 \mathrm{~V} \mathrm{e}+1,8 \mathrm{~V} v s$ QRE-Ag. 


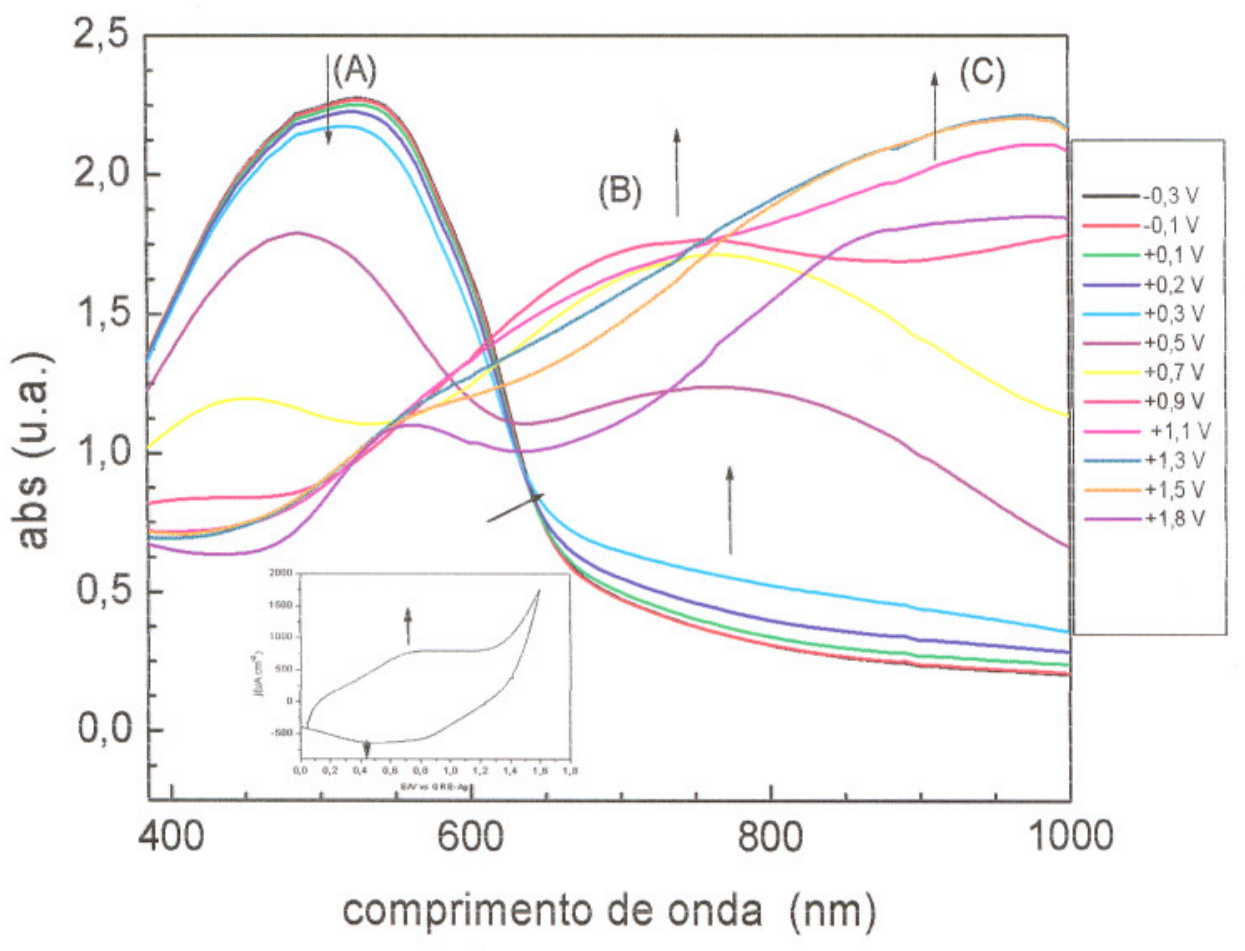

Figura 4.12 Espectros de absorção no UV-VIS de filmes de CP3MET em meio de $0,01 \mathrm{~mol} \mathrm{~L}^{-1}$ de $\mathrm{TBAClO}_{4} \mathrm{em}$ ACN a diferentes potenciais aplicados. As letras representam as diferentes bandas dos espectros.

Para melhor visualização, as curvas foram desconvoluídas em diferentes regiões espectrais (Figuras 4.13). 

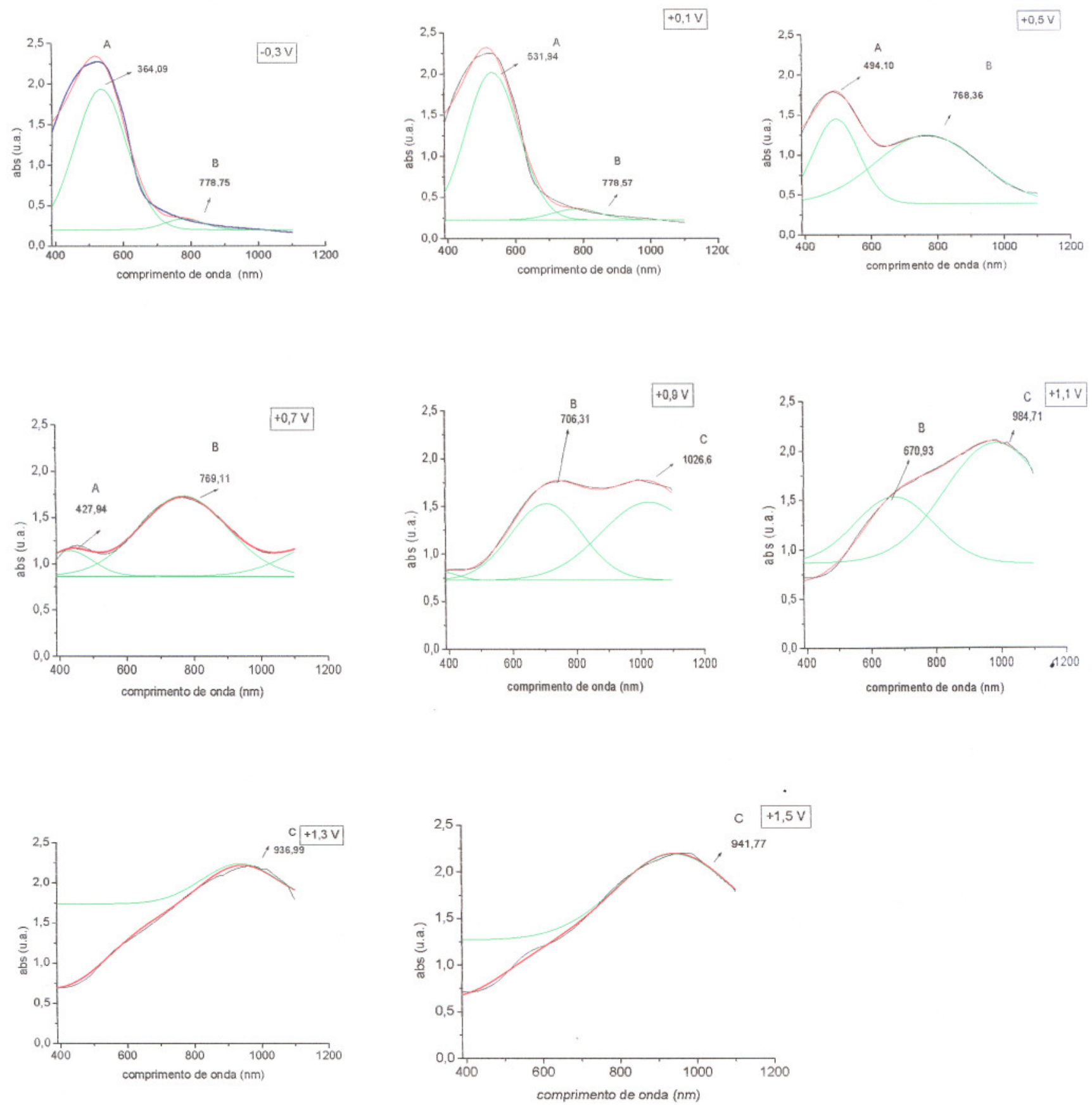

Figura 4.13 Curvas de desconvolução dos espectros de absorbância dos filmes de CP3MET obtidos a partir da Figura 4.12. 
A partir das curvas de desconvolução dos espectros de UV-VIS in situ dos filmes de P3MET, Figura 4.8 e do CP3MET, Figura 4.12, observa-se uma igualdade nas bandas de absorção, que ocorrem nas mesmas regiões espectrais para ambos os filmes.

Observa-se também que o espectro de UV-VIS in situ do filme de CP3MET apresenta a banda referente o estado neutro do filme mais alargada e bandas de transição mais intensas em relação ao espectro do filme de P3MET, deslocadas para um maior comprimento de onda. Fato esse, que comprova um aumento na conjugação do filme de CP3MET devido à formação do filme misto de PPP/P3MET.

A partir de 1,3 V, que é um potencial alto o suficiente para a degradação do filme de CP3MET, há a formação de bandas atribuídas ao filme de CP3MET degradado, pois estas bandas diminuem a sua intensidade com a varredura sucessiva do potencial.

No final da medida, o filme do de CP3MET apresentou uma coloração marrom avermelhada, caracteristica do filme de P3MET em sua forma completamente oxidada.

\subsubsection{CPPI}

Na Figura 4.14, podem ser observados os espectros de absorção no UV-VIS durante a aplicação de diferentes potenciais para filmes de CPPI. Na parte interior do espectro, é apresentada a resposta voltamétrica de um filme de CPPI. Os potenciais foram aplicados entre $-0,1 \mathrm{~V}$ e $+0,9 \mathrm{~V} v s \mathrm{QRE}-\mathrm{Ag}$. 


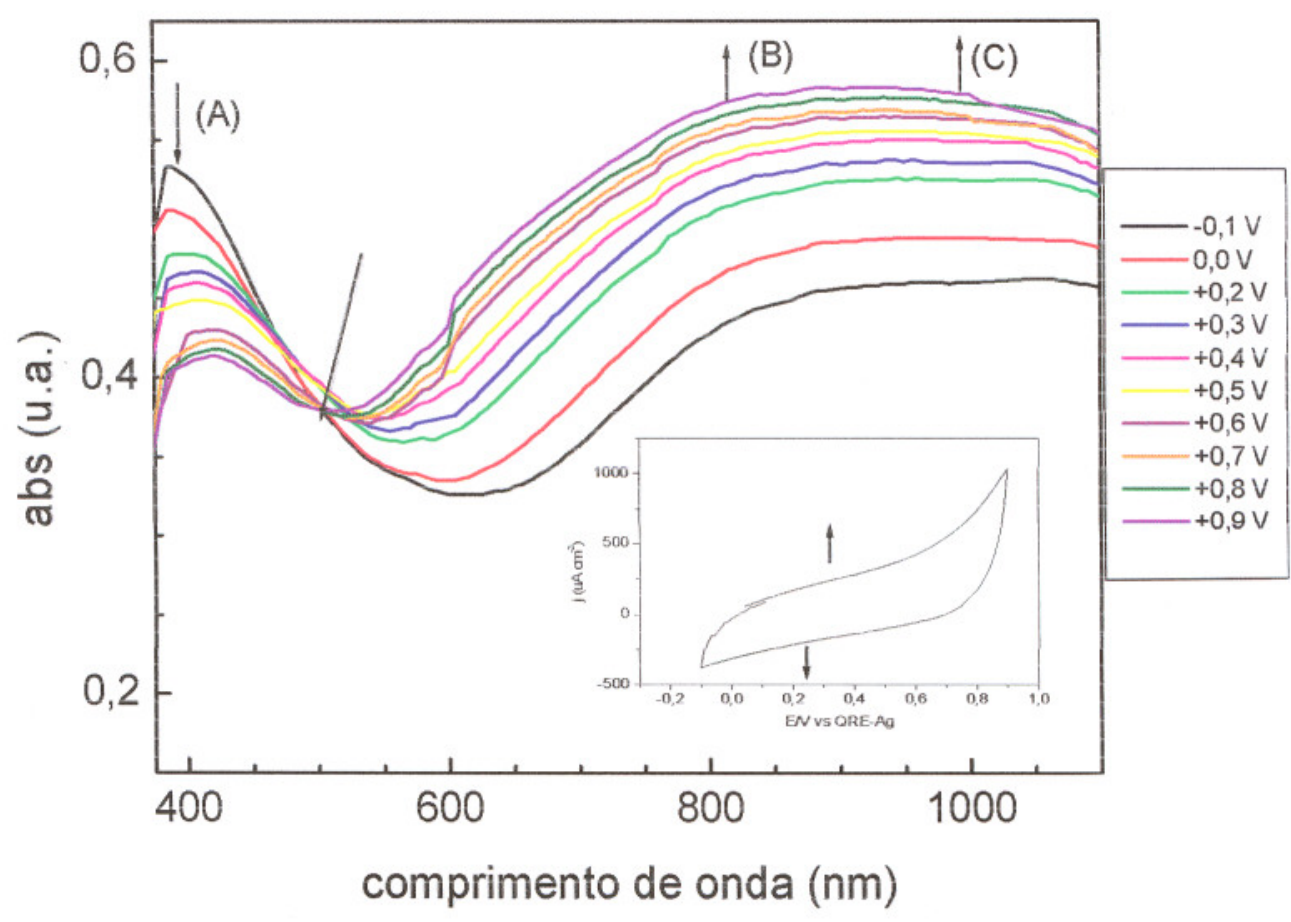

Figura 4.14 Espectros de absorção no UV-VIS de filmes de CPPI em meio de $0,01 \mathrm{~mol}$ $\mathrm{L}^{-1}$ de $\mathrm{TBAClO}_{4}$ em $\mathrm{ACN}$ a diferentes potenciais aplicados. As letras representam as diferentes bandas dos espectros.

Para melhor visualização dos espectros da Figura 4.14, as curvas foram desconvoluídas em diferentes regiões espectrais (Figura 4.15). 
IFSC - Ciência e Engenharia de Materiais
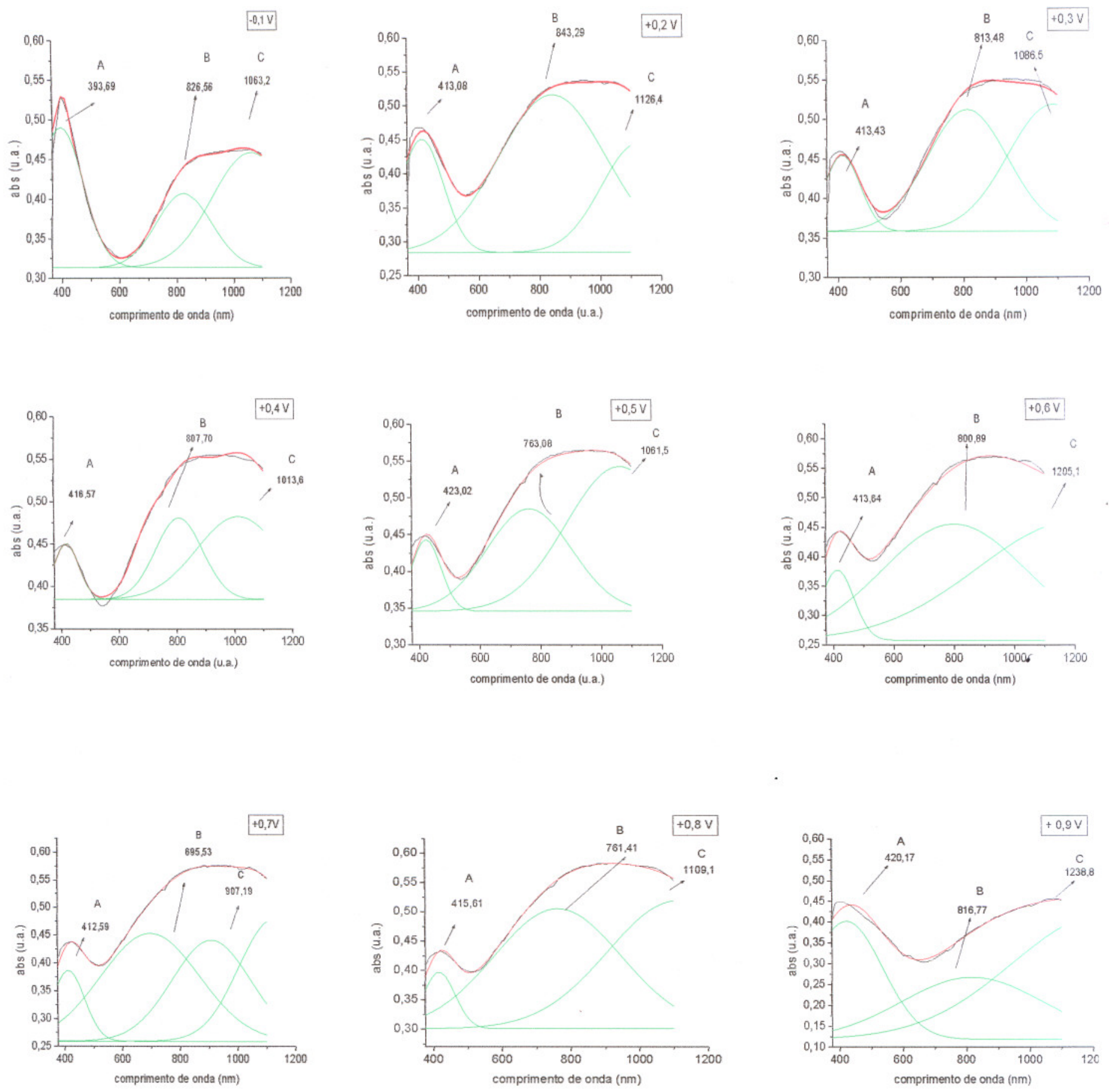

Figura 4.15 Curvas de desconvolução dos espectros de absorbância dos filmes de CPPI obtidos a partir da Figura 4.14. 
A Figura 4.14 mostra as mudanças no modo de reflectância do espectro de UVVIS durante a oxidação do filme de CPPI. Pode-se observar que a porção neutra do espectro do filme de CPPI é semelhante à porção neutra do espectro de UV-VIS in situ do filme de PPP e a porção oxidada, é semelhante à porção oxidada do espectro do filme de PPI, sendo que ambas ocorrem na mesma região espectral.

A partir das curvas de desconvolução da Figura 4.15, pode-se observar que as bandas formadas durante a oxidação do filme no intervalo de $-0,1$ a $+0,9 \mathrm{~V} v s$ QRE-Ag na região entre 423 - $413 \mathrm{~nm}$ (A) caracterizam o filme de CPPI no seu estado neutro ${ }^{[1,2]}$, e que as formadas na região em $690 \mathrm{~nm}$ (B) são correspondentes ao filme no seu estado polarônico ${ }^{[3]}$ e na região em $843-1240 \mathrm{~nm}$ (C), são correspondentes ao filme no seu estado bipolarônico ${ }^{[3]}$, ou seja, ocorrem as mesmas transições eletrônicas e as bandas são formadas nas mesmas regiões daquelas do espectro do filme de PPI. Ainda na Figura 4.15, as bandas entre $1013-1240 \mathrm{~nm}(\mathrm{C})$ caracterizam o filme no seu estado dopado-desprotonado ${ }^{[1]}$, com uma absorção que aumenta com a varredura do potencial para valores mais positivos. No final das medidas, o filme apresentou uma coloração marrom acinzentado.

\subsubsection{Bibliografia}

1- QIBING P., RENYUAN Q. Protonation and deprotonation of polypyrrole chain in aqueous solutions. Synthetic Metals, v.45, p.35-48, 1991.

2- CROWEL K., CASSIDY J. In situ resonance Raman spectroelectrochemistry of polypyrrole doped with dodecylbenzenesulfonate. J. of Electroanalytical Chemistry, v.547, p.75-82, 2003.

3- FERMÍM D.J., TERUEL H., SCHARIFKER B.R. Changes in the population of neutral species and charge carriers during electrochemical oxidation of polypyrrole. J. of Electroanalytical Chemistry, v.401, p.207-214, 1996. 


\subsection{Caracterização dos filmes dos homopolímeros e dos filmes mistos por FT-Raman}

Na Figura 4.16, são observados os espectros FT-Raman dos homopolímeros PPP, PPI, P3MET e dos filmes de CP3MET e CPPI realizados partir de uma radiação de 1064 $\mathrm{nm}$.
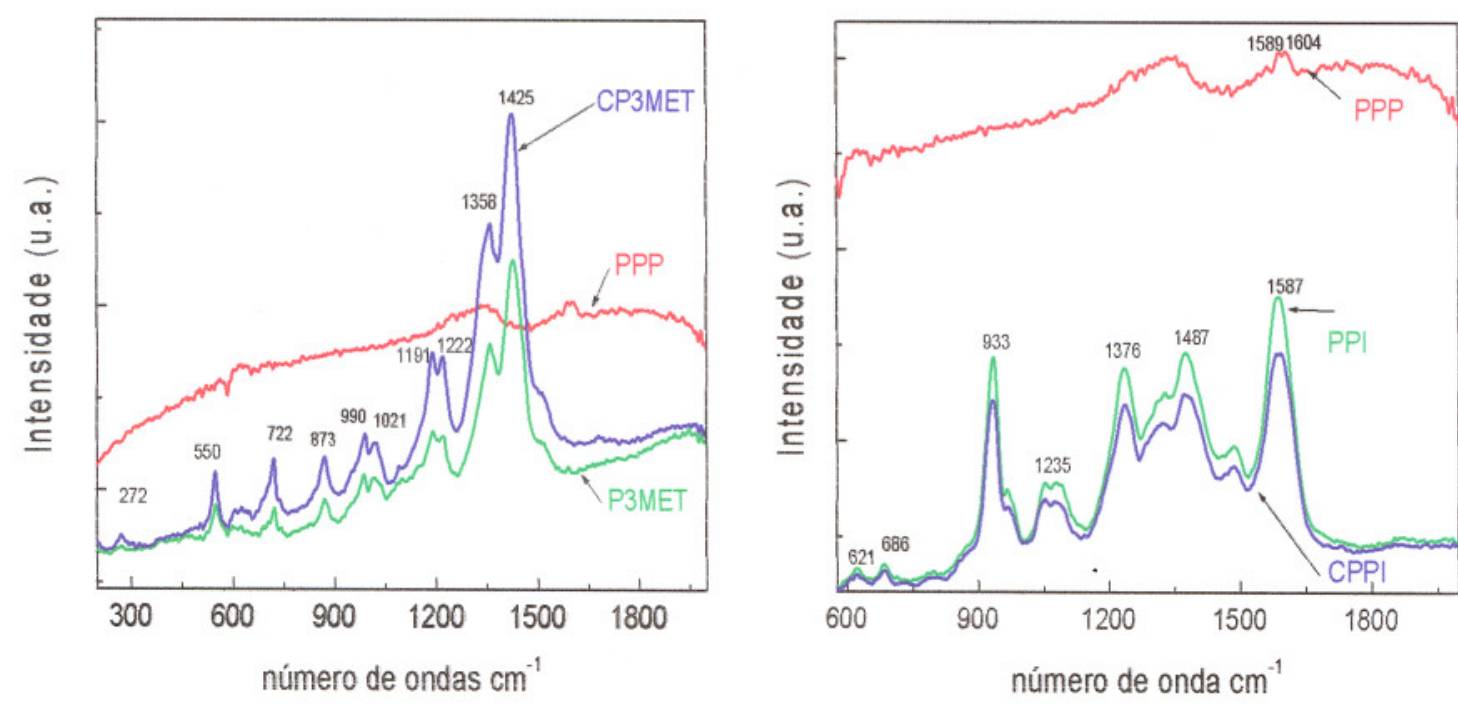

Figura 4.16 Espectros de FT-Raman dos filmes dos homopolímeros PPP, P3MET e PPI e dos filmes mistos CP3MET e CPPI, sintetizados sobre FTO em meio a ACN e $0,01 \mathrm{~mol} \mathrm{~L}^{-1}$ de $\mathrm{TBAClO}_{4}$.

Observa-se na Figura 4.16 que os espectros dos filmes de CP3MET e CPPI se assemelham aos espectros dos filmes dos homopolímeros, ou seja, não apresentam os picos de absorção referentes ao PPP, mas apenas aos dos filmes de P3MET e PPI. 
$\mathrm{Na}$ Tabela 4.2, são apresentados os picos obtidos nos espectros do homopolímero PPI e do derivado CPPI e na Tabela 4.3, os picos do homopolímero P3MET e do derivado CP3MET. Os espectros de FT-Raman, tanto do PPI quanto do CPPI, apresentaram picos idênticos nas mesmas regiões espectrais e que caracterizam o filme do homopolímero PPI. O mesmo ocorreu nos espectros dos P3MET e CP3MET. Abaixo de $1300 \mathrm{~nm}$, o espectro do filme de PPP mostrou que este apresenta um efeito térmico ainda desconhecido, impossibilitando a observação dos picos característicos do PPP nesta região espectral.

Tabela 4.2: Atribuições dos picos Raman nos espectros dos filmes de PPI e CPPI eletrossintetizados sobre FTO e mostrados na Figura 4.1 (c) e 4.2 (b) respectivamente ${ }^{[1] \text {. }}$

\begin{tabular}{|c|c|c|}
\hline \multicolumn{3}{|c|}{ PPI-CPPI } \\
\hline $\begin{array}{c}\text { Pico }\left(\mathbf{c m}^{-1}\right)- \\
\text { valores observados }\end{array}$ & $\begin{array}{c}\text { Pico }\left(\mathbf{c m}^{-1}\right)- \\
\text { valores da literatura [1] }\end{array}$ & Atribuições \\
\hline 1587 & $1560-1630$ & Estiramento C=C \\
\hline 1487 & $1510-1460$ & $\begin{array}{c}\text { Deformação da ligação } \\
\text { C=C e C-N no plano }\end{array}$ \\
\hline 1376 & $1386-1328$ & Estiramento do anel \\
\hline 1235 & 940 e 990 & $\begin{array}{c}\text { Deformação do anel } \\
\text { associada ao bipólaron e ao } \\
\text { pólaron - PPI }\end{array}$ \\
\hline & 932 & $\begin{array}{c}\text { Estiramento simétrico do } \\
\text { dopante ClO }\end{array}{ }^{-}-$PPI \\
\hline 933 & & \\
\hline 686 & & \\
\hline 621 & & \\
\hline
\end{tabular}


Tabela 4.3: Atribuições dos picos Raman nos espectros dos filmes de P3MET e CP3MET eletrossintetizados sobre FTO e mostrados na Figura 4.1 (b) e 4.2 (a), respectivamente ${ }^{[1] .}$

\begin{tabular}{|c|c|l|}
\hline \multicolumn{3}{|c|}{ P3MET-CP3MET } \\
\hline $\begin{array}{c}\text { Pico }\left(\mathbf{c m}^{-1}\right) \\
\text { valores observados }\end{array}$ & $\begin{array}{c}\text { Pico }\left(\mathbf{c m}^{-1}\right) \text { - } \\
\text { valores da literatura [1] }\end{array}$ & \multicolumn{1}{|c|}{ Atribuições } \\
\hline 1425 & 1445 & Estiramento C=C do anel \\
\hline 1358 & 1352 & Estiramento C-C do anel \\
\hline 1222 & $1240-1195$ & Deformação C=C no plano \\
\hline 1191 & 1182 & Deformação angular C-H \\
\hline 1021 & $1100-1070$ & Deformação C-H no plano \\
\hline 990 & 983 & Estiramento CH - Anel $^{-}$ \\
\hline 873 & 872 & Estiramento C-S do anel \\
\hline 722 & 718 & Deformação C-S-C do anel \\
\hline 550 & 548 & $\begin{array}{l}\text { Deformação angular do } \\
\text { anel no plano }\end{array}$ \\
\hline 272 & & \\
\hline
\end{tabular}

Tabela 4.4: Atribuições dos picos Raman nos espectros do filme de PPP eletrossintetizados sobre FTO, mostrado na Figura 4.1 (a).

\begin{tabular}{|c|c|c|}
\hline \multicolumn{3}{|c|}{ PPP } \\
\hline $\begin{array}{c}\text { Pico }\left(\mathrm{cm}^{-1}\right) \\
\text { valores observados }\end{array}$ & $\begin{array}{c}\text { Pico }\left(\mathrm{cm}^{-1}\right)- \\
\text { valores da literatura [1] }\end{array}$ & Atribuições \\
\hline 1589 & & $\begin{array}{c}\text { Estiramento das ligações } \\
\mathrm{C}=\mathrm{C} \text { do anel fenilênico }\end{array}$ \\
\hline
\end{tabular}

O não aparecimento das bandas referentes ao PPP nos filmes dos derivados CP3MET e CPPI se deve a um efeito térmico que é semelhante à fluorescência, apresentado pelo PPP quando irradiado no comprimento de onda de $1064 \mathrm{~nm}$. A fluorescência é um fenômeno que compete com o efeito Raman, é mais intenso e mascara o efeito Raman do filme de PPP nos filmes dos derivados. 
IFSC - Ciência e Engenharia de Materiais

\subsubsection{Bibliografia}

1- EIRAS Carla. Eletrossíntese e propriedades ópticas e morfológicas de filmes de poli-p-fenileno e derivados. São Carlos, 2004, 148p. tese (Doutorado)Instituto de Física de São Carlos, Universidade de São Paulo.

\subsection{Caracterização dos filmes dos homopolímeros e dos filmes mistos por FTIR por reflectância}

Foram feitas medidas de FTIR dos filmes de PPP, PPI, P3MET, CPPI e CP3MET que foram sintetizados sobre Pt e não sobre FTO, como anteriormente.

A Figura 4.17 mostra os espectros de FTIR por reflectância do filme de PPP. 


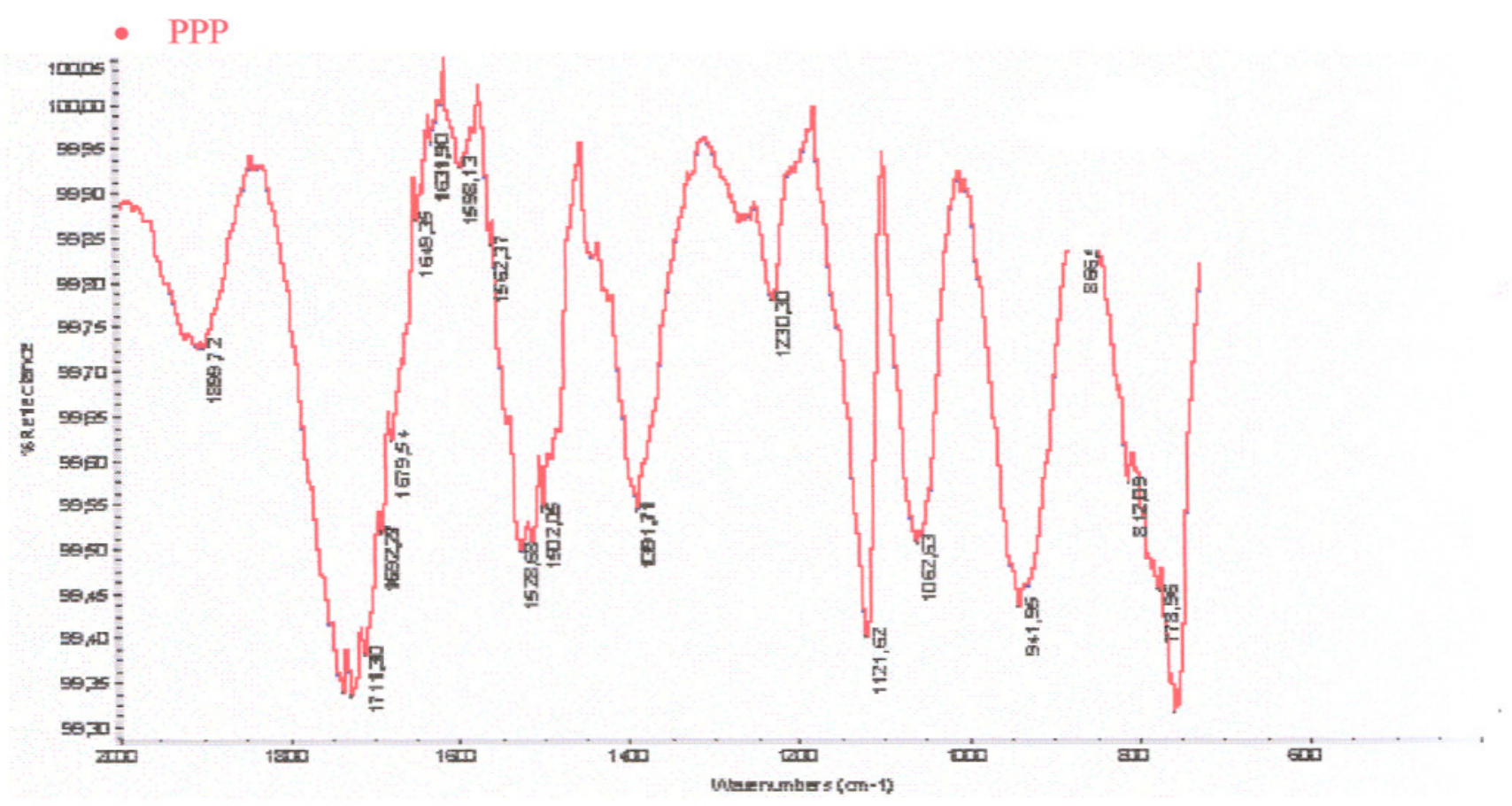

Figura 4.17 Espectro FTIR por reflectância de filmes de PPP eletrossintetizados sobre FTO em meio de uma solução de $0,1 \mathrm{~mol} \mathrm{~L}^{-1}$ de bifenila, $0,01 \mathrm{~mol} \mathrm{~L}^{-1}$ de $\mathrm{TBAClO}_{4} \mathrm{em} \mathrm{ACN} \mathrm{a} \mathrm{v}=50 \mathrm{~m} \mathrm{~V} \mathrm{~s}^{-1}$.

No espectro FTIR do filme de PPP, foi possível observar o surgimento das bandas características do $\mathrm{PPP}$, como o estiramento $\mathrm{C}=\mathrm{C}$ atribuído aos anéis fenilênicos e também uma banda atribuída à vibração $\mathrm{C}-\mathrm{H}$ fora do plano para átomos de hidrogênios adjacentes em anéis para-substituídos.

De acordo com a literatura ${ }^{[1]}$, os espectros de FTIR de um filme de PPP preparado eletroquimicamente a partir do benzeno, apresentavam as bandas entre $650 \mathrm{e}$ $750 \mathrm{~cm}^{-1}{ }^{[2]}$ típicas de vibrações fora do plano de 5 átomos de hidrogênios adjacentes em anéis de fenileno terminal, e a banda em $805 \mathrm{~cm}^{-1}{ }^{[2]}$, característica de vibrações $\mathrm{C}-\mathrm{H}$ fora do plano para átomos de hidrogênios adjacentes em anéis para-substituídos em ${ }^{[1]}$. 
Em outro trabalho ${ }^{[3]}$, a partir do PPP depositado por evaporação de oligômeros, os espectros apresentaram a banda a $765 \mathrm{~cm}^{-1}$ atribuída à deformação $\mathrm{C}-\mathrm{H}$ fora do plano de anéis fenilênicos mono -substituídos é característica da estrutura 1,4 substituído; já, a banda observada entre $800-830 \mathrm{~cm}^{-1}$ foi atribuída aos fenilenos para-substituídos ${ }^{[3]}$. A banda em $1393 \mathrm{~cm}^{-1}$, como encontrada na literatura foi atribuídas às vibrações de ligações $\mathrm{C}=\mathrm{C}$ em anéis fenilênicos ${ }^{[4]}$.

A Tabela 4.5 mostra as principais bandas observadas no espectro do filme de PPP.

Tabela 4.5: Atribuições das bandas de FTIR do filme de PPP eletrossintetizado sobre FTO e mostrado na Figura 4.1 (a)

\begin{tabular}{|c|c|c|}
\hline \multicolumn{3}{|c|}{ PPP } \\
\hline Bandas $\left(\mathrm{cm}^{-1}\right)$ & $\begin{array}{l}\text { Bandas encontradas } \\
\text { pela literatura }\left(\mathrm{cm}^{-1}\right)\end{array}$ & Atribuição \\
\hline 778 & $650-750$ & $\begin{array}{l}\text { Vibração } \mathrm{C}-\mathrm{H} \text {, com átomos } \\
\text { de hidrogênios adjacentes em } \\
\text { anéis de fenileno terminal }\end{array}$ \\
\hline 812 & $830-800$ & $\begin{array}{c}\text { Vibração C-H fora do plano } \\
\text { para átomos de hidrogênios } \\
\text { adjacentes em anéis para- } \\
\text { substituídos }\end{array}$ \\
\hline \multicolumn{3}{|l|}{941} \\
\hline \multirow{2}{*}{\multicolumn{3}{|c|}{$\frac{1062}{1121}$}} \\
\hline & & \\
\hline 1230 & $1225-1175$ & $\begin{array}{c}\text { Anéis de fenilenos } \\
\text { substituídos: } 1,2 ; 1,4 ; 1,2,4\end{array}$ \\
\hline 1391 & 1393 & $\begin{array}{c}\text { Estiramento } \mathrm{C}=\mathrm{C} \mathrm{em} \text { anéis de } \\
\text { fenilenos }\end{array}$ \\
\hline
\end{tabular}

A Figura 4.18 mostra os espectros FTIR por reflectância dos filmes de P3MET e CP3MET. 


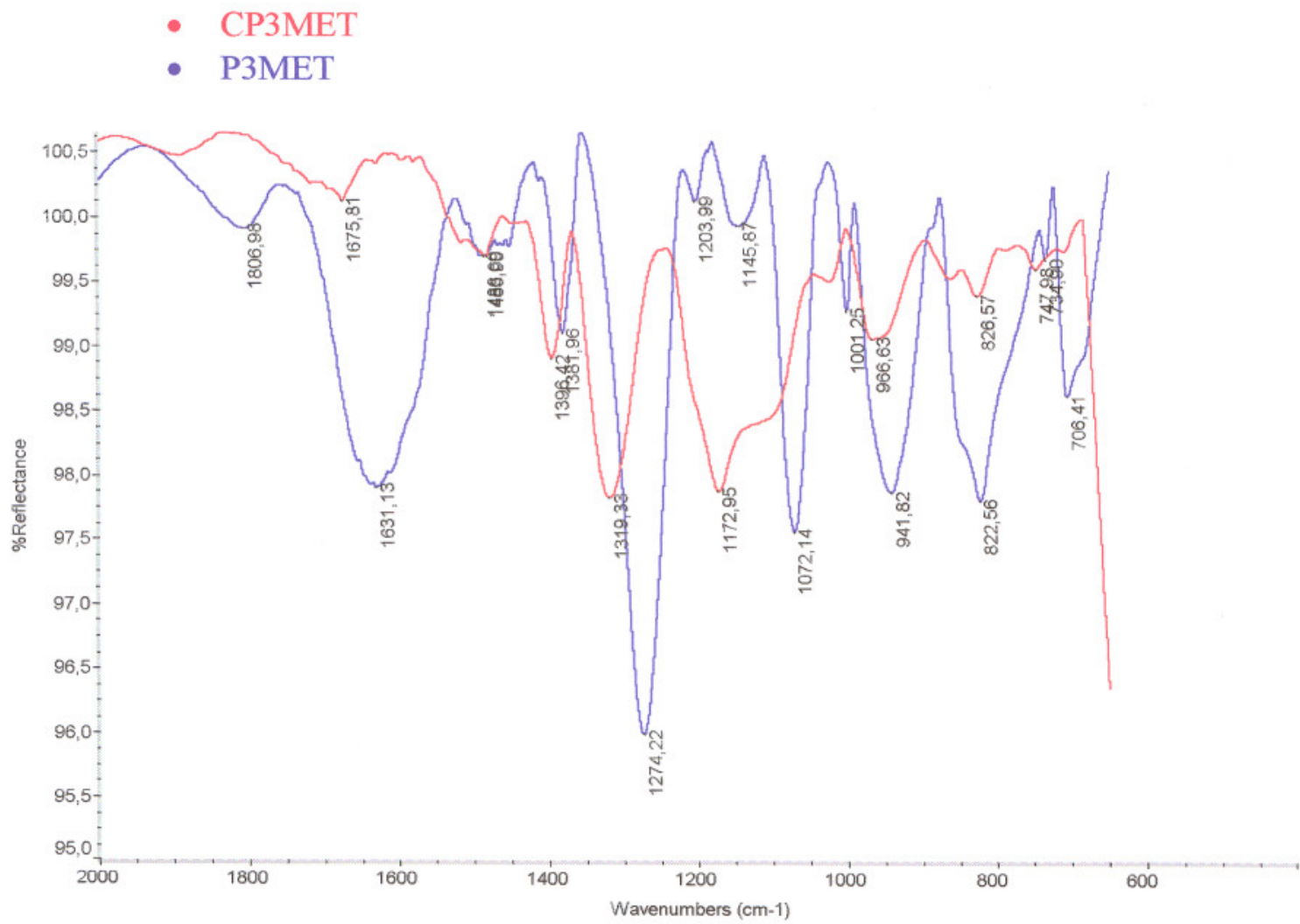

Figura 4.18 Espectro FTIR por reflectância do filme de CP3MET eletrossintetizados sobre FTO em meio de uma solução de $0,1 \mathrm{~mol} \mathrm{~L}^{-1}$ de bifenila, $0,05 \mathrm{~mol} \mathrm{~L}^{-1}$ de 3metiltiofeno, $0,01 \mathrm{~mol} \mathrm{~L}^{-1}$ de $\mathrm{TBAClO}_{4} \mathrm{em} \mathrm{ACN} \mathrm{a} \mathrm{v}=50 \mathrm{~m} \mathrm{~V} \mathrm{~s}^{-1}$.

A partir dos espectros FTIR por refletância, pôde-se verificar o aparecimento apenas das bandas referentes aos homopolímeros no espectro do filme misto, CP3MET. Os espectros dos filmes de P3MET e CP3MET apresentaram praticamente as mesmas bandas, como, por exemplo, em $825 \mathrm{~cm}^{-1}[6]$, que pode ser atribuída à deformação $\mathrm{C}-\mathrm{H}$ fora do plano do 3-metiltiofeno. De acordo com a literatura ${ }^{[5]}$, a banda na região de 946 $\mathrm{cm}^{-1}$ é característica da vibração da ligação C-S do P3MET. Na região de $1005 \mathrm{~cm}^{-1}$, surgem bandas referentes à deformação da ligação $\mathrm{C}-\mathrm{H}$ no plano em aromáticos e entre $1089 \mathrm{~cm}^{-1}$, atribuída à deformação da estrutura aromática de cinco membros do tiofeno. 
Em 1383 e 1638-1665 cm ${ }^{-1}$, são observadas a bandas de deformação $\mathrm{C}-\mathrm{C}$ e $\mathrm{C}=\mathrm{C}$ em aromáticos.

A Tabela 4.6 mostra as principais bandas observadas nos espectros dos filmes de P3MET e CP3MET.

Tabela 4.6: Atribuições das bandas de FTIR de filmes de P3MET e CP3MET eletrossintetizados sobre FTO e mostrado na Figura 4.1 (b) e 4.2 (a), respectivamente $^{[1,2] \text {. }}$

\begin{tabular}{|c|c|c|c|}
\hline P3MET & CP3MET & & \\
\hline Bandas $\left(\mathrm{cm}^{-1}\right)$ & Bandas $\left(\mathrm{cm}^{-1}\right)$ & $\begin{array}{c}\text { Bandas } \\
\text { encontradas } \\
\text { pela literatura } \\
\left(\mathbf{c m}^{-1}\right)\end{array}$ & Atribuição \\
\hline 822 & 826 & 825 & $\begin{array}{l}\text { Deformação C-H fora } \\
\text { do plano }{ }^{[6]}\end{array}$ \\
\hline \multirow[t]{2}{*}{942} & 967 & 946 & $\begin{array}{l}\text { Deformação da } \\
\text { ligação } \\
\text { C-S }{ }^{[5]} \text { no plano }\end{array}$ \\
\hline & 1001 & 1005 & $\begin{array}{l}\text { Deformação da } \\
\text { ligação C-H no plano } \\
\text { em aromáticos }\end{array}$ \\
\hline 1072 & 1172 & 1089 & $\begin{array}{l}\text { Deformação da } \\
\text { estrutura aromática de } \\
\text { cinco membros do } \\
\text { tiofeno }^{[4]}\end{array}$ \\
\hline 1381 & 1396 & 1383 & $\begin{array}{l}\text { Estiramento das } \\
\text { ligações } C=C \text { de uma } \\
\text { estrutura aromática de } \\
5 \text { ou } 6 \text { membros }{ }^{[4]}\end{array}$ \\
\hline 1631 & 1675 & $1638-1665$ & $\begin{array}{l}\text { Deformação da } \\
\text { ligação } C=C \text { no anel }\end{array}$ \\
\hline
\end{tabular}

A Figura 4.19 mostra os espectros de FTIR por reflectância propostos para os filmes de PPI e para o filme de CPPI. 
- CPPI

- PPI

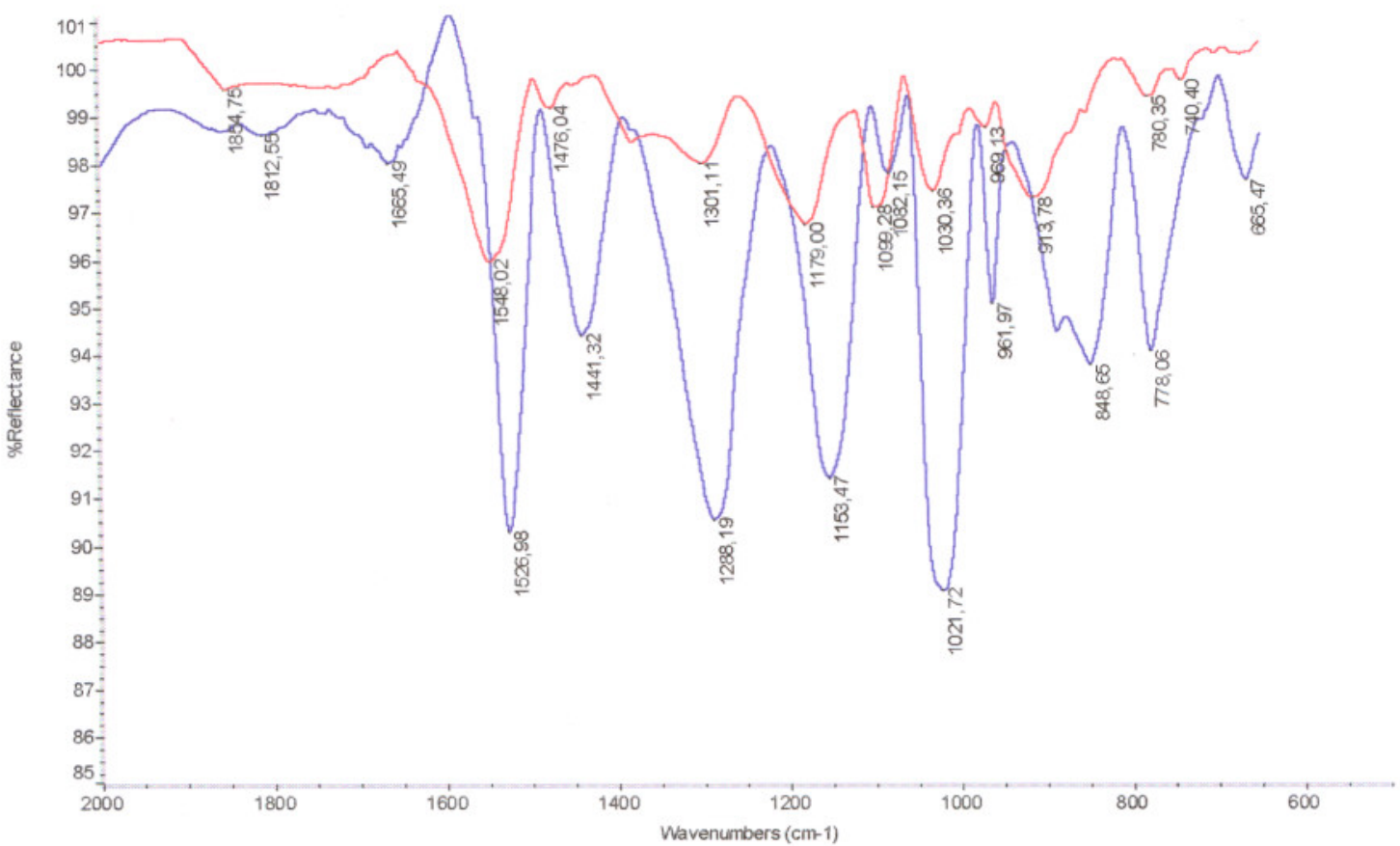

Figura 4.19 Espectro de FTIR por refiectância do filme de CPPI eletrossintetizados sobre FTO em meio de uma solução de $0,1 \mathrm{~mol} \mathrm{~L}{ }^{-1}$ de bifenila, $0,01 \mathrm{~mol} \mathrm{~L}^{-1}$ de pirrol, 0,01 mol L-1 de $\mathrm{TBAClO}_{4} \mathrm{em} \mathrm{ACN} \mathrm{a} \mathrm{v}=50 \mathrm{~m} \mathrm{~V} \mathrm{~s}^{-1}$.

A partir dos espectros FTIR por refletância, pôde-se observar que os espectros dos filmes dos filmes mistos somente apresentam bandas menos intensas em relação aos espectros dos filmes dos homopolímeros. Os espectros dos filmes de PPI e CPPI apresentaram praticamente as mesmas bandas, como, por exemplo, em $1527 \mathrm{~cm}^{-1}$ e 1548 $\mathrm{cm}^{-1}$, que podem ser atribuídas ao estiramento $\mathrm{C}=\mathrm{C}$ e $\mathrm{C}-\mathrm{C}$ de compostos aromáticos com mais de 5 ou 6 membros. A banda na região de $779 \mathrm{~cm}^{-1}$, observada nos espectros dos filmes de PPI em $778 \mathrm{~cm}^{-1}$ e no de CPPI em $780 \mathrm{~cm}^{-1}$, pode ser atribuída à presença de hidrogênios adjacentes na estrutura do pirrol. Na região entre $1180-1190 \mathrm{~cm}^{-1}$, são observadas nos espectros as bandas atribuídas ao estiramento $\mathrm{C}-\mathrm{N}$ e da deformação $\mathrm{C}-\mathrm{H}$ 
${ }^{[7]}$ do PPI. As bandas em $1480,1545 \mathrm{~cm}^{-1}$ podem ser atribuídas aos modos de vibração de compostos aromáticos com mais de 5 ou 6 membros.

A Tabela 4.7 mostra as principais bandas observadas nos espectros dos filmes de PPI e CPPI.

Tabela 4.7: Atribuições das bandas de FTIR de filmes de PPI e CPPI eletrossintetizados sobre FTO e mostrado na Figura 4.1 (c) e 4.2 (b), respectivamente ${ }^{[3]}$.

\begin{tabular}{|c|c|c|c|}
\hline PPI & CPPI & & \\
\hline Bandas $\left(\mathrm{cm}^{-1}\right)$ & Bandas $\left(\mathrm{cm}^{-1}\right)$ & $\begin{array}{c}\text { Bandas } \\
\text { encontradas pela } \\
\text { literatura }\left(\mathrm{cm}^{-1}\right)\end{array}$ & Atribuição \\
\hline 778 & 780 & 779 & $\begin{array}{l}\text { Hidrogênios } \\
\text { adjacentes no pirrol }^{[4]}\end{array}$ \\
\hline 849 & 914 & 912 & $\begin{array}{l}\text { Deformação do anel } \\
\text { de pirrol }^{[7]}\end{array}$ \\
\hline 1153 & 1179 & $1180-1190$ & $\begin{array}{l}\text { Estiramento C-N e } \\
\text { deformação C-H }\end{array}$ \\
\hline 1441 & 1476 & 1480 & $\begin{array}{l}\text { Vibrações } \mathrm{C}=\mathrm{C} \text { e } \mathrm{C}-\mathrm{C} \\
\text { de compostos } \\
\text { aromáticos com mais } \\
\text { de } 5 \text { ou } 6 \text { membros }{ }^{[4]}\end{array}$ \\
\hline 1527 & 1548 & 1545 & $\begin{array}{l}\text { Vibrações } \mathrm{C}=\mathrm{C} \text { e C-C } \\
\text { de compostos } \\
\text { aromáticos com mais } \\
\text { de } 5 \text { ou } 6 \text { membros }{ }^{[4]}\end{array}$ \\
\hline
\end{tabular}

Observou-se nos espectros de FTIR, um pequeno deslocamento das bandas referentes à vibração de compostos aromáticos com mais de 5 ou 6 membros, como, por exemplo, das bandas em 1381 e $1631 \mathrm{~cm}^{-1}$, para o P3MET, e 1396 e $1675 \mathrm{~cm}^{-1}$, para o CP3MET, sendo que uma nova banda surgiu a $1005 \mathrm{~cm}^{-1}$, atribuída à deformação da ligação C-H no plano em aromáticos ${ }^{[6]}$. Nos espectros de PPI e CPPI, observou-se 
também um pequeno deslocamento das bandas: 1441 e $1527 \mathrm{~cm}^{-1}$ para o PPI e $1476 \mathrm{e}$ $1548 \mathrm{~cm}^{-1}$ para o CPPI. ${ }^{[4]}$.

Na literatura ${ }^{[8]}$, foram obtidos os espectros de IR de blendas PANI-CSA/PMMA com 20,50 e $75 \%$ de polímero condutor, e estudou-se o deslocamento de algumas bandas nestes espectros. Observou-se que a banda devido ao grupo $\mathrm{C}=\mathrm{O}$ de PMMA em $1744 \mathrm{~cm}^{-1}$ deslocou-se para $1750 \mathrm{~cm}^{-1}$ com o aumento na concentração de polímero condutor na blenda. Este deslocamento foi relacionado a uma diminuição na concentração de ligações hidrogênio entre os nitrogênios do grupo amina da PANI-CSA e o grupo carbonila do PMMA. Os resultados obtidos mostraram que uma maior interação dos componentes das blendas era evidenciada com a diminuição da freqüência da banda de carbonila e o aumento na concentração de ligações hidrogênio.

Neste caso, observamos que os polímeros, P3MET e PPI, sofreram alterações em sua estrutura macromolecular quando realizamos a síntese do 3-metiltiofeno com a bifenila e do pirrol com a bifenila, para formar os filmes de CP3MET e de CPPI, respectivamente. Para que pudéssemos analisar suas estruturas, fizemos uma comparação entre os espectros de FTIR dos homopolímeros P3MET e PPI com os respectivos espectros de FTIR dos derivados CP3MET e CPPI, e percebemos a formação de novas interações ocorridas no anel aromático dos polímeros formados pelo PPP/P3MET e dos polímeros formados pelo PPP/PPI, o que comprova a formação de ambos os polímeros em cada eletrodo, comprovada por meio das mudanças nas freqüências das bandas que foram deslocadas nos espectros de FTIR desses polímeros. 


\subsubsection{Bibliografia}

1- GEETHA S. Electrochemical synthesis and characterization of conducting polyparaphenylene using room-temperature melt as electrolyte. Synthetic Metals. v. 148, p.187-194, 2005.

2- SOURBIAN P., AEIYACH S., AARON J.J., DELAMAR M., LACAZE P.C. Electrosyntesis and spectroscopic characterization of poly-para-phenylene films prepared by oxidation of benzene in liquid sulfur dioxide. Journal of Electroanalytical Chemistry. v.251, p.89-102, 1988.

3- MIYASHITA K., KANEKO M. Vacuum-deposited poly(p-phenylene) thin film and its structure, morphology and electronic properties. Synthetic Metals. v. 68, p. 161-165, 1995.

4- EIRAS C. Eletrossintese e propriedades ópticas e morfológicas de filmes de Poli-p-fenileno e derivados. São Carlos, 2004, 148p. tese (Doutorado)-Instituto de Física de São Carlos, Universidade de São Paulo.

EIRAS CARLA.

5- SARAÇ S.A., SPRINGER J., Electrografting of 3-methylthiophene and carbazole random copolymer onto carbon fiber: characterization by FTIR-ATR, SEM, EDX. Surface and Coatings Technology, v.160, p.227-238, 2002.

6- WANG J., IR spectroelectrochemical investigations of solvent roles in deactivation of poly(3-methylthiophene) films. Electrochimica acta. v.42, p.25452554, 1997.

7- GIACOMINI M.T., TICIANELLI E.A. Influência da acidez do meio sobre a síntese e o comportamento redox do polipirrol. Química Nova v.22, n. 5, p.1-28, 1999.

8- SILVA J.E.P. Caracterização espectroscópica de blendas condutoras de polianilina e a sua aplicação para a proteção ativa contra a corrosão de metais. São Paulo, 2003, 158p. tese (Doutorado)-Instituto de Química de São Paulo, Universidade de São Paulo. 


\section{Capítulo 05: Conclusões finais e perspectivas futuras}

Pudemos concluir por meio da técnica de voltametria cíclica que os filmes de PPP, P3MET, PPI, CPPI e CP3MET apresentaram uma boa eletroatividade e são estáveis. Em atmosfera controlada, os filmes de CPPI e de CP3MET se mostraram mais espessos e homogêneos e com uma maior quantidade de carga total final do que os filmes dos homopolímeros, PPI e P3MET. As respostas voltamétricas dos filmes de CPPI e CP3MET mostraram a definição de um par redox, diferentemente das respostas dos homopolímeros, PPI e P3MET. Dessa forma, pode-se dizer que houve a formação de filmes mistos, ou seja, um depositado sobre o outro. A síntese dos filmes de CP3MET e de CPPI foi realizada em uma região de potencial próxima à da síntese dos homopolímeros P3MET (entre 0,0 e 1,7 V) e PPI (entre 0,0 e 1,0 V). Por isso, houve a formação de filmes de CP3MET e de CPPI contendo pouca quantidade de PPP, já que a bifenila oxida em uma região de potencial entre 0,0 e 2,0 V vs $\mathrm{QRe}-\mathrm{Ag}$.

Os espectros de UV-VIS in situ dos filmes de PPP, CPPI e CP3MET mostraram a presença de bandas referentes aos polímeros em seu estado neutro, ao pólaron e bipólaron, e com isso, as mudanças na estrutura eletrônica dos filmes durante a aplicação de diferentes faixas de potencial. Estas mudanças estruturais só foram notadas nos espectros dos filmes dos homopolímeros, PPI e P3MET, devido à semelhança entre seus espectros com os do CPPI e CP3MET, devido à pouca quantidade do homopolímero, PPP, formado durante a síntese do CP3MET e CPPI.

Os espectros de FT-Raman dos filmes dos homopolímeros PPP, PPI e P3MET não apresentaram mudanças em relação aos dos filmes de CPPI e CP3MET devido a um 
efeito térmico semelhante à fluorescência apresentado pelo filme de PPP a um comprimento de onda de $1064 \mathrm{~nm}$, que mascara o efeito Raman do PPP.

A partir dos espectros de FTIR por refletância, pôde-se comprovar o surgimento apenas das bandas referentes aos homopolímeros PPI e P3MET nos filmes de CPPI e CP3MET. Este trabalho se baseou no pressuposto de que os filmes de CP3MET e CPPI seriam formados a partir de uma possível reação de copolimerização entre os monômeros 3-metiltiofeno/ bifenila e entre o pirrol/ bifenila. Porém, foram observados somente pequenos deslocamentos das bandas para maiores números de ondas, devido a interações nos filmes de CP3MET, entre o PPP e o P3MET, e nos filmes de CPPI, entre o PPP e o PPI. Assim pôde-se concluir que esses filmes podem ser caracterizados como mistos e não copolimeros, e portanto, formados um sobre outro.

Ao final desse trabalho podemos concluir, a partir das caracterizações feitas pelas medidas espectroscópicas de UV-VIS in situ, FT-Raman e FTIR, que os filmes de CP3MET e CPPI apresentaram basicamente as mesmas estruturas que as dos filmes de P3MET e PPI, comprovadas pelas medidas realizadas, já que as bandas apresentadas nos espectros, tanto de FT-Raman, FTIR e UV-VIS in situ, não apresentaram características dos espectros do filme de PPP.

Em relação às perspectivas para trabalhos futuros, a partir desses resultados obtidos, pode-se dar continuidade a esse trabalho realizando-se medidas de fotoluminescência e eletroluminescência, fazer uso de outras técnicas de caracterização, como ressonância magnética nuclear (RMN) para elucidar a estrutura desses filmes mistos de CPPI e de CP3MET e também realizar um estudo dos estágios iniciais de nucleação desses filmes mistos. 